\title{
USING LEARNING STORIES IN SECONDARY SOCIAL STUDIES: GATHERING, ANALYSING AND USING EVIDENCE TO SUPPORT LEARNERS' CONCEPTUAL UNDERSTANDINGS
}

BY

Amanda Josephine Picken

A three-paper thesis submitted in partial fulfillment

of the requirements for the degree of

Master of Education

Victoria University of Wellington

2012 


\begin{abstract}
This research examined the use of learning stories as a way to gather, analyse and use evidence to support the development of social studies conceptual understandings. This is important because there is limited research in New Zealand related to social studies assessment in secondary school environments, or in the monitoring of conceptual changes in understanding. The limited research that can be drawn upon highlights the challenges social studies teachers face teaching and assessing conceptually.

Sociocultural theory featured strongly throughout the research, through the decision to investigate learning stories as an assessment approach, as well as the lens with which to approach the methodology. In order to investigate the Learning Story Framework, as an intervention, a qualitative design-based methodology was utilised involving one in-depth case study. The research composed of three iterative phases, gathering evidence using semi-structured interviews, participant observation and documentation analysis, including reflective journals.

The findings suggested that learning stories can be used to support the development of conceptual understandings in conjunction with a reflective class culture, strong community relationships, clarity of planning for and sharing conceptual understandings, and support for students to critically reflect.
\end{abstract}




\section{ACKNOWLEDGEMENTS}

There are a number of people I would like to acknowledge and thank for their support in the undertaking of this thesis.

Firstly, I would like to sincerely thank the principal for allowing the research to be carried out in your school, and to James, Sam and the eight students involved in the research. It was a privilege to spend the six months in your classrooms. I appreciated your openness and honesty and willingness to be part of the project and the time you spent talking with me.

I would like to thank my two supervisors: Andrea Milligan and Dayle Anderson, for your wisdom, flexibility and encouragement throughout this journey. Your enthusiasm, insightful questions and support have been greatly appreciated.

Thank you to Kelly, for your editing and constructive feedback at a time that I know has been very busy for you.

Thank you to my family, friends and colleagues, you have always believed in me and encouraged me and shown (genuine) interest along the way.

In particular I would like to thank my husband Ian for your patience and understanding of my need to study. You have cared for and supported me in so many ways throughout this time and made it possible for me to complete my research. 


\section{CONTENTS}

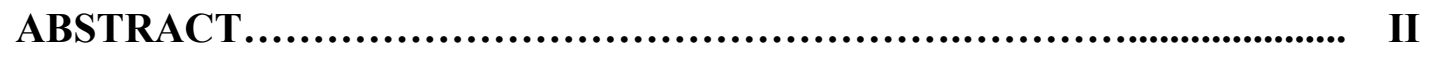

ACKNOWLEDGEMENTS............................................ III

CONTENTS............................................................ IV

LIST OF FIGURES .......................................................................................... VII

CHAPTER ONE: INTRODUCTION

1.1 Introducing the issue.............................................. 1

$1.2 \quad$ Aims of the research.................................................. 2

1.3 Motivation for this research and personal perspective............... 2

1.4 Approach to this research.......................................... 4

1.5 The structure of this thesis............................................. 4

CHAPTER TWO: LITERATURE REVIEW

2.1 Introduction...................................................... 5

2.2 Conceptual understanding in social studies

2.2.1 Defining social studies.................................5

2.2.2 Concepts in social studies................................. 6

2.2.3 Conceptual understandings in social studies.................... 7

2.2.4 Why focus on teaching for conceptual understanding?.................... 8

2.2.5 Why is teaching for conceptual understanding an issue in

New Zealand?

2.3 Gathering, analysis and use of evidence in social studies

2.3.1 What is the gathering, analysis and use of evidence in

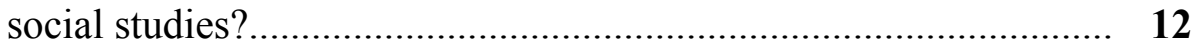

2.3.2 Why is there a need to focus on the gathering, analysis and use of evidence? ....................................................................... $\quad 15$

2.3.3 Moving towards a sociocultural approach to assessment........... $\mathbf{1 8}$

2.4 Learning stories as an approach to gathering, analysing and using evidence

2.4.1 What are learning stories?........................................................ 20

2.4.2 Sociocultural influences on learning stories.................... 21

2.4.3 Learning story use in education............................. 23 
2.4.4 Learning stories, a culturally inclusive assessment.

2.5 Students leading learning....................................... 26

$2.6 \quad$ Summary....................................................... 28

\section{CHAPTER THREE: METHODOLOGICAL APPROACH}

3.1 Introduction.................................................... 29

3.2 Sociocultural approach to the research................................. 29

3.3 Research design................................................... 30

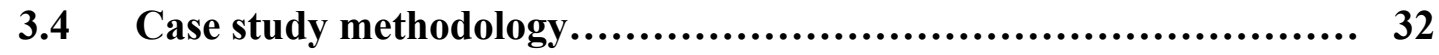

3.5 Case study participants....................................... 33

3.6 Design of the learning story framework............................ 35

3.7 Data collection methods

3.7.1 Introduction.............................................. 37

3.7.2 Semi-structured interviews................................ 40

3.7.3 Interview procedure..................................... 41

3.7.4 Participant observation................................... 42

3.7.5 Documentation............................................ 43

3.8 Ethical considerations........................................... 43

3.9 Data analysis framework....................................... 45

3.10 Drawing the sociocultural threads together......................... 48

CHAPTER FOUR: ANALYSIS OF EVIDENCE

$4.1 \quad$ Introduction....................................................... 49

4.2 Setting the scene................................................ 49

4.3 Departmental perception practice and procedures................... 50

4.3.1 Senior school (Years 11-13) ............................ 51

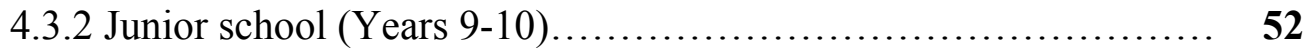

4.3.3 Departmental planning for conceptual understanding............. 54

4.4 Our learning stories

4.4.1 Introduction............................................... 55

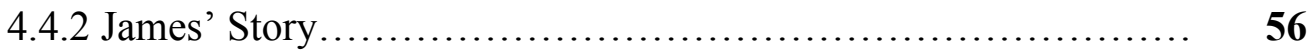

4.4.3 Sam's Story .............................................. 59

4.4.4 My story: Researcher intervention ......................... 63

4.4.5 Moments of convergence and divergence................... 66

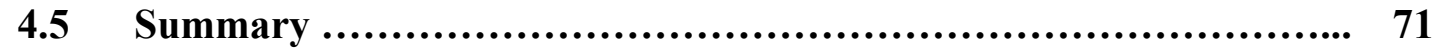




\section{CHAPTER FIVE: DISCUSSION, RECOMMENDATIONS AND CONCLUSIONS}

$5.1 \quad$ Introduction................................................. 72

5.2 Evaluation and adaptation of the Learning Story Framework in a secondary environment........................................... 72

5.3 The role of advisers and researchers.............................. 76

5.4 Considerations for teachers when using a Learning Story Framework......................................................... 77

5.5 The sociocultural context............................................... 81

5.6 Limitations to the study.............................................. 83

5.7 Conclusion............................................................... 84

REFERENCES...................................................... 86

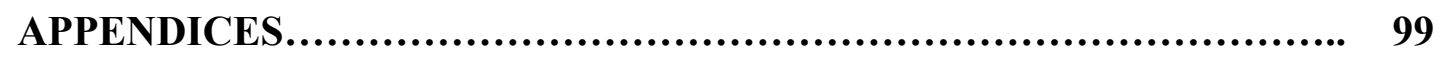




\section{LIST OF FIGURES}

Figure 2.1: $\quad$ Social Science outcomes identified in the Best Evidence Synthesis Iteration Effective pedagogy in Social Sciences/Tikanga ā iwi

Figure 2.2: A visual representation of Bruner (1960) and Taba's (1962) structure of knowledge

Figure 2.3: Ten principles of assessment for learning to guide classroom practice

Figure 2.4: Key elements of assessment for learning practice

Figure 3.1 Five key characteristics of design-based research

Figure 3.2 Case study demographics

Figure 3.3 Factors that influenced the design of the Learning Story Framework

Figure 3.4 Learning story implementation process for Inquiry Cycles One and Two

Figure 3.5 Methodological process

Figure 3.6 Coding process during disassembling phase - a snapshot

Figure 4.1 Teacher perception of the purpose of assessment

Figure 4.2 Communication of learning intentions in each phase of the research

Figure 4.3 Actual learning story implementation process for Inquiry Cycle One 


\section{CHAPTER ONE \\ Introduction}

\subsection{Introducing the issue}

This research aims to investigate the use of learning stories as a way to gather, analyse and use evidence to support the development of Year 9 social studies conceptual understanding. In New Zealand social studies is the foundational, integrating subject for the social sciences in Years 1-10. It has existed as a subject in New Zealand for nearly 70 years. First introduced in 1944 after The Thomas Report, it has undergone a number of reviews as differing ideological, political, economic and social influences have pervaded (Aitken, 2005). More recently, and in light of changing societal demands, there is a growing awareness of the need to prepare our children for a world where understanding and application of ideas and concepts far outweighs the traditional emphasis on the acquisition of knowledge and regurgitation of facts and figures. Concurrently there has been growing support for an approach to assessment that goes beyond summative purposes to inform the teaching and learning process and hence improve student outcomes (Black \& Wiliam, 1998; Crooks, 1988; Timperley, Wilson, Barrar \& Fung, 2007). A shift in emphasis towards a concept-led approach has left social studies teachers struggling to teach and assess in an authentic manner (Crooks, Flockton, \& Meaney, 2006; Education Review Office, 2007;

Flockton \& Crooks, 2002), The complexity of conceptual thinking that is particular to social studies makes the assessment of the subject that much harder (Aitken, 2005; Taba, 1962) and it requires an assessment approach that can capture this complex learning. Research originating in the early childhood sector suggests that learning stories, a form of narrative assessment, can capture the complex ways in which students learn (Carr, 2001). Learning stories provide a way to enhance learning by integrating the teaching, learning, and assessment processes. Learning stories acknowledge the unpredictability and non-sequential way that students learn and they reflect this learning in a manner that may not easily be captured by other, more traditional forms of assessment. They protect and enhance the setting as a learning community developing a collaborative interpretation of the learning and seeking the perspective of the student (Carr, 2001). Furthermore, learning stories protect and enhance learning communities through the development of a collaborative 
interpretation of the learning, whilst seeking the perspective of the student (Carr, 2001).

This research aims to investigate the use of learning stories as a tool to gather, analyse, and use evidence to support the development of Year 9 social studies conceptual understandings. Reflecting the underpinning theoretical orientation of a learning story approach, this research project is framed by a sociocultural perspective (Vygotsky, 1978), which emphasises social and cultural influences on learning. The nature of social studies, and its pedagogy, along with assessment practices, naturally aligns this research with a sociocultural foundation.

\subsection{Aims of the research}

The purpose of this research is to investigate the use of learning stories to gather, analyse and use evidence to support the development of conceptual understanding in Year 9 social studies. I have developed the following questions to structure this research and to guide the literature review, the research methodology, and the resulting analysis and discussion.

1. What is the current teacher practice for gathering, analysing and using evidence to support the development of social studies conceptual understandings?

2. What is the impact of teachers using learning stories to support the development of social studies conceptual understandings?

3. What is the impact of students using learning stories to support the development of social studies conceptual understandings?

\subsection{Motivation for this research and personal perspective}

I have 18 years experience teaching, lecturing, and now advising in the social sciences field. I have experienced curricula change in England and again in New Zealand, which led to my increasing realisation of the need to develop conceptuallybased teaching and learning programmes. This knowledge was gained through academic study, trial and error, successes and failures in the classroom, and the accumulation of professional learning experiences along the way. Parallel to the changes in the curriculum was an assessment revolution - a significant move towards standardised, criterion-based assessment and more formative styles of assessing. 
Integrating the teaching, learning, and assessment of concepts and ideas was new territory for me.

In the midst of this journey, I was privileged to broaden my perspective further through watching the growth in learning of both of my sons as they went through the early childhood system. It was here that I began a new learning journey that helped me to understand the value of learning stories. I began to consider the worth of learning stories with older children expressing and directing their own learning, but this time for complex social studies outcomes.

A career change into education advisory stimulated my thinking about the productive potential of learning stories. Along with advising in the social sciences, I was charged with supporting primary and secondary schools in the Wellington region to implement The New Zealand Curriculum: draft for consultation (Ministry of Education, 2006). Central to this new learning was the teaching as inquiry process, a mechanism for teachers to use to reflect on their teaching and learning, and the impact this has on students. I became more familiar with the phrase evidence based practice, and it led me to reflect on my own teaching experiences and the robustness of the evidence that I used to make teaching and learning decisions and how narratives such as learning stories could contribute towards supporting teachers' inquiries. Aware that learning stories provide a positive avenue for links between secondary schools, and their families, whānau, and communities and the increasing emphasis on nurturing home-school partnerships (Bull, Brooking, \& Campbell, 2008), I considered whether they could also be used to authentically support conceptual development for all students.

In addition, the Ministry of Education's focus on priority groups, namely Māori, Pasifika and students with special educational needs, led me to consider whether an assessment tool like learning stories could be used to authentically support conceptual development for all students.

In summary, I felt that the bridge between theory and practice needed to be crossed. My wonderings and literature review resulted in the development of this research project that involved a social studies department, two teachers and eight students. Together, we explored the potential of learning stories. 


\subsection{Approach to this research}

The research takes the investigation of assessment practices in Year 9 social studies into previously unchartered territory through the exploration of learning stories as a tool to to gather, analyse and use evidence to support conceptual understanding. As such, it lends itself to a design-based methodology, which applies previous research into the use of learning stories in early childhood to a Year 9 social studies setting (Bannan-Ritland, 2003; Cobb, 2003). Design-based methodology allows for inquiry and interpretation of the intervention in a naturalistic setting, which supports the iterative ideology of this research. In order to gain an in-depth understanding of the research, a case study approach has been chosen (Stake, 1995) and this allows for a variety of perspectives and greater insight into the research (Baxter \& Jack, 2008). Further discussion related to the approach of design-based methodology using an in-depth case study will be discussed in Chapter Three.

\subsection{The structure of the thesis}

This chapter has provided an introduction and an overview to the research. Social studies teachers are facing particular challenges when teaching and assessing conceptual understandings. Learning stories may provide a way of supporting teachers to gather, analyse, and use evidence to support students to develop conceptual understandings.

Chapter Two draws on research related to social sciences and learning stories. It examines literature about teaching, learning, and assessment in social studies. This chapter also reviews existing research about learning stories and their use as an assessment tool to gather, analyse, and use evidence.

Chapter Three describes the theoretical approach to this research. This includes the research design, the case study approach, and the development of the Learning Story Framework. Methods of data collection and analysis are also outlined.

Chapter Four analyses the research findings through the presentation of learning stories for James Sam and I, and a discussion of the convergences and divergences that occurred through the research process.

Chapter Five discusses and analyses the findings in relation to the aim of the research. This is followed by a discussion related to the limitations and considerations arising from the research, with some final thoughts to draw the research together. 


\section{CHAPTER TWO \\ Literature Review}

\subsection{Introduction}

The purpose of this chapter is to review existing literature about conceptual understandings in social studies and the difficulties teachers face when teaching and assessing these. It includes analysis of what it means to gather, analyse, and use evidence to improve student outcomes in social studies. Learning stories are introduced as a possible assessment tool for secondary social studies. Sociocultural perspectives are interwoven and discussed through the research, and are especially evident in the decision to use learning stories to examine the gathering, analysis, and use of evidence. The chapter concludes with research into the role students can take in the learning and assessment process.

\subsection{Conceptual understanding in social studies}

\subsubsection{Defining social studies}

What constitutes social studies has been hotly debated over the years (Aitken, 2005; Barr, 2005; Barr, Graham, Hunter, Keown \& McGee, 1997; Beck, 2008; Mutch, Hunter, Milligan, Openshaw \& Siteine, 2008; Taba, 1962). One recent interpretation of the purposes of social studies is contained within the Best Evidence Synthesis Iteration Effective pedagogy in Social Sciences/Tikanga à iwi (Aitken \& Sinnema, 2008), which identifies desired outcomes across the social science domain. The authors have highlighted five outcomes sets, which are shown in Figure 2.1. 
Figure 2.1: Social Science outcomes identified in the Best Evidence Synthesis Iteration Effective pedagogy in Social Sciences/Tikanga ā iwi

\begin{tabular}{ll}
\hline Outcome & Explanation \\
\hline Cultural identity & $\begin{array}{l}\text { Outcomes related to students' understanding and awareness of personal identity and } \\
\text { layered/multiple identities. }\end{array}$ \\
\hline Knowledge & Outcomes related to students' understanding of concepts or ideas central to the social \\
sciences domain. & Outcomes related to students' use of methods (for example, the planning of inquiry) \\
akills & $\begin{array}{l}\text { of techniques (for example, graphing, mapping, reading) central to the development } \\
\text { for example, writing, drawing, speaking). } \\
\text { Outcomes related to students' ability to participate, contribute, become involved, } \\
\text { interact, and engage in dialogue. These outcomes included both inclusive personal } \\
\text { behaviour (such as non-racist and non-sexist interactions with peers) and negative } \\
\text { participation (such as the development of destructive or resistant responses). } \\
\text { Outcomes related to students' dispositions and emotional responses to learning, to } \\
\text { their ability to explore and analyse their own and others' values, and to the } \\
\text { development of a commitment to such values as social justice and equity. }\end{array}$ \\
\hline Affective &
\end{tabular}

(Aitken \& Sinnema, 2008, p.37)

This research focuses on the knowledge outcome, while acknowledging that the outcome sets do not exist in isolation (Aitken \& Sinnema, 2008). The development of conceptual understandings is integral to the knowledge outcome, and is described by Aitken and Sinnema (2008) as "concepts expressed as single words (for example, 'conflict', 'culture', 'government') or elaborated as ideas or generalisations." (p.229). I have chosen this focus because developing in conceptual understanding will enhance student outcomes and provide students with the capacity to apply their learning from one context to another. The following sections discuss this in more detail.

\subsubsection{Concepts in social studies}

There are multiple perspectives regarding the interpretation of the nature of concepts and conceptual understandings. For example, Jonassen (2006) contrasted Plato's perception of concepts as the essence of things, (abstract and unworldly) with interpretations by neuroscientists where concepts are viewed as patterns of synaptic connections and psychological views regarding concepts as discrete entities. 
Hilda Taba (1962), whose work has been highly influential in social studies curriulum development, viewed concepts as highly abstract ideas such as cultural change and interdependence. Likewise, Ellis (2007) described concepts as sitting above a multitude of contexts as they transcend time and space. This universality of concepts is echoed by Erickson (2007), who stated that concepts are a "mental construct that frames a set of examples sharing common attributes" (p. 129). In contrast, Jonassen (2006) stressed that concepts are the basis for meaning making and communication. Acknowledging the philosophic debate that exists over the precise nature of concepts, for the purposes of this thesis I will adopt the definition used in a recent supporting document for assessing senior social studies, which states: “A concept is a general idea, thought, or understanding. They can be expressed in a single word such as 'democracy' or 'needs' or a simple phrase such as 'social decision making' or 'cultural practices'.” (Ministry of Education, 2007a).

\subsubsection{Conceptual understandings in social studies}

The terms 'understandings' and 'generalisations' have been used in related literature to illustrate what learners know and understand about a concept or set of concepts. However, there are differences in opinion as to whether these understandings (generalisations) are constructed through the multiple meanings made from single concepts, or the multiple connections made from context to another, or the identification of patterns between concepts. Fraenkel (1992) purported that generalisations are one way to organise ideas and make connections that are generally less abstract than concepts. However, the guide notes for assessment for senior social studies state that when concepts are elaborated into generalisations, they become conceptual understandings or social studies ideas (Ministry of Education, 2007a). In addition, Erickson (2007) took the view that to be a generalisation, two or more concepts must have a relationship when transferred to other situations, times, or across cultures. This viewpoint is evident in Bruner (1960) and Taba's (1962) ideas related to the structure of knowledge. They indicated that generalisations could be viewed as an element of the structure of knowledge, which emphasises the relationships between one or more concept (see Figure 2.2), which are built on the building blocks of facts (Savage \& Armstrong, 2008). To understand structure then means to learn how things are related (Bruner, 1960). 
Figure 2.2: A visual representation of Bruner (1960) and Taba's (1962) structure of knowledge

(Savage \& Armstrong, 2008)

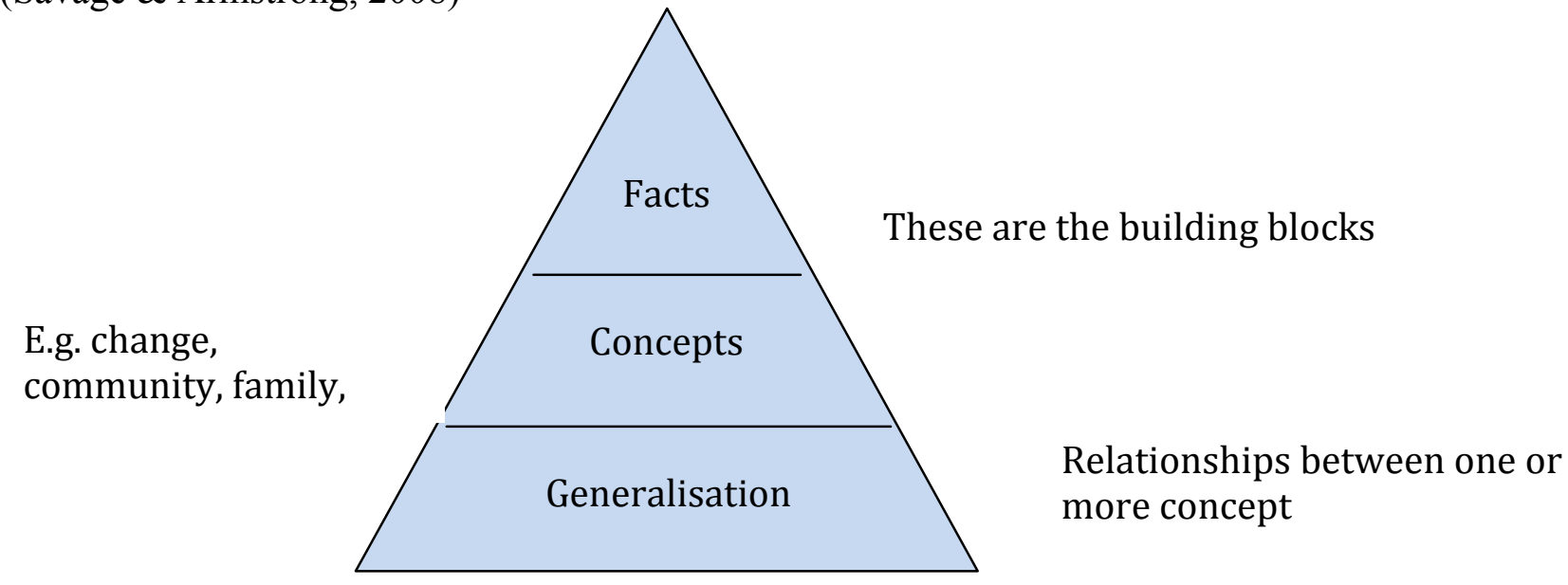

For the purposes of this thesis, I will use Jonassen's (2006) view that conceptual understandings connect concepts, and are developed, across multiple contexts. These understandings are complex and can be drawn from the study of one or more concepts, and have the effect of re-organising personal theories about the world.

\subsubsection{Why focus on teaching for conceptual understanding?}

Having developed working definitions for concepts and conceptual understandings, this section examines the literature related to the reasons why a concept-led approach is desirable in social studies. In the 1960's Taba (1962) posited that regurgitation of information is no longer an acceptable educational outcome. She argued that learning should focus on the understanding of ideas because teaching specific facts only provided a temporary source for acquiring ideas and retaining this wealth of information is too difficult. Instead she proposed approaching teaching and learning by emphasising the acquisition, understanding, and use of ideas and concepts. Taba supported the inclusion of learning of specific facts to act as the raw material for the development of ideas, generalisations, and insights (Taba 1962). Bruner (1960) was another key educational thinker who agreed that the emphasis should be more on the understanding of ideas and took the view that facts are highly 'obsolescent', as the facts of one day were the fiction of the next. Later, Rosch (1978) argued that taking a conceptual approach to teaching and learning fosters a more efficient form of learning, by promoting 'cognitive economy' where knowledge is maximised through the categorisation process. This enables teachers to focus on what 
knowledge counts when focusing on conceptual understandings (Milligan and Wood, 2009). Similarly, Erickson's (2007) theory of the structure of knowledge states that principles and generalisations (understandings) enable large numbers of specific facts and events to be summarised and organised.

Thus, focusing on conceptual understandings is not just organisationally appealing; teaching and learning that focuses on developing conceptual understandings allows students to apply facts and information to an endless variety of settings. When students develop understandings and make networks of connections, they have the ability to apply ideas from one situation to another (Barr, 2005). This enables them to use higher order skills (such as critical, creative, synthesising, and thinking skills) to create new knowledge. However, and to re-emphasise Taba's point, this is not to say that facts are unimportant. Anderson and Krathwohl (2001) believed that working through lower levels of the taxonomy would be required in order to ensure that students have sufficient factual detail to support the development of conceptual understandings.

In summary, the research indicates that developing social science conceptual understandings in relation to student's own lives, improves learning outcomes. This is evident in McNeight's (1998) action research study with Year 13 classical studies students. When the Pasifika students in her study were given the opportunity to compare ancient Roman cultural practices with present day Samoan culture, they were able to personalise the meaning and double their level of achievement compared to previous assessments. The students also reported a greater sense of inclusion and increased engagement with the work.

Similar links have been found in research in the science learning area. Asko (2002) identified the need to transform abstract scientific ideas into concrete concepts that students can relate to, without losing the scientific essence in the process. In addition, Hodson and Hodson (as cited in Middleton, 2001) indicated the importance of teachers' conceptual understandings when improving student outcomes. In New Zealand, the response to this research has seen the development of a series of building concepts books that provide teachers with some examples to use in the development of their science programmes. The Building Science Concepts series was designed on the premise that primary school students would be introduced to a network of partially developed concepts, called foothills, which become more complex as they progressed through the curriculum. 


\subsubsection{Why is teaching for conceptual understanding an issue in New Zealand?}

To develop an appreciation for why it is important to investigate teaching and learning of conceptual understandings in New Zealand this section provides a curricular overview of the journey towards a concept-led approach. Section 2.3 goes on to discuss the ways in which teachers gather analyse and use evidence to support the development of conceptual understandings.

A review of New Zealand's social studies curricula over the last half-century unearths the tentative journey towards teaching for conceptual understandings (Aitken, 2005). The 1977 social studies curriculum (Department of Education, 1977) was redesigned after ten years of consultation and was built upon the spiral curriculum ideas of Hilda Taba (1962) and Bruner (1960). This approach reflected elements of Hermann Ebbinghaus' (1885) methodology, which emphasised the repeated revisiting of ideas (concepts) in such a way that the ideas are learned over time, with appropriate spacing as to increase the students cognitive ability to learn and retain the concepts (cited in Davis, 2007). However, Taba (1962) argued that repetition alone would not lead to deeper learning. She argued that instead, the cumulative building upon knowledge and previously gained understanding should be "woven into the fabric of the curriculum" (p.178). This approach to social sciences learning contrasted with the usual practices of the time that focused on teaching facts and knowledge.

More recently, New Zealand social studies curricula (Ministry of Education, 1990; Ministry of Education, 1997, Ministry of Education, 2007a), and guiding documents to support teaching and learning (Ministry of Education, 2009a), have explicitly supported a move away from the teaching of facts and transmission of knowledge towards teaching for conceptual understanding. The Building Conceptual Understanding in the Social Sciences series provide guidance for teachers with two of the books specifically supporting the ideas relating to "Being part of global communities" and "Belonging and Participating in Society." This is also evident in the conceptual nature of the current achievement objectives, for example a Level Five achievement objective refers to students understandings of "how the cultures of people in New Zealand are expressed in their daily lives." (Ministry of Education, 2007b)

Despite the spiral, concept-led nature of recent social studies curriculum design Aitken (2005) claims that there is little evidence that teachers closely monitor the 
development of conceptual understanding. Successive reviews and reports have indicated that teaching for conceptual understanding was not widespread in New Zealand social studies classrooms (Benson \& Openshaw, 2005; Crooks et al., 2006; Education Review Office, 2006; Flockton and Crooks, 1998; Flockton \& Crooks, 2002; National Education Monitoring Project, 2005; National Education Monitoring Project, 2010; Smith, Crooks, Gilmore \& White, 2010). The National Education Monitoring Project (NEMP) revealed that from 1997 to 2009, Year 8 student performance in social studies remained relatively unchanged, and that significant gaps in conceptual understanding remained.

Aitken (2005) reported that facilitators working on the development of the Social Studies exemplars for The New Zealand Curriculum Exemplars project also indicated that few teachers were aware of the conceptual basis that underpinned the achievement objectives. Cubbitt (2005) added that secondary social studies departments faced the considerable challenge of drawing on a multitude of social science and non-specialist teachers to teach the Year 9 and 10 programmes, and that if concepts are poorly understood then teachers avoided incorporating them into their teaching. Whether the curriculum documentation assisted teachers to make conceptual links is an important question; ERO (2001) commented that, for teachers, the achievement objectives read as distinct bodies of knowledge, which made it difficult for them to see the concepts buried within these. Milligan and Wood's (2010), recent article also raises the concern that (summative) assessment, is challenged by the apparent lack of conceptual progression between the achievement objectives, and the same can be said for more formative ways of assessing.

A review of the literature relating to conceptual understandings in social science has found that there is considerable literature regarding conceptual change, but very little of it addresses how to effectively assess conceptual change. Instead, most research focuses on the theories of conceptual change, and recommends assessing patterns of concepts and conceptual understanding. In the New Zealand context Aitken and Sinnema (2008) confirm that there is a distinct lack of research evidence in relation to the pedagogy associated with the development of conceptual understanding. Literature describes multiple interventions that may be influential in achieving outcomes, but there is a lack of specificity over which outcomes are more effective. Furthermore, Aitken and Sinnema (2007) also note that there is minimal research that involves Māori and Pasifika students in social science contexts, and 
none focusing on assessment for Māori and Pasifika students. This is pertinent to the research as it is my contention that the Learning Story Framework is an inclusive method of assessment, this is explored in further detail in Section 2.4.4. The following section looks at the literature related to the gathering analysis and use of evidence that can be used in social studies.

\subsection{Gathering, analysis and use of evidence in social studies}

\subsubsection{What is the gathering, analysis and use of evidence in social studies?}

During my time as an adviser supporting schools to implement the New Zealand Curriculum I had the opportunity to develop my understanding and knowledge of the 'Teaching as Inquiry' approach (Ministry of Education, 2007b). The primary purpose of this model is to achieve improved outcomes for all students using evidence to inform teaching and learning decisions. Support for the use of evidence to improve student outcomes is widely documented (Alton-Lee, 2003; Black \& Wiliam, 1998; Torrance \& Pryor, 2001; Weeden et al., 2002) and it is clear that how the evidence is used has a significant impact on student achievement. In the Teacher Professional Learning and Development: best evidence synthesis iteration, Timperley, Wilson, Barrar, and Fung (2007) show that teachers who use assessment data to inform their teaching programmes see more significant gains in student achievement.

It is clear that if used appropriately, assessment information cannot be separated from the teaching and learning process. Assessment can improve teaching and learning when teachers adjust their teaching to take account of the results of assessment (Alton-Lee, 2003; Black, 1998; McManus, 2008). During the 'focusing' stage described in the teaching as inquiry approach, teachers gather information from a variety of sources to identify the outcomes for the students. Teachers consider how well students are achieving these outcomes and this informs the 'teaching' stage of their inquiry. Subsequently, teachers plan and critically analyse approaches using best practice, literature and student input. This research focuses on the information that teachers use to inform their inquiries, reflecting for action; which involves considering past events and processes, for example, student achievement information to change future events and processes (Killon \& Todnew, 1991).

Harlen, Gipps, Broadfoot, and Nuthall (1992) define assessment as: "Assessment in education is the process of gathering, interpreting, recording and 
using information about students' responses to an educational task" (p.217). This interpretation serves to support student learning, contrary to other, accountabilityfocused functions of assessment such as a summary of learning or certification progress and transfer (Black, 1998). As this research focuses on how assessment improves standards, rather than just measuring them (OFSTED, 1998), I will draw on the literature related to formative assessment and assessment for learning.

Formative assessment has been defined in various ways in related literature sometimes in contrast with the summative process, sometimes defined in terms of the methodology adopted, and sometimes described as a process. Categorising formative assessment as either a tool or as a process, risks oversimplifying it. Instead, formative assessment can be regarded as a thoughtful integration of process and purposefully designed methodology and tool (Bennett, 2011). Assessment is ongoing and reflective, meant to help make improvements along the journey and at best it is perceived as a natural and logical part of the teaching and learning process (Ellis, 2007). Formative assessment has been criticised as being too technical in its approach, focusing on techniques to feedback on progress or recording of the achievement. Therefore, in order to exemplify the pedagogy and the ideas about learning and how to support learning, this research will also explore the literature related to assessment for learning.

There are 10 principles of assessment for learning (see Figure 2.3), which were developed by the Assessment Reform Group. They exemplify the dynamic and interactive nature of this approach, and constantly respond to the teaching and learning process. The social and cultural influences pervade the approach through the active role required by teachers and students in the learning process (Atkins, 2010; Gipps, 1999; Moss, 2008).

\section{Figure 2.3: Ten principles of assessment for learning to guide classroom practice} Assessment for learning:

- is part of effective planning of teaching and learning

- focuses on how students learn

- $\quad$ is central to classroom practice

- $\quad$ is a key professional skill for teachers

- should be sensitive and constructive because any assessment has an emotional impact

- fosters motivation

- promotes commitment to learning goals and a shared understanding of the criteria by which they are assessed

- helps learners know how to improve through constructive guidance

- develops the capacity for self-assessment so that students can become more reflective and self managing

- should recognize the full range of educational achievement

(Assessment Reform Group, 2002) 
Teachers integrating the gathering, analysis and use of evidence within their teaching and learning programmes use a range of tools to do so. Bennett (2011) regards the use of any tool as formative as long as it is used to change teacher practice. Heritage (2007) adds to this when he describes the four key elements of assessment for learning practice (see Figure 2.4).

Figure 2.4: Key elements of assessment for learning practice

\begin{tabular}{|c|c|c|}
\hline & Element & Explanation \\
\hline - & $\begin{array}{l}\text { Identifying the gap between } \\
\text { the desired outcomes for } \\
\text { learning and where the student } \\
\text { is currently achieving. }\end{array}$ & $\begin{array}{l}\text { Identification of the size of the gap } \\
\text { is dependent on individual students } \\
\text { and their abilities }\end{array}$ \\
\hline • & $\begin{array}{l}\text { Feedback specifically related } \\
\text { to the learning/task }\end{array}$ & $\begin{array}{l}\text { This encompasses both the } \\
\text { feedback to the teacher about } \\
\text { where a student is at, and feedback } \\
\text { to guide the student to the next } \\
\text { level }\end{array}$ \\
\hline - & $\begin{array}{l}\text { Student involvement including } \\
\text { peer and self assessment }\end{array}$ & $\begin{array}{l}\text { This enables the student to } \\
\text { collaborate with the teacher to } \\
\text { develop a shared understanding of } \\
\text { their learning }\end{array}$ \\
\hline & $\begin{array}{l}\text { Learning progressions are } \\
\text { clearly articulated goals }\end{array}$ & $\begin{array}{l}\text { This assists students to map the } \\
\text { journey towards a more holistic } \\
\text { learning outcome }\end{array}$ \\
\hline
\end{tabular}

(Heritage, 2007).

Research also supports the importance of assessment-as-learning that focuses on the central role of the student in the teaching, learning, and assessment process (Earl, 2003). It emphasises the importance of using assessment to assist with the development of students' metacognitive skills, it focuses on the students taking an 
active role to critically engage with the learning, making sense of information and using it for new learning. It is up to the students to self-regulate as they are responsible for monitoring their own understanding, through feedback and adjustments to their learning. Research by Bransford, Brown and Cocking (1999) found that students' performance improves when they are actively involved in choosing and evaluating strategies, considering assumptions, and receiving feedback. In the Quality teaching for diverse students in schooling: best evidence synthesis iteration, Alton-Lee (2003) identified a number of assessment practices that are influential towards student outcomes. These centre on the student being an active participant in the assessment process, with the teacher responding positively to the results of the assessment. This student-centred approach is a key motivator for this research and will be explored during Inquiry Cycle Two.

\subsubsection{Why is there a need to focus on the gathering, analysis and use of evidence?}

Through the presentation of the research this section discusses the reasons why there is a need to focus on the gathering, analysis and use of evidence in New Zealand, in particular social studies. It will also present the findings from international research consistent with the ones presented here.

Firstly, the benefits of an integrated assessment approach have been widely endorsed; with evidence to show the improvement of student outcomes and achievement (Alton-Lee, 2003; Assessment Reform Group; 1999; Black \& Wiliam; 1998; Wood \& Milligan, 2010), and this sentiment is reflected in the policy guidance for teachers. The New Zealand Curriculum (Ministry of Education, 2007) guides teachers to gather, analyse and use assessment information in a focused and timely manner, and goes on to outline some characteristics of effective assessment. Despite this guidance studies have shown that confusion regarding the application of assessment for learning approaches is still apparent.

Secondly, there is limited research related to Year 9 and 10 social studies assessment practice in New Zealand. Aitken and Sinnema (2008), Atkins (2010), Milligan and Wood (2009), Taylor (2009), and Plummer (2011) have made recent contributions to the study of assessment in social studies in New Zealand. However, many researchers are required to extrapolate findings from pre-secondary contexts or general research on teaching, learning, and assessment (Atkins, 2010). 
In the New Zealand context, Dixon and William for example (2003) investigated teachers' understanding and use of assessment for learning in literacy learning. They found that teachers had a grasp of assessment for learning at a theoretical level, but when asked to articulate practice there were still gaps and confusion. They concluded that teachers need more assistance in understanding how to integrate assessment for learning into practice.

Thirdly, the research focusing on social studies assessment practice in New Zealand draws largely on social studies primary level contexts (Alton-Lee, 2003, Education Review Office, 2006; Flockton \& Crooks, 2002). Recently, research has described teachers' difficulty in teaching and assessing for conceptual understanding (Education Review Office, 2007; Flockton \& Crooks, 2002; Crooks, et al., 2006). An ERO (2006) review into the quality of teaching and learning of social studies in Years 4 and 8 reported that more than half of the teachers in the review gathered little or no social studies assessment information and what was gathered was meaningless and lacked reliability and validity. The focus of the teaching and learning was clearly on knowledge of facts rather than deeper conceptual understandings. The review concluded that assessment practice in social studies was "generally poor, directly influencing how well teachers were able to meet the needs of all students, and report student progress to parents" (Education Review Office, 2007, p.1). These findings are in contrast to McGee's (2004) survey results which indicated that social studies teachers reported to use a variety of assessment practices, although these results were taken out of a large-scale study not just intended for social studies focusing on curriculum implementation. Hence, there is a continuing need to develop the potential of classroom assessment (Assessment Reform Group, 1999; Black \& Wiliam, 1998) especially within the realm of social studies conceptual understanding. Findings from the NEMP report elaborate on this. The report identified that "the richness and diversity of the conceptual nature of much of the content of social studies presents special challenges for the design and administration of assessment tasks." (Crooks et al., 2006).

Research has also indicated that the trickle down effect from NCEA may negatively influence Year 9 and 10 social studies teachers' assessment practices, as the purpose of NCEA is focused on summative assessments for qualification purposes. It is suggested that pressure on summative approaches could potentially 
hijack attempts to look towards more formative ways of assessing (Mutch, Hunter, Milligan, Openshaw \& Siteine, 2008).

Findings from New Zealand research are consistent with findings from overseas. International social studies research mirrors the challenges social studies teachers face in New Zealand. Confusion regarding assessment for learning practice and unclear policy documents has led to the avoidance of the practice (Harlen \& James, 1997). Bell and Cowie's (2001) research indicates that teachers who have a basic understanding of assessment for learning believe that they are assessing formatively but in reality they are still using summative practices. In addition, a longitudinal study carried out by Hargreaves, McCallum and Gipps (2000) showed that many teachers who indicated an understanding of assessment for learning did not fully understand the role of the teacher and learner in the process. Szymanski, Sunal and Hass (2005) also noted that culturally relevant alternative assessments are required to improve educational achievement for social studies students from diverse background. Additional literature has highlighted the challenges social studies teachers face when attempting to integrate the assessment of complex conceptual understanding into the teaching and learning process as a seamless whole. Ellis (2007) contended that authentic integrated assessment strategies are necessary as they promote a reflective culture in the classroom allowing students and teachers to be participants in the process.

From a social studies perspective, getting students to assess their own work develops citizens who are independent judges and decision-makers. Research question three specifically refers to the exploration of student-led learning stories, justifying the need to explore the literature in this area. Research has shown that effective gathering, analysis and use of evidence practice is closely linked to recognising the integral importance of the students' role. Weeden, Winter and Broadfoot (2002) argued that student voice and involvement is vital - stating that if students are part of the process of identifying the gap between current and desired achievement then they will have a greater understanding and awareness of what they need to do to raise their achievement, and therefore, student voice and involvement is vital. In their research about effectiveness of the "thinker tools" curriculum, Minstrell and Kraus (2007) showed that self-assessment helped to deepen students' conceptual understanding and improve achievement as students became more capable and could justify their scores. In Gallavan and Kottler's (2009) research into the construction of rubrics and 
assessing progress collaboratively with social studies, they concluded that when given "voice choice and ownership in their education" (p. 154) students will be more engaged, take increased responsibility and develop their self efficacy.

\subsubsection{Moving towards a sociocultural approach to assessment}

The previous section has indicated that social studies teachers in New Zealand face a number of challenges regarding the formative assessment of conceptual understandings. It is further notable, that educational research in recent years appears to support formative assessment approaches that are based on a more holistic, interpretive methodology (Black \& Wiliam, 1998; Cowie \& Bell, 1999; Gipps, 1994; Moore, Molloy, Morton, Davis, \& Wright, 2008; Sadler, 2002; Timperley \& Parr, 2004). This is because if schools are to respond to the learning, interests, strengths and capabilities of the children, the assessment approach must be capable of capturing these (Margrain, 2009). Current assessment practice in New Zealand, England and Wales, is indicative of recent curricula reform and as some researchers view it, a paradigm shift in the way in which assessment is perceived (Broadfoot, 1994; Wolf, Bixby, Glenn \& Gardner, 1991). The focus has shifted towards a broader, less compartmentalised, assessment of the individual. This sociocultural approach to assessment is a relatively new phenomenon, which does not align with previous motives for assessment, such as ease of generalisation and replication associated with a more traditional type of testing. A number of researchers point out that viewing assessment in a scientific objective way is flawed, as assessment is not an exact science (Broadfoot, 1994; Wolf, Bixby, Glenn III \& Gardner, 1991). Our interpretation of knowledge is determined by our own values and beliefs and the continuing re-interpretation and evolvement of this knowledge must take into account the social and cultural influence around us. Bruner and Haste (1987) state that through "social life, the child acquires a framework for interpreting experience and learns how to negotiate meaning in a manner congruent with the requirements of the culture.

'Making sense' is a social process; it is an activity that is always situated in a cultural and historical context." (p.1).

Assessment, according to this viewpoint, is a social activity and we can only fully understand it when taking into account the social, cultural, economic, and political frame in which is operates (Delandshere, 2002; Moss, 2008). The manner in which assessment is carried out, for example through more objective standardised 
tests or through more subjective criterion based assessment, illustrates a particular ideological perspective, and the way in which students respond to the assessments suggest particular social and cultural influences (Gipps, 1999).

Approached in this way, it can be claimed that assessment has the potential to support the development of learning and contribute towards positive outcomes for students in social studies (Aitken \& Sinnema, 2008; Gipps, 1999). However, there still remains a tension between the political behaviourist driven demands of standardised testing that aims to sort and rank students, as in the practice in the United States and the personal practice driven more so by sociocultural principles. This tension is illustrated by Yildirim's (2004) study of 81 Turkish schools. Yildrim described the 'personal angst' that teachers felt following an inspector-driven assessment regime when they valued assessment practice that aligned more so with an assessment for learning ideology. In the New Zealand context, Year 9 and 10 curriculum and assessment guidelines currently support a more sociocultural approach, although as indicated earlier the pressure to perform in high stakes NCEA assessments, may impact this practice. One could argue that focusing on one outcome set in this thesis contrasts with the holistic philosophy underpinning the assessment approach. However, the focus on conceptual understandings in relation to the students' cultural and social situatedness has the potential to go beyond these boundaries. It enables conceptual understandings to be examined through a variety of perspectives, including looking at the decisions related to understandings.

Furthermore, it provides the basis to view the skills and competencies developed and the values modeled and explored (Ministry of Education, 2007b), as well as linking to other outcomes such as participatory and affective outcomes (Aitken \& Sinnema, 2008).

Despite these tensions I believe a more sociocultural approach to the gathering, analysis and use of evidence is an area worthy of further investigation. The following sections will, therefore, examine the literature related to narrative assessment, specifically learning stories, as a sociocultural approach. 


\subsection{Learning stories as an approach to gathering, analysing and using evidence}

Through the examination of the literature, this section explains why learning stories, a form of narrative assessment, has been used as the approach to gather, analyse and use as evidence to support the development of conceptual understandings. The first part will look at what learning stories are, how they have been influenced by sociocultural theory, and their use in education today.

\subsubsection{What are learning stories?}

Learning stories are a form of narrative assessment that are one way in which evidence can be gathered, analysed and used to support learning. Narrative is the medium through which we come to know; through which meanings are made (Bruner, 1991). Simply put, narrative assessment is the recounting of an event or sequence of events. It enriches and deepens experiences, by way of being meaningful to the storyteller and capturing their experience (Kramp \& Humphreys, 1993). Learning stories provide a particular way of seeing and interpreting a student's learning progress. When used in early childhood settings meaning is made though the sharing, construction and reconstruction of stories with other individuals, including the student. This interpretation, construction and re-interpretation process leads to a greater insight into the learner and provides valid, powerful assessment information to be fed back into the teaching and learning process (Carr, 2001).

Learning stories are seen as an effective educational tool because they are believable, memorable, and entertaining. Research shows that educational programmes that aim to foster tolerance, appreciate diversity and have a capacity for perspective-taking draw upon narratives or stories (Rossiter, 2002). Learning stories permit and even compel students to include their experiences of doing the work as well as the work itself. Learning stories, then, relate process and product. They help students to understand how they did what they did, as well as what this means for themselves as learners. A study carried out by Kramp and Humphreys (1993) supports this notion. They investigated adult learners using stories, self-assessment and reflection at Alverno College in the United States. The researchers found that the learning stories enriched learners' understanding and appreciation for the many aspects of self-assessment. Often the students' own words led to insightful 
observations. As one student said, "I didn't really notice it happening to me, until I kinda stepped back away from it, like the painting, you know, where you stand too close you just see the little dots, and once you back up, you go, 'Wow!' And you see the whole thing" (Kramp \& Humphreys, 1993, p. 85).

Whilst the benefits of learning stories are considerable, research has shown that there can be difficulties with a narrative approach. One study looked at high school student's perceptions of narrative evaluations as summative assessments. They concluded that students found narrative evaluations more stressful, but ultimately more useful in terms of the amount of personalised information supplied. The teachers also found the personalising very useful, although it was noted that the approach was time consuming (Bagley, 2008). In this thesis it is hoped that the learning stories, written from the student's perspectives should reduce the stress students feel, as they own the work, and will also reduce the time factor for the teachers involved.

Smith and Gorard (2005) carried out an experimental study in a British middle school on the use of assessment for learning narrative feedback. The findings were surprising and contrasted with existing assumptions. Their research was based on a Year 7 group where students were split into four mixed-ability classes. One of the classes was identified as the experimental group and the only feedback they received was in the form of comments. The other classes received feedback that was related to the current practice at the time - dominated by grades. The researchers found that the experimental group's achievement was substantially inferior to the other groups. One possibility given for this surprising finding, was that the feedback comments, such as such as "good" and "try harder next time" that were given to the experimental class were not 'formative' in nature and did not feed back into the learning process. This highlights the importance of good feedback. In Glenn's (2010) research into using feedback logs to improve academic writing in secondary classrooms, she concluded that feedback by teachers is a key influence on successful learning. However, the effectiveness of the feedback relies on its quality. These research findings are pertinent to this study as potentially both parents and teachers will be providing feedback to the student on their learning stories.

\subsubsection{Sociocultural influences on learning stories}

The sociocultural approach to the research is described in Chapter Three; therefore this section will review the literature pertaining to the sociocultural nature of 
the learning stories themselves. It gives a brief overview of the three key features of sociocultural theory in relation to learning stories; firstly, the situatedness of learning; secondly, viewing learning as the increasing ability to participate in the community of practice; and thirdly, the distributed nature of cognition across the community. Situatedness of learning refers to the development of individual intelligence embedded in the social and cultural context (Bruner, 1996), whereby meaning is made from the cultural communities we find ourselves in. Therefore, at an educational level we need to be aware of the communities our students belong to so we can best meet their learning needs and view schools as part of society, and therefore part of our culture.

Some researchers argue that curriculum and assessment practices should construct "communities of practice" (Wenger, 1998). Communities of practice are groups of people who share a concern or a passion for something they do. Newer and younger members learn from those who are experienced at the practice of the community. Learning is found to be more effective when students actively increase their ability to participate in co-constructing knowledge in supportive communities of learners (Lave \& Wenger, 1991). From a sociocultural point of view, the people involved in the community of practice contribute to the processes involved at the same time as having inherited practices. Rogoff's (1995) work emphasises how crucial it is to the learning process that participants possess a sense of belonging to the community, identify themselves as members and share common values. Lave and Wenger (1991) also agree that social participation is integral to learning but view it more in the value of the difference in perspective of members of the community. Therefore, learning takes place with all members of the community, although it is the 'apprentice' who gains the most from the learning process. This is highly pertinent when considering the application of learning stories, as the community, student, teachers, parents and whānau, are all active participants in the process. This participation includes not only the learning but also the assessment about every day responsive and reciprocal relationships with people places and things (Carr, 2004; Gipps, 1999).

Whilst the concept of the distributed nature of cognition is not a new idea it was revived in the 1990's by cognitive science researchers such as Edwin Hutchins (1995). His seminal study on the investigation of a ship's navigation referred to cognition not just being in one person's head, but also extending beyond the skin to 
the material and social world. He described his view on the distributed nature of cognition by explaining how the ships navigation was fixed as a result of complex individual components that came together. Cole and Engestrom (1993) took an educational view of the distributed nature of cognition, using the analogy of learning to read, and illustrating how the process is not just an individual activity, but joint efforts by the teacher, student and child to regulate the learning to read process, much like learning how to research. This distributed nature of cognition can also be extrapolated to the learning story process, whereby social and material aspects determine cognition, these social aspects in particular involve the collective responsibility of the community with the learner at the centre as well as teachers, colleagues, family and whānau. (Karasavvidis, Kommers and Stoyanovan, 2002).

\subsubsection{Learning story use in education in New Zealand}

The introduction of learning stories in New Zealand, in the late 1990's demonstrated a significant shift in thinking about assessment and learning from an objective, checklist, deficit thinking, skills based approach to a more interpretive, complex, credit enhancing approach which focused on enhancing dispositions in the context of the learning (Carr, 2001; Carr et al., 1999). The credit enhancing approach is a positive appreciative way of documenting the learning that is being observed and displayed, rather than highlighting the learning that is absent (Moore et al., 2008).

The learning story approach has been used extensively in early childhood education to align with Te Whäriki, the curriculum document guiding early childhood education in New Zealand (Ministry of Education, 1996), and reflects early childhood philosophies and practices. Te Whāriki is informed by Urie Bronfenbrenner's (1979) ecological-contextual model, which provides a framework for understanding the contexts in which humans develop. It is an approach that emphasises the importance of relationships and whānaungatanga (connecting as one people). Bronfenbrenner's (1979) model is founded on the idea that the social worlds of children and their families are intimately connected in a number of ways. Learning is enhanced when there are connections and relationships between settings away from home and other places and spaces in children's lives. In Carr's (2004) view, complex connections such as these require assessment to keep it complex.

A dispositional framework guides the learning story approach, where learning outcomes combine knowledge, skills, and attitudes (Ministry of Education 1996). 
Carr's $(1998,2001)$ research with teachers explored five dispositions-in-action taking an interest; being involved; persisting with difficulty, challenge, and uncertainty; expressing a point of view or feeling; and taking responsibility. These dispositions gave the basis for individual learning communities to explore what learning dispositions were important and relevant to them. Carr et al. (1999) found that learning stories were well received and reflected research into how and why children learn, and the methodologies that best assess and evaluate this process.

The practice of assessing using learning stories has also been applied in primary education with regard to the key competencies and in secondary special education to capture aspects of curriculum not easily assessed in any other way (Dunn, 2000; Margrain, 2009). Recently, the Ministry of Education developed a narrative assessment resource to be used with students with special educational needs (Ministry of Education, 2009b). This resource has been used, along with other material, to inform the design of the learning stories in this thesis and is described in more detail in Chapter Three.

There is limited evidence of further application in New Zealand beyond the instances described above. In primary and secondary education the use of digital stories and electronic portfolios have characteristics in common with learning stories. Digital storytelling is regarded as the "modern expression of the ancient art of story telling" through the powerful display of images, music and narrative (Rule, n.d.). Both learning stories and digital stories aim for the learner to be intrinsically motivated in their learning by the development of ownership and engagement with the stories. This allows for learners to emotionally connect with the process, which in turn supports deep learning. Deep learning involves reflection, is developmental, integrative, self-directive and lifelong (Cambridge, 2007), all aspects that educationalist strive to achieve for their learners. Barrett (2005) contends that greater learner control over content, purpose and process of portfolios will lead to the development of student intrinsic motivation. However, Barrett (2004) also acknowledges this assumption is untested and requires future research.

This section has described the literature relating to the use of learning stories in New Zealand; the following section presents the literature to support the learning stories as a culturally inclusive assessment. 


\subsubsection{Learning stories, a culturally inclusive assessment}

Another key motivator for this research was the belief that learning stories could be a tool that could authentically support learning for all and provide rich information about that learning (Wolf et al., 1991). The literature has already explored how learning stories can be applied in early childhood settings, primary and special education, and the following section explores how it can reach out across cultures.

Culturally responsive teaching and learning is an area of national interest in education in New Zealand. Our education system, through the national curriculum, is striving to develop competent confident actively engaged lifelong learners, "who will work to create an Aotearoa New Zealand in which Māori and Pākehā recognise each other as full Treaty partners and in which all cultures are valued for the contributions they bring” (Ministry of Education, 2007b, p. 8). To promote success for Māori students, the Education Review Office has recently highlighted a number of areas that schools need to focus on when being reviewed. ERO stated that, in addition to good classroom teaching and appropriate pedagogy, schools need to adopt effective classroom and school-wide practices for assessment, improve relationships with whānau so that home and school can work in partnership to improve learning and build better relationships with Māori students, to help raise the expectations for achievement while also recognising the importance of te ao Māori (Education Review Office, 2010).

Initiatives such as Te Kōtahitanga (Bishop, Berryman, Powell \& Teddy, 2007) demonstrate how principles of culturally responsive teaching made a significant difference to student achievement and engagement through the commitment by teachers to build caring and learning relationships and interactions with Māori students, holding the belief that Māori students can improve their achievement, in conjunction with students taking responsibility for their learning (Bishop, Berryman, Powell, \& Teddy, 2007b). The student-centred, community driven principles of the learning stories, using students own stories to bring their learning alive appear to align well with a culturally responsive approach to teaching and learning. The learning stories have the potential to capture rich descriptions of learning in the context of culturally responsive pedagogy. The learning stories respond to local cultures, communities and contexts (Absolum, Flockton, Hattie, Hipkins \& Reid, 2009), enable teachers to view the students as mindful and competent in a variety of learning contexts, and allow multiple participants to engage and have their voices represented. 
The guiding principles of learning stories and the principles underpinning culturally responsive teaching and learning go hand in hand. The learning stories are student-centred, they provide a connection with whānau/family, use a positive credit enhancing approach and provide a basis for learning focused relationships, which allows for and encourages the expression and identification of all students learning. It relies on a reflective culture in action, with whānau involvement and the students directing their own assessment of their learning. Learning occurs through engagement and if it is reconceptualised then students feel a sense of belonging and responsibility. In Wearmouth, McKinney and Glynn's study on restorative justice for troubled Māori young men they noted how community norms and values of belonging helped encourage more socially appropriate behaviour (2007). This sense of belonging, therefore, could be fostered through a pedagogical assessment strategy such as the learning story approach.

\subsection{Students leading learning}

Whilst the previous sections have stressed the importance of involvement of the community in education, this section explores the specific roles that teachers and students are required to perform when supporting the development of conceptual understandings. At all levels of education teachers require sophisticated assessment skills if they are to identify what students know and can do as well as the further learning that is required (Timperley et al., 2007). In early childhood, learning stories are one method that teachers use to assess children's learning. These stories are usually written by the teachers and include family and whānau within the process (Carr, 1998).

This thesis explores assessment of, and with, Year 9 social studies students. It maintains the involvement of the family and whānau and teacher in the process, although the application of the learning story process has been adapted with the emphasis moving towards the students taking the responsibility for the storytelling. This storytelling can be viewed as one way that students can participate in selfassessment. It is an integral part of the teaching and learning process (Timperley et al., 2007), which if carried out honestly and transparently can have a significant influence on learning (Black, Harrison, Lee, Marshall \& Wiliam 2003).

Research states that if students are actively engaged in the learning process they will take ownership of their learning and become more independent (Absolum, 
Flockton, Hattie, Hipkins, \& Reid, 2009; Ministry of Education, 2010). This is reinforced in research by Harlen and James (1996) who argue that students "... have to be active in their own learning (teachers cannot learn for them) and unless they come to understand their own strengths and weaknesses, and how they might deal with them, they will not make progress." (The Nature of Formative Assessment). Sadler (2002) Crooks (1988) Natriello (1987) Black and Wiliam (1998) all report that personal reflections and social interactions involved in self assessment are particularly effective in supporting the development of deeper understanding and therefore higher achievement. Assessment-capable students are more likely to be more self-motivated, (Ministry of Education, 2010) and as Minstrell and Kraus (2007) found, students who engage in self-assessment deepen their grasp of conceptual understanding.

With students taking on this responsibility, the role of the teacher may change from assessor of learning to a facilitator of learning. Students do not automatically know how to self-assess and so teachers will need to support the development of metacognitive skills so that students learn how to be reflective, understand the main purpose of their learning, and understand what they need to do to achieve (Black \& Wiliam, 1998). McManus (2008) asserts that clear guidelines and criteria for success need to be developed, and teachers need to model how to give good feedback.

Torrance and Pryor's (2001) action research study pointed towards the critical role the teacher plays. The researchers concluded that the teacher's judgement is vital in building the reference framework for self-assessment. Furthermore, OECD research findings reported that modeling learning behaviour, teaching self-assessment skills and supporting students to analyse this information, was shown to be effective, particularly for students who do not have extra support for learning at home (OECD, 2003; OECD/CERI, 2008).

As students move through the curriculum, the scaffolding provided by teachers changes. Absolum and his colleagues (2009) believe that as students get older they should be given more practice at making judgements about their own learning. This practice supports them to become less reliant on feedback from their teachers and better able to reflect critically on the assessment evidence of their own learning progress and goals. Assistance given by the teacher may not be in the provision of judgements or feedback, but the resources provided that could assist students to develop a range of strategies for self-assessment. 


\subsection{Summary}

Research shows that learning stories are able to communicate the complex ways in which students learn and provide a powerful picture of the strengths, skills, and values that more traditional forms of assessment fail to capture (Moore et al., 2008; Margrain, 2009). Social science research also indicates that this is an area that social studies can benefit from. Aitken and Sinnema (2008) stress the need to move beyond simplistic, one-dimensional assessment towards a more complex understanding of outcomes such as conceptual understandings. In response, this thesis will investigate how learning stories can contribute to the gathering, analysis, and use of evidence to support the development of conceptual understandings. The literature in Chapter Two highlighted how the learning story approach is grounded in sociocultural theory (Gipps, 1999). In addition, the review found that teachers' conceptions of assessment are usually based on their conceptions of learning - a teacher who holds a sociocultural view of learning will tend to favour assessment practice that aligns also, and this includes narrative assessments (Harlen, Gipps, Broadfoot, \& Nuttall, 1992). Similarly, learning stories have grown out of a sociocultural approach to education, particularly in relation to the dispositional elements of Te Whāriki, the early childhood curriculum. Thus, using a sociocultural approach to the methodology aligns naturally within the context of this research and will be discussed further in Chapter Three. 


\section{CHAPTER THREE Methodological approach}

\subsection{Introduction}

This chapter outlines the methodological approach to this research using a sociocultural perspective. It explains why the approach to the research is design-based and qualitative and why it is made up of a single in-depth case study. The chapter outlines the data collection methods and the framework used to analyse the data, including the assessment of the ethical considerations regarding this approach.

\subsection{Sociocultural approach to the research}

The theoretical orientation to my research, sociocultural theory, frames the nature of the research and strengthens the validity of my findings and the arguments and explanations I put forward (Mutch, 2005). Sociocultural theory draws on the work of Vygotsky (1978) who argued that a child's development cannot be understood by the study of the individual alone but within the context of the social environment. Vygotsky (1978) argued that the mind is mediated, and that humans use psychological and tangible tools to change the world and mediate our relationships with others and ourselves. Children develop their use of human and psychological tools via interactions with more highly skilled partners within their zone of proximal development. For example, children's higher mental processes are formed through the scaffolding of their understanding through social interactions with skilled partners (Smith, 1999) and these partners can be their peers, teachers, family or whānau. Therefore, each generation reworks their cultural inheritance to meet the needs of their communities and individuals (Lantolf, 2000). This acknowledgement of learning, reflection and growth within a community of practice formed the basis of this research. Sociocultural approaches are increasingly being used to make sense of classroom teaching (Cowie, Moreland, Otrel-Cass \& Jones, 2008), and it was therefore appropriate to situate this research in an educational setting where social and cultural influences can be absorbed.

My role as a researcher is influenced by sociocultural theory through the ideas of situatedness and distributed cognition. Firstly, the approach to this research is 
designed to be iterative and informed by each phase. To do this in a sociocultural sense, it was important to initally immerse myself and develop an understanding of the community I found myself within. Once this was established, my researcher role became part of the community of practice with the shared aim of evaluating the learning story approach. The mutual learning by the teachers, students and myself, through Inquiry Cycles One and Two, then worked towards a convergence of understanding.

\subsection{Research design}

The research utilised a qualitative approach within a sociocultural framework. The qualitative methodology was fundamentally interpretive, allowing for the genuine exploration of the learning story approach in an educational environment, as the research emerged and evolved (Marshall \& Rossman, 2006).

This research used a design-based methodology as it allowed for inquiry, interpretation and multiple iterations of the learning story approach. as an intervention in a naturalistic setting. Design-based researchers argue that the interweaving of theory, research and practice can produce meaningful products or models, through a series of iterations (Bannan-Ritland, 2003; Cobb, 2003; The Design-Based Research Collective, 2003). Design-based research does not seek to identify causal links, and is more interpretable in its approach. It also allows for aspects of teaching, such as assessment to be studied through the theoretical lens that contributes to the learning, in this case sociocultural theory. The research approach considers the practical aspects of the intervention and how it can be applied to everyday settings, along with the consideration of multiple voices - in this case the participants involved in the research (Brown, 1992).

To understand why this approach was chosen it is important to consider briefly its origins. Design-based research studies can be dated back to Dewey (1896) who pioneered a research model that employed the systematic study of teaching and learning associated with the enactment of complex educational interventions at the laboratory school at the University of Chicago. The approach re-emerged in the 1990's, and was referred to as design experiments, design studies and design-based research in education (Bell, Hoadley \& Linn, 2004; Collins, Joseph \& Bielaczyc, 2004). Design-based research aims to inform educational theory and practice (The 
Design-Based Research Collective, 2003), as well as focusing on specific contexts. The term design experiments was introduced by Ann Brown (1992) and Allan Collins (1992) to describe a methodology that addressed theoretical questions in real life settings and that was formative in its approach. It is important to note that there is no one type of methodology, practice and theoretical approach associated with design experimentation, which poses difficulties for the advancement of this area (The Design-based Research Collective, 2012). Whilst, Dede, Nelson, Jass Ketelhut, Clarke and Bowman (n.d.) affirm that the community are still at odds to define design-based research, they explain how the focus of design-based research is on how the strengths and limits of a design informs theories of learning. So, in the case of this research, the Learning Story Framework provides the design, and the study of this will help to inform the sociocultural approach for assessment. Dede, Nelson, Jass Ketelhut, Clarke and Bowmann. (n.d.) go on to present five key characteristics of design-based research (see Figure 3.1) that are useful when considering this research.

Design-based research tends to follow a three-phase approach; design, enactment and detailed study (Bannan-Ritland, 2003). In this research, I extended this idea further to include multiple re-designs, this is illustrated in Figure 3.5, which shows the three phases to the inquiry, with opportunities for detailed study and reenactment within and between each phase.

\section{Figure 3.1: Five key characteristics of design-based research}

- Goals of designing learning environments and developing theories or 'prototheories' of learning are intertwined.

- Development and research takes place through continuous cycles of design, enactment, analysis and redesign.

- Research leads to theories that communicate relevant implications to practitioners and other designers.

- Research accounts for how designs function in authentic settings, not only documenting success or failure, but also focusing on interactions that refine our understanding of the learning issues involved.

- Research relies on methods that can document and connect the process of enactment in conjunction with outcomes of interest.

Dede, Nelson, Jass Ketelhut, Clarke and Bowmann (Design-based research, n.d.) 
For the purposes of this research, I needed to take into account the sociocultural perspective upon which it had been grounded, and the context the research was based within. This is because the learning story intervention needs to be a practical tool that teachers will be able to use in their everyday situations. This approach relied markedly on the respectful, mutual partnership developed between teachers, the students and myself. The learning story approach was co-constructed as the study moved through each inquiry cycle; a partnership that exemplified a sociocultural approach to the research, which considers all participants, including myself, as mutual learners in the process.

Design-based experiments tend to utilise a quasi-experimental approach, combining ethnographic research with quantitative data. However, as I discussed in Section 3.2 the sociocultural nature of this research in conjunction with the Learning Story Framework lent itself more to a qualitative approach, allowing for an in-depth exploration and adaptation of the learning story approach. If future research is warranted, then a more mixed-methods design could be considered to widen the scope of the exploration of the final version (three), of the Learning Story Framework. The quasi-experimental approach would assist to increase experimental validity, but is dependent on the nature of future research in this area.

\subsection{Case study methodology}

Case study research can be presented in a variety of forms, with Yin (2003) describing case studies as being explanatory, exploratory, descriptive, and either as single, holistic or multiple case studies. This research used an exploratory case study approach as I was attempting to explain or describe phenomena, and inquire into the outcomes related to the use of learning stories. Using a case study approach allowed for the learning story intervention to be explored through a variety of lenses; in this case, firstly myself as the researcher, and secondly the students and the teachers; providing the opportunity for greater insight (Baxter \& Jack, 2008). Using the multiple interpretations from the participants and myself in their school, situated the case study within a specific social and cultural setting, using a specific set of boundaries (Denzin \& Lincoln, 2005; Yin, 2003).

I considered the case to be exploratory for two reasons, firstly I was interested in looking in-depth at the assessment practice and secondly as the focus of this 
research had not been carried out before, I considered it a prelude to other research, enabling me to gather information from a variety of sources including direct observation, interviews as well as documents and artefacts (Yin, 2009). Case study research depends on the use of a variety of methods to be used in an attempt to gather the complexity and richness of the information (Denzin \& Lincoln, 2005). Rather than seeking to objectively validate information (the motive of quantitative research), I aimed to triangulate practice using observation, reflection, participant perspectives and empirical evidence to make sense of the information.

\subsection{Case study participants}

The research used a purposive sampling procedure to select a case study that typified a multi-cultural, culturally and academically diverse secondary school social studies department (Patton, 2002). Figure 3.2 presents the demographic information for the case study, and the procedure for requesting the participants follows. 
Figure 3.2: Case study demographics

\begin{tabular}{|c|c|c|}
\hline College details: & $\begin{array}{ll}\text { - } & \text { Single sex, boys } \\
\text { - } & \text { decile } 8 \\
\text { - } & \text { multicultural }\end{array}$ & $\begin{array}{l}\text { - } 800 \text { students } \\
\text { - } \quad \text { Wellington region }\end{array}$ \\
\hline $\begin{array}{l}\text { Ethnic } \\
\text { breakdown }\end{array}$ & $\begin{array}{l}\text { NZ European/Pākeha } \\
\text { Pacific } \\
\text { Asian } \\
\text { Māori } \\
\text { Other ethnic groups }\end{array}$ & $\begin{array}{l}46 \% \\
18 \% \\
13 \% \\
11 \% \\
12 \%\end{array}$ \\
\hline Department: & \multicolumn{2}{|c|}{$\begin{array}{l}\text { Four social science teachers involved in the research: } \\
\text { - Idris, history teacher, } 9 \text { years teaching experience } \\
\text { - Hohepa, history teacher, } 2 \text { years teaching experience } \\
\text { - Sam, geography teacher, } 5 \text { years teaching experience } \\
\text { - James, history teacher and head of the social science } \\
\text { department, } 12 \text { years teaching experience }\end{array}$} \\
\hline Students: & $\begin{array}{l}9 \text { Year } 9 \text { students in tota } \\
\text { From James' class: Ben } \\
\text { introductory phase only } \\
\text { From Sam's class: Thon } \\
1 \text { Asian of origin }\end{array}$ & $\begin{array}{l}4 \text { years } \\
\text { nie and Ryan. Henry for the } \\
\text { of origin } \\
\text { iam, Blake. } 3 \text { Pākeha of origin and }\end{array}$ \\
\hline
\end{tabular}

A systematic process was instigated for requesting participant involvement. Firstly, the school principal was initially approached to request the involvement of the social studies department and students in the study. Once consent had been given, the head of the social studies department was contacted. The teachers in the department were invited to participate in one of two ways. They could contribute to one department meeting, alternatively they could participate in-depth. The in-depth participation involved the teachers being involved in two inquiry cycles (see Figure 3.5 for the methodological process), whereby they were subject to interviews and researcher observation of their Year 9 class from which the students were drawn. For 
comparison purposes, it was desirable for the two teachers participating in-depth to be teaching the same units of work at the same time. Once the two in-depth teachers were confirmed, these teachers chose five students from their own social studies classes to be involved in the research. Students were initally chosen on the basis of reflecting the cultural and academic diversity in the school and their likelihood to be able and willing to be involved, including the acceptance of parents, guardians and whānau involvement. Students were not obliged to take part in the study and a careful process was followed to ensure students felt safe and secure in their decision to participate. The details of this process can be found in Section 3.8, which elaborates on the ethical procedures followed. As part of the sociocultural nature of the research, I also viewed myself as a participant in the process, learning, analysing and coconstructing alongside the other participants.

Two information meetings took place at the beginning of the research, the first meeting served to familiarise the social studies department with the research and the second meeting was a more formal introduction to the research which all potential participants were invited to attend. Two further meetings were arranged for the teachers and students to become familiar and confident with the use of the Learning Story Framework. These occurred between the Introductory phase and Inquiry Cycle One, and between Inquiry Cycle One and Two. The final meeting was for all participants to share in the research findings and draw the research to a close.

\subsection{Design of the Learning Story Framework}

A Learning Story Framework (see Appendix A) was developed to examine the use of learning stories to support the development of conceptual understandings. The framework served as a guidance template whilst the teachers and students got used to the learning story approach. The literature provides some guidance in this area, although as section 2.4.3 highlights, there is little application in secondary settings. Figure 3.3 summarises the factors that were synthesised from the literature and considered when designing the Framework. 
Figure 3.3: Factors that informed the design of the Learning Story Framework

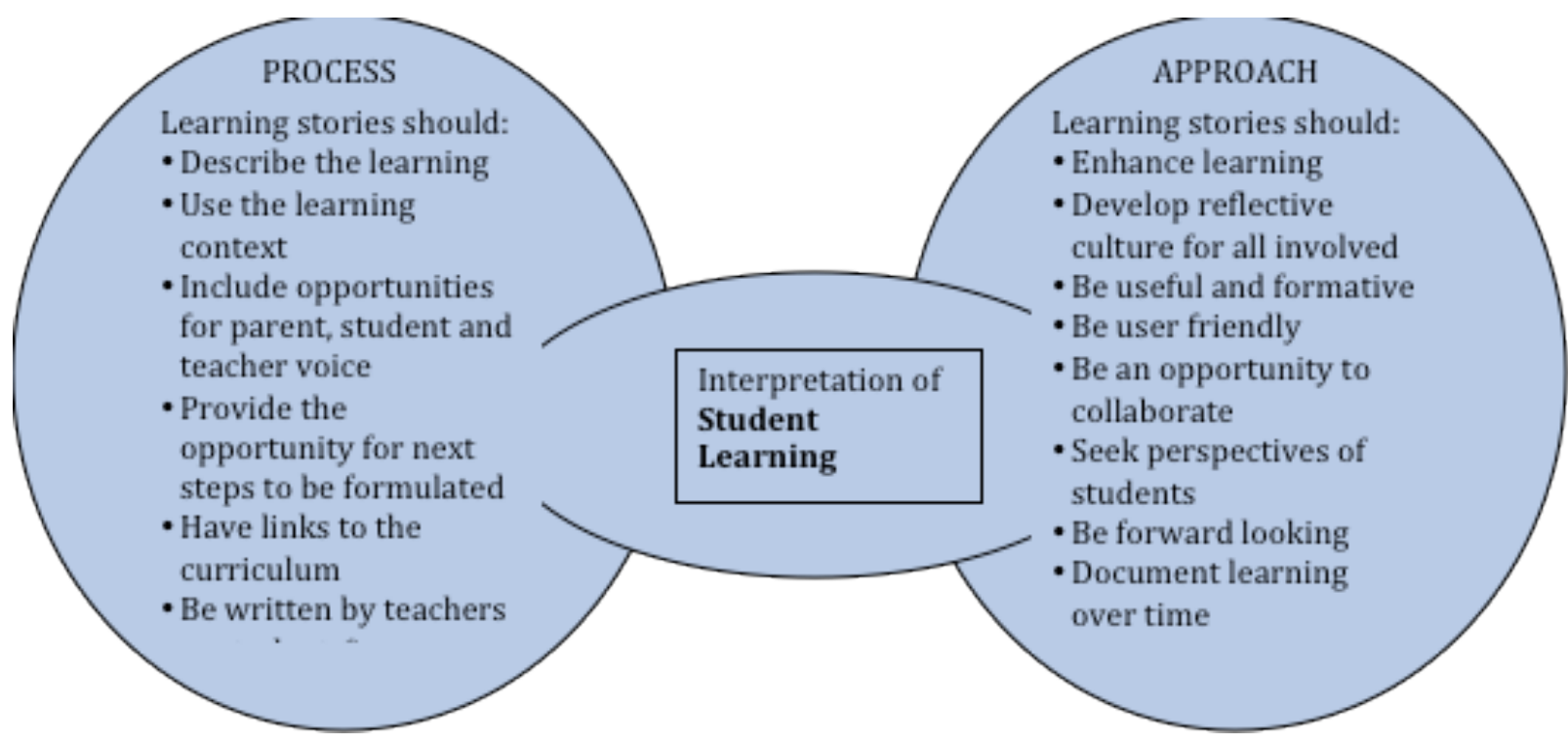

Developed using Carr, et al., 1999; Carr, 2001; Ministry of Education, 2004; Ministry of Education, 2007; Moore, et al., 2008).

Taking into account these factors from the literature at the beginning of the research, I developed the first version of the Learning Story Framework (Appendix A). It was intended that teachers would use this framework during the first inquiry cycle as the basis for critique and development of further iterations of the Learning Story Framework. Whilst the literature referred to teacher-written learning stories, I was interested in teacher written stories only during Inquiry Cycle One, as a means for exploring student written stories during Inquiry Cycle Two.

It is important to note that the early childhood frameworks steer teachers towards noticing children's learning dispositions evident in Te Whäriki the early childhood curriculum (Ministry of Education, 1996). By contrast, and in line with my research questions, this framework attends to social studies students' conceptual understandings in relation to the Level 5 achievement objectives of The New Zealand Curriculum (Ministry of Education, 2007). 


\subsection{Data Collection methods}

\subsubsection{Introduction}

The case study approach described in Section 3.4 guides researchers to collect a range of qualitative evidence to enhance the validity of the research (Denzin $\&$ Lincoln, 2005). In this study, I intended to use a range of tools which could be triangulated to inform the analysis of information. The main data collection tools were participant observation, semi-structured interviews and document analysis including reflection journals, student artefacts and departmental planning documents. A range of documentation was also collected to strengthen the validity of the interviews and observations. It has been shown that studies which use only one method of data collection are vulnerable to the inaccuracies, it is recommended to include a range of collection information that can be cross checked and validated (Patton 1999).

The methodological approach summarised in Figure 3.5 illustrates the iterative nature of the research. Data collection followed three phases, spanning six months. This was longer than originally intended, but unavoidable delays, including teacher absence and summative student assessments extended this time period.

To situate myself within the community of practice, I examined current assessment practice through participant observation and document analysis during the Introductory phase. This also served to provide an understanding of practice prior to the exploration of the Learning Story Framework. Inquiry Cycle One served to introduce the Learning Story Framework to all participants, with James and Sam taking responsibility for the writing of these. This modeling was to feed into Inquiry Cycle Two, when the students took responsibility for the writing of the learning stories. Interviews, conversations and reflections in response to Cycle One were integrated into an evaluative process that allowed adaptations to be made to the learning story approach in readiness for Inquiry Cycle Two (see Figure 3.4.) 
Figure 3.4: Learning story implementation process for Inquiry Cycle One

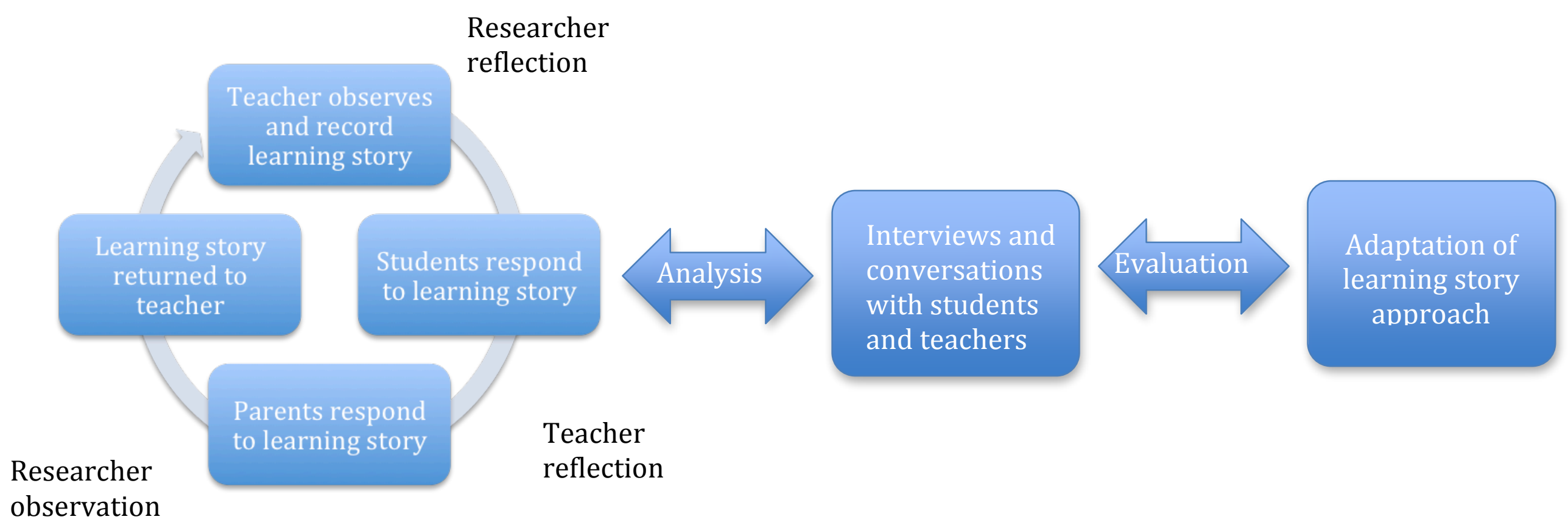




\section{Figure 3.5: Methodological process}

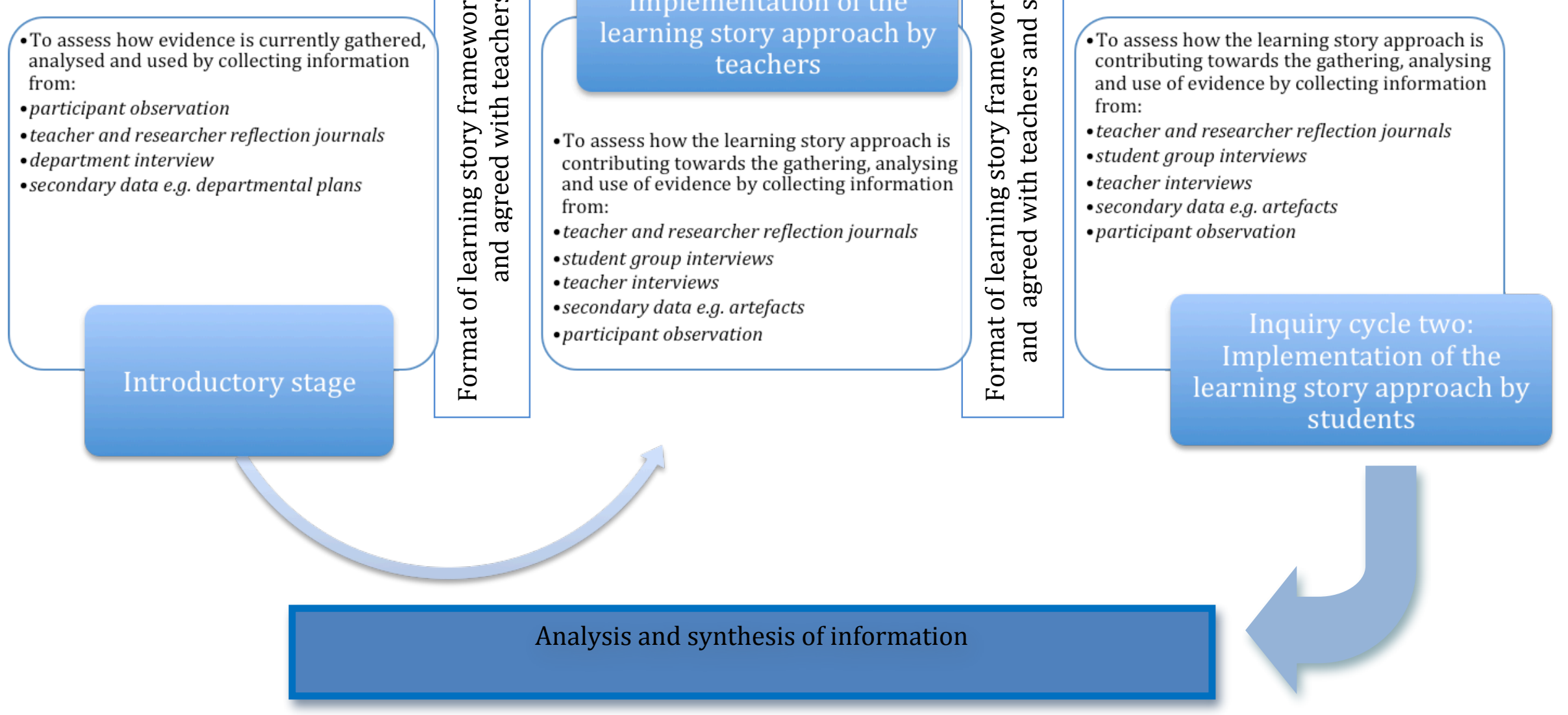




\subsubsection{Semi-structured interviews}

The interview provided a significant source of qualitative case study information, it gave conversations depth, detail and richness (Patton, 2002). Furthermore, it allowed for deeper responses because semi-structured interviews are open ended (Yin, 1994), and this prompts students and teachers to express their knowledge, perspectives and opinions. Wilkinson and Birmingham (2003) caution that interviews are not an easy option, and that researchers require a high level of skill to manage the conversation in an open, yet guided fashion. To overcome this, I combined the openness of the interview with a semi-structured approach where I planned the questions prior to the interviews. This provided a framework to guide the conversation (see Appendix B). It offered a flexible approach and allowed me to build on points of interest that emerged through the process (Cohen, Manion, Morrison \& Morrison, 2000).

During the research study the students were involved in two semi-structured focus group interviews. Focus group discussions offer participants the opportunity to construct for meaning and the power to contribute to be constructed amongst the students (Krueder \& Casey, 2000). It was envisaged that this would lead to more insightful recall and construction of ideas and sharing of perspective (Anderson, 1998 ) as the students would feel freer to express their opinions. To enable the students to participate fully, focus group protocols were drafted and then agreed upon (see Appendix C).

A semi-structured conversational approach was adopted for the in-depth interviews with teachers in the social studies department. Conversational interviewing is designed to assure that all participants understand the questions as the interviewer intends. I attempted to say what was needed to help participants interpret the questions correctly. Therefore, it was the correct communication of the meaning of the questions that was important rather than the wording (Conrad \& Schober,1999). Analysis of the information collected in this way can be complex and time-consuming (Patton, 2002), but this was outweighed by the insight and depth of responses which occurred. Chapters Four and Five include references for the material collected from student and teacher interviews using the following format: (name/I/day and month). The names are pseudonyms to protect the participants' identities, 'I' stands for interview and the date refers to the actual date the interview was carried out. Personal 
journals and documentation analysis were also used and this followed a similar format, replacing the $I$ for $J$ or $D$ respectively.

\subsubsection{Interview procedure}

The focus group interview with the social studies department took place at the beginning of the research, in a classroom, after school. The student focus group interviews were held at the end of Inquiry Cycle One and end of Inquiry Cycle Two. In the initial research design the plan was for all students to be interviewed as one group. However, it proved difficult to get all the students together, and in an attempt to minimise disruption, the student interviews were carried out during their social studies lessons. The students were interviewed in two groups of four. It was hoped that students felt more comfortable with their peers from their own class, and more conversation would be forthcoming. The students were interviewed in a large room adjoining the classroom. There were a few interruptions and distractions, but these had minimal impact on the flow of the interview. In an attempt to put students at their ease, group protocols were initially established using a co-constructed approach (see Appendix C). The interview questions were open ended manner and in the order that best suited the group and the discussion (Johnson \& Christensen, 2008). The framework for the interview questions can be seen in Appendix B. Interviews were recorded by a voice-recorder and brief observation notes were taken so that all details and context could be noted for analysis, but did not take away from managing the flow of conversation, allowing for student voice to be acted upon.

The conversational interviews were held with the two teachers at the end of the Introductory stage, end of Inquiry Cycle One and the end of Inquiry Cycle Two, as shown in Figure 3.5. The first interview was held in the classroom, which provided privacy. The second was held in the staffroom, which provided an informal atmosphere for the interview. However, due to the number of disruptions in the staffroom, it was decided that the final interview was held back in the classroom. In the original design of the research only two interviews were planned to take place at the end of each inquiry cycle. However, as the research followed an emergent model, it was felt that an informal interview was required to discuss and share findings from the Introductory stage of the research to inform Inquiry Cycle One. The framework for the interview questions can be seen in Appendix C. Interviews were once again recorded by a voice recorder and brief observation notes taken. 


\subsubsection{Participant observation}

Observation of participants at each stage of the research provided another form of rich data for analysis (Yin 1994). Interviews and participant observations are complimentary methods of data collection. Participant observation, from a sociocultural perspective, refers to the method of collecting data within a social and cultural context. Jorgensen (1989) believed that participant observation is appropriate for exploratory studies and hence it is entirely appropriate for the use of exploring the implementation of learning stories. Participant observation allows for a perspective that is difficult to capture in an interview. My involvement as a participant in the research, learning alongside the teachers and students meant that I could develop an understanding of the perspectives of the students and the teachers (Sociology Central, 2003). This is integral to the design-based nature of the research, which aims to develop a practical tool that can be used in the classroom. It allowed me to gain an indepth understanding over the six-month period and identify the context in which attitudes values and knowledge were developed and portrayed (Becker \& Greer 1957). However, my observation is limited to this one case study (Kawulich, 2005) which impacts on the generalisability of this research. My participation evolved as the research progressed. Firstly I was a learner, but as students and teachers got used to my presence and my participation, I became more integrated into the classes.

Participant observations were carried out for the duration of the research in James and Sam's Year 9 social studies classes. This occurred three times a week, for fifty minutes. One of James and Sam's lessons clashed, and so my attendance was split between these times. During the introductory stages the participant observation focused on collecting evidence relating to James and Sam's current assessment practice, student responses to this practice and the development of conceptual understandings. The use of the assessment practice was only formally noted when interactions involved the focus students as permission had not been sought to use the information from other members of the class. During the inquiry cycles assessment practice and responses continued to be observed. I developed an observation framework to record this data (Appendix D). However, as the research evolved and my role in class became increasingly integrated into the teaching and learning process, by assisting students with their teaching and learning, I frequently completed my observation notes after the class. 


\subsubsection{Documentation}

Documentation can be an important element of triangluating the evidence to enhance credibility. Documentation can reveal what people do and what they value and can corroborate what interview participants report. It can reveal broader thinking than the snapshot of participant observation and interviewing, and may reveal thinking that has occurred without researcher intervention (Bowen, 2009).

During this research a range of documentation was collected. This included relevant department documentation, such as the unit plan and summative assessment, samples of student work as and when appropriate, and reflection journal notes which I completed to record my personal reflections and thinking at that time of the research. The teachers and students were also provided with reflection journals but these were rarely used, the implications of this can be found in Chapter Five.

\subsection{Ethical considerations}

Ethical consideration refers to "paying attention to the way in which the research is presented to potential participants, the likely impact of taking part in the research, the effects of sampling strategies, engaging with the researcher, and dissemination sessions" (Barbour 2008, pp. 78-79). This research strives to respect and consider ethical issues.

Approval for this study was given by the Victoria University of Wellington Human Research Ethics Committee. To gain this permission, consent was sought from the principal, head of department, teachers, focus group students, and parents. All potential participants received information sheets explaining the aims of the research, what would be required of them, and a learning story resource (see Appendices A and E for a sample of these). In addition, all participants were offered the opportunity to talk through the research and ask questions.

Signed consent forms were collected from all participants, a sample of the information letter and permission form can be found in Appendix E. Variations of the letters and permission forms were given to the principal, teachers, parents and students. It was explained to all participants that they could withdraw from the research at any time but information would be used up to the time of withdrawal if data analysis had begun. As this was a qualitative study, analysis began during the collection of evidence. No participants officially withdrew, although Henry went on 
holiday for six weeks, so whilst he was included in the introductory stages, it was not possible to include Henry during the inquiry cycles. To protect the identities of the school, teachers and students, pseudonyms were given.

Student participation was considered carefully, and all risks minimised. If a student declined to be involved in the research, it was clearly communicated that they would not be disadvantaged. The criteria for selection for the research was clearly communicated to all students in the classes so that everyone was aware that there was no negative reason or conversely no special reason for selection. It took approximately one week to organise the student participants, as some initally declined and others were reluctant to join and were not pursued. This eventuated in four students from each class agreeing to be part of the research, however this did not fit the original criteria of representing the multicultural nature of the school. Group protocols (Appendix C) were communicated and agreed upon during the focus group interviews with the aim to minimise discomfort. Where possible, I sought to address any concerns the students may have had. For example, it was clearly communicated that involvement in the study had no negative impact on assessments they were likely to participate in. It was also considered that Year 9 students may feel uncomfortable about parent involvement in the research. Family and community involvement is a specific focus of this research, so the students' concerns were discussed and they were reminded that they were under no obligation to participate. It was anticipated that students may also feel concern about any extra work required. In response, I explained to students that most of the 'extra work' would be carried out during class time, and they would miss some class time for interviews but would be expected to keep up with the work missed. This did not eventuate as an issue, students easily kept up with the work, and I chose times that had minimal impact on their study.

It was also important to consider the impact for the teachers involved in the research and the possible increase in workload. The expectations for teachers were outlined in the information letters. This concern was monitored and opportunities to discuss and mitigate this aspect provided if necessary. Both James and Sam were willing participants throughout the process, and did not express that taking the time to participate in the interviews was an issue. These issues were perhaps avoided as the interviews were arranged at times that suited all the participants.

Design-based researchers assert that to produce meaningful change there needs to be a strong partnership between the researcher and participants (The Design- 
Based Research Collective, 2003). The term partnership implies a shared collaborative relationship to mutually analyse the intervention of the learning story. As a new researcher, a major area of consideration for me was the conflict between my professional role as an adviser and my research role, being unsure of the separation and the overlap of the two and what it fully meant to participate in the community without using an expert-apprentice approach. Awareness of the potential influence of my own bias and the intention to maintain the integrity of the research (Gay \& Airasian, 2000) led me to write two reflection journals during the intial stages of the research - one for the research and one that could possibly overlap into my professional role. Writing the professional journal served as an outlet, keeping both responsibilities apart. As the research progressed the need to complete the adviser journal lessened as I became confident and comfortable with the qualitative researcher role, but I continued with the researcher journal for data collection purposes.

I also considered the trustworthy nature of the research and this is presented in Chapter Five, the following section explains the choice of analytic framework that was used.

\subsection{Data analysis framework}

Qualitative analysis does not follow a rigid formula to organise and interpret information, however related literature suggests some common approaches. Yin (2011) presented a five-phased cycle that includes compiling data, disassembling, reassembling, interpreting, and concluding. This is very similar to the pathway suggested by Creswell (2008), which refers to the organisation of material, coding, categorising, and identification of patterns to assist with analysis. In both cases the process is non-linear and dynamic, with movement back and forth, especially between assembling and disassembling of data.

The compiling phase began when the data was still being collected. Compiling can involve a basic organisation of data collected, including field notes, observations, interviews and empirical evidence. In this case, it specifically involved compiling my material in a logical order by transcribing the first interview and organising the observation and journal material. I then moved into the disassembling phase and immersed myself in the data, considering the meaning of this information with reference to the understanding of current assessment practice gained from the 
literature and from the evidence itself, so as significant new information came to light, it was included in the coding procedure. I followed a systematic procedure to note patterns and generate Level One codes (Marshall \& Rossman, 2006; Patton, 2002). I formatted each piece of evidence so that there was room to write notes on the side and around the text and then highlighted and marked significant elements of text and applied initial codes to the data. In a journal, I jotted down any key words that were repeated, key themes that were arising from the data, and initial interpretive thoughts. I read through the evidence again, disassembling and reassembling the data as many times as necessary (Yin, 2011). As I applied codes to the data I made constant comparisons to other pieces of text that were identified in the same way to ensure consistency of application (Gibbs, 2010). Further analysis of this data and the assigned coding led to the recognition of commonalities between codes and therefore they were grouped into Level Two codes. An example of this can be seen in Figure 3.6. This disassembling and reassembling occurred a number of times until appropriate codes were assigned and real meaning was created out of the data. The themes and concepts were then examined again for overlaps and collapsed into new codes or broader themes such as 'teacher driven practice.' Again, an example of this can be seen in Figure 3.6, whereby two elements of an assessment for learning approach were collapsed to produce this theme. This led to tentative interpretation and conclusions that could feed into the next cycle of the research (Yin, 2011). 
Figure 3.6: Coding process during disassembling phase - a snapshot

\begin{tabular}{|l|l|l|}
\hline \multicolumn{1}{|c|}{ Resource example } & \multicolumn{1}{|c|}{ Level One code } & \multicolumn{1}{c|}{ Level Two code } \\
\hline $\begin{array}{l}\text { Observation - T1 going } \\
\text { to each group checking } \\
\text { understanding }\end{array}$ & $\begin{array}{l}\text { Group checking by } \\
\text { teacher at their desks }\end{array}$ & Teacher walk \\
\hline $\begin{array}{l}\text { Observation - T1 } \\
\text { presented learning } \\
\text { intentions at the } \\
\text { beginning of the lesson, } \\
\text { linking back to the } \\
\text { previous lesson }\end{array}$ & $\begin{array}{l}\text { Link with prior learning } \\
\text { strategy }\end{array}$ & $\begin{array}{l}\text { Assessment for learning } \\
\text { strategy }\end{array}$ \\
\hline $\begin{array}{l}\text { Observation - T2 co- } \\
\text { constructed 'marking' } \\
\text { criteria with groups }\end{array}$ & Use of peer assessment & $\begin{array}{l}\text { Assessment for learning } \\
\text { strategy }\end{array}$ \\
\hline $\begin{array}{l}\text { Observation - basic } \\
\text { questions individually } \\
\text { completed }\end{array}$ & $\begin{array}{l}\text { No teacher or student } \\
\text { checking }\end{array}$ & $\begin{array}{l}\text { No formative assessment } \\
\text { strategy presented }\end{array}$ \\
\hline $\begin{array}{l}\text { Observation - Group } \\
\text { work involves peer- } \\
\text { checking understanding }\end{array}$ & Peer checking & $\begin{array}{l}\text { Co-operative learning } \\
\text { strategy }\end{array}$ \\
\hline
\end{tabular}

The focus for analysis of the inquiry cycles shifted from establishing current assessment practice to the examination of the learning story approach. Therefore, the five phase process was repeated, using an integrative approach (Johnson \& Christensen, 2008) drawing on the student and teacher transcribed interviews, observation and journal material and completed learning stories. The final write up consisted of 'vivid and detailed' and 'holistic' descriptions of the case study and its parts in the form of learning stories (Johnson \& Christensen, 2008, p. 409), drawing together this in-depth analysis of primary and secondary data in order to address the research questions for this study. 


\subsection{Drawing the sociocultural threads together}

This chapter has outlined the methodological approach developed from a sociocultural perspective. The decision to use a design-based research framework with the employment of a single case study arose from the need to develop an interpretive study that took into account the social and cultural context. Through the research process varying partnerships were nurtured to inquire into the learning story intervention. The methodological tools described reflected the need to locate the research in a naturalistic setting, ensuring multiple voices within the learning community of the project. The framework for analysis continued this interpretative, iterative approach and the findings related to this are presented in Chapter Four. 


\section{CHAPTER FOUR}

\section{Analysis of evidence}

\subsection{Introduction}

This chapter documents the journey of data collection and analysis. As described in Chapter Three, this research uses a case study approach to investigate the use of learning stories as part of the gathering, analysis and use of evidence to support the development of social studies conceptual understandings. This chapter begins by setting the scene for the research. It presents the departmental evidence that answers the first research question: What is the current teacher practice for gathering, analysing, and using evidence to support the development of social studies conceptual understandings? The chapter also presents the themes that arose from the organisation and interpretation of information using the five-phase analysis cycle (Yin, 2011). Using a sociocultural approach to the research, these themes are presented in an integrative manner - in the form of learning stories for James, Sam and I, investigating the second and third questions: What is the impact of teachers using learning stories to support the development of social studies conceptual understandings? What is the impact of students using learning stories to support the development of social studies conceptual understandings? The chapter concludes with discussion of the learning stories including the themes of 'convergences' and 'divergences'.

\subsection{Setting the scene}

Towards the end of term 2, 2011, I met with the social studies department involved in this research. I introduced the research project that I hoped to carry out. During this meeting the teachers agreed to take part in a department meeting to collect evidence. Two of the teachers, James and Sam, also agreed to participate in-depth in the research. James, is a history teacher and head of the social studies department, and Sam is in his fifth year of teaching social studies and geography. The data collection for the case study spanned a period of six months - divided into three phases, Introductory, Phase One and Phase Two. The Introductory Phase began with a department meeting on 11 July. It was decided at that meeting that the observations would begin in term 3 . 
I was introduced to the Year 9 students on 1 August. In James' class there were five students who were willing to participate in the research - Ben, Daniel, Jamie, Ryan and Henry. In Sam's class I worked with Thomas, Felix, Liam and Blake. At this stage, both classes were approximately three weeks into a unit titled 'Government Past and Present'. The scheme of work presented the Level 5 Achievement Objective which would be assessed as: How systems of government in New Zealand operate and affect people's lives and how they compare with other systems. The specific learning outcomes for the unit described were:

- Students will gain knowledge, skills and experience to: Identify the features of different government systems

- Describe the New Zealand political systems

The scheme listed the concepts the unit was to explore: Authority, beliefs and values, democracy, government, justice, leadership, organisation, processes, laws, sovereignty, political systems.

In addition, the scheme of work outlined the links to The New Zealand Curriculum, resources, and teaching and learning activities (including key questions to pursue), and related resources. (D, 11/7)

This unit was the focus for James' and Sam's teaching and assessment for term 3. During the first three weeks of term 4 (the final stage for the collection of evidence), the teachers focused on individual programmes. This is discussed in more detail in the learning stories.

\subsection{Departmental perception practice and procedures}

In order to understand current practice in relation to assessment and conceptual teaching and learning, departmental planning, a semi-structured department interview, observation notes, and a researcher reflection journal were sources of evidence. Whilst the emphasis of the research was on Year 9 social studies, it was useful to view this base-line information (Fa'alogo McNaughton, 2011) in the context of the wider departmental assessment practices that encompassed both junior and senior school. 


\subsubsection{Senior school (Years 11-13)}

The findings from the department interview indicated that departmental practice related to the gathering, analysis and use of evidence in Years 11-13, was often based on the teachers gaining a clear understanding of the requirements of the standards, then establishing where students were at in order to assist them further. In both history and geography, this understanding was developed when the teachers worked together and used examination marking schedules to inform their thinking.

In addition, the departmental moderation process was reported to be aligned with school-wide processes and integrated into one of the expected practices in the appraisal system. Idris, Steven and James (I/11/07) indicated that it was the social nature (Herman, Osmundson, Ayala, Schneider, \& Timms, 2006) of these procedures that made them useful. They spoke positively of the shared understanding they gained about assessment practice, including the depth and complexity of student understanding required for varying levels of achievement by sharing perceptions and judgments of student work through the marking and moderation process.

The department-wide use of evidence was indicated in two ways. The first was through the use of individual self-assessment. James indicated that it was departmental practice to foster self assessment through the provision of exemplars of work. "We give the students a range of exemplars of student work.....so that when they hand in a piece of work, they (the students) can see in their mind why they got that mark opposed to the mark that they have got" (James/I/11/07). This practice provided students with a benchmark to gain a clear understanding of what was required for differing levels of achievement and what was needed to get to the next level. If used consistently students could clearly identify what standard they were working towards and set goals to improve their achievement (Fa'alogo McNaughton, 2011). The second department-wide practice was evident through the analysis of data for departmental and teacher goal setting. James indicated that he provided common templates for all teachers in the department to assist with their reflection and the formulation of annual goals. There were clear links between these departmental practices and the gathering, analysing and using of evidence. 


\subsubsection{Junior school (Years 9-10)}

The findings indicated that the teachers provided a very different picture of the departmental practices in the junior school. James held overall responsibility for writing the scheme of work for Years 9 and 10 social studies and collaborated with the teachers to a degree. Idris and James explained how the Year 9 and 10 scheme of work had been a "few years in development" (James, I, 17/11), and there was an explicit focus on the development of conceptual understanding. Terminology such as learning outcomes and learning intentions were used to express the aims of each unit, for example, 'Students will gain knowledge, skills and experience to describe the New Zealand political system.' The scheme of work guided teachers to carry out diagnostic assessments to establish prior knowledge and understanding. However, there was no further guidance as to how evidence should be gathered, analysed and used throughout the unit. Teachers were directed to carry out a summative assessment and all students were involved in an end-of-year exam which assessed largely skills and knowledge outcomes. The methods of summative assessment varied across the department. Hohepa (I, 17/11) explained how he used an NCEA style assessment for one of his summative assessment tasks in order to prepare students for Year 11. This replication of senior school practice in the junior school has been noted as increasingly common practice, evident in half of the schools surveyed for Taylor's (2009) $\mathrm{PhD}$ study into the lessons learned from senior social studies developments. Hohepa (I, 17/11) also mentioned that he used end-of-topic tests as another form of summative assessment. I also observed student participation in a summative assessment project which lasted over a period of two weeks.

Unlike in Years 11-13, there were no formal procedures to analyse achievement data to inform teaching and learning. Idris (I, 17/11) indicated that social studies data was only used by the senior management to band the students in Year 10. James (I, 17/11) explained that school-wide e-asTTle writing assessments were carried out at Year 9 and 10, analysed by the assistant Head of Department and shared amongst staff. However, the social studies teachers did not describe what was then done with this information. This suggests that perhaps that teachers were unsure how the information applied to their classes, or they used the information primarily at the beginning of the year to become more familiar with the abilities and needs of students. 
From a sociocultural perspective it is vital to understand the social and cultural conditions that would shape the use of learning stories, therefore investigating the teachers' attitudes toward assessment is a valid method of analysis. Figure 4.1 illustrates the teachers perceptions of the purpose of assessment from the department interview (I, 11/07). All words used are direct quotations from Idris, James, Sam and Hohepa.

Figure 4.1 Teacher perception of the purpose of assessment

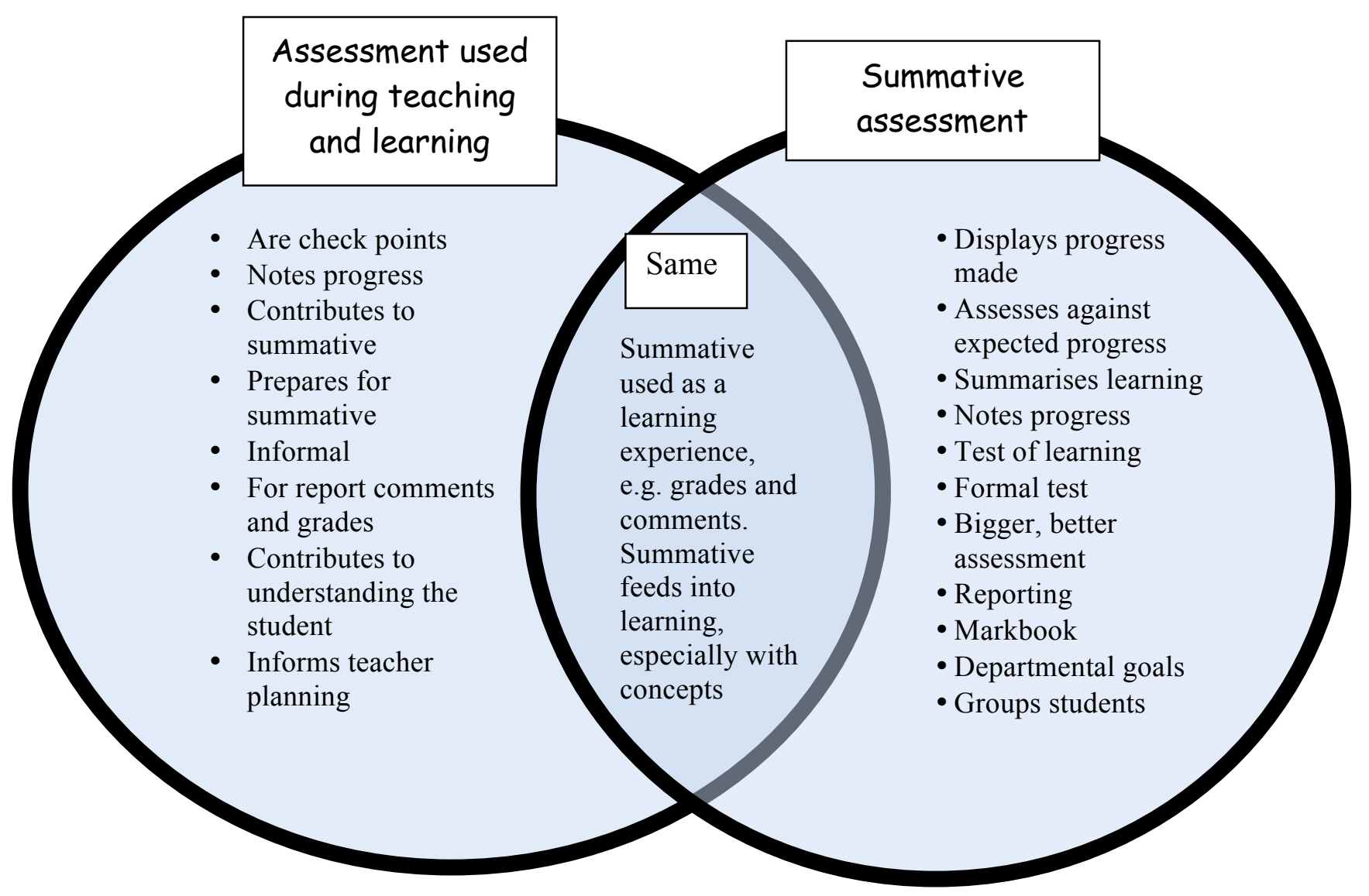

The comments in Figure 4.1 provide an indication of the teachers' beliefs regarding assessment approaches. All except one comment associated with summative assessment focused on the end-point of the learning process, particularly for purposes of reporting. Likewise, when discussing their perspectives on various types of assessment in the departmental interview the teachers' tone and comments implied a hierarchical perspective. Summative assessments were described as being 'bigger' 'better' 'test' 'significant' 'major assignment'. (Idris, James, Sam, Hohepa, I, 11/07). Other methods of assessments were referred to as 'small', 'checkpoints', 'prepares 
for' (Idris, James, Sam, Hohepa, I, 11/07). The following conversation exemplifies the worth Idris and Sam put upon summative assessment.

Idris: We have just had a report round for our juniors. So we need numbers and ideas ourselves of how the boys have progressed, so the parents will know. Academically that's one of our tools.

Sam: It assists with the comment as well.

Idris: Yeah, the comment too. So we know what their strengths are (I/07/).

They appeared to view it as higher stakes due to the purpose it is used for, rather than considering the value of improved student outcomes when used as part of the learning process. This could potentially impact on the genuine use of assessment tools if the teachers tend to value summative assessment solely as an end point.

Whilst using summative assessments for reporting purposes is noted to be a valid use of assessment (Black, 1998), the informal use of teacher assessment to inform the learning process was also discussed during the interview. These practices differed and the teachers were genuinely interested in hearing about each other's practice. Providing opportunities for these conversations might shift the practice and perception of assessment from an emphasis on summative to a more integrative process.

When discussing the methods of assessment used during the teaching and learning process Sam explained "I like using discussion to check in. I don't ever record what is happening or who is asking the questions, it is kind of just a mental check, a mental note." (I, 11/07). James mentioned that he liked using journals with another class, but that it was difficult to sustain the practice. This informal, on-going type of approach is indicative of James and Sam's observed practice but, if assessment is to improve student outcomes and understandings, this informal noticing may need to more explicitly inform next steps and discussions with students. (Heritage, 2007).

\subsubsection{Departmental planning for conceptual understanding}

The teachers explained that conceptual understandings were reported to be an integral element of curriculum planning at Year 9 and 10. The evidence from the department interview suggested that while teachers believed some units lent themselves to being more conceptually-based, other units were better focused on acquisition of facts. Teachers thought that this was in part due to student demand. If 
the topic required new learning, such as 'Economies in Asia', the teachers reported that students preferred to learn about it first, before developing their conceptual understanding. This approach is mirrored in Erickson's (2007) theory of the structure of knowledge, whereby she claimed that facts are the building blocks for knowledge and from these emerge generalisations.

The problem can arise when teachers and students get drawn into the allure of learning contextual details purely out of interest, rather than thinking about the bigger ideas related to learning within these interesting contexts. Idris observed that perhaps the factual approach to teaching was due to the teachers' own lack of pedagogical knowledge about conceptual understandings, as the individual teachers in the department had come with different social science subject strengths (Barr, 1999). Sam and Hohepa supported this observation and reported that they were more inclined to teach facts, rather than understanding, if it was not an area of strength. On a more positive note, Idris thought that using a conceptual approach to teaching and learning allowed the use of varying contexts that related to student's lives (Aitken \& Sinemma, 2008). Idris explained how he had recently finished teaching a Year 10 unit called 'Forge, Crisis and Challenges' and decided to use Christchurch as the example as it was so topical and everyone had a story to tell about it.

All the teachers agreed that finding the time to develop a shared understanding about concepts was a real challenge for the department. Furthermore, in an attempt to reduce the workload for the part-time members of staff who were responsible for planning teaching and learning in more than one subject, James led the writing of schemes of work and units at Year 9. This reduced the work load for teachers, but it may have negatively impacted on teacher engagement and understanding of the social studies concepts identified in the scheme of work.

\subsection{Our learning stories}

\subsubsection{Introduction}

The learning stories presented in Section 4.4 relate to my interpretation of the learning that occured during the data collection phase. James and Sam's learning stories explore their conceptual, pedagogical and assessment practice during the Introductory phase, Inquiry Cycle One (the teacher written learning stories) and finally into Inquiry Cycle Two, (the student-led learning stories).To ensure accuracy 
of interpretation, these were member checked by James and Sam during the analysis phase. My learning story will examine the researcher intervention that took place, and the reasons for this. This is followed by an analysis of the themes that have arisen through the presentation of evidence.

\subsubsection{James' Story:}

James is an experienced history and social studies teacher and, amongst other responsibilities, is also head of the social studies department. Due to a timetable change, James had only been teaching his Year 9 social studies class for about three weeks before I began collecting evidence. The class had begun the "Government Past and Present" unit. I observed that there was already a positive learning atmosphere established in the class and while James had not been teaching the students for very long there were already good quality relationships. His students, Ben, Daniel, Jamie, Ryan and Henry agreed to participate in the research. Henry was only able to participate in Phase One of the research due to an overseas trip, but the remaining four students continued through all three phases.

During the Introductory phase of the research I observed how James' use of pedagogical strategies laid the foundation for him to gather, analyse and use evidence to support the development of conceptual understandings. James consistently communicated learning intentions, which formed the basis of teacher and student evaluation of understanding. During one lesson James used the co-construction of success-criteria to enable his students to assess one another. On another occasion he supported the students to reflect on their successes and consider how their performance could be improved in the future. The clarity of teaching and learning was not just limited to the communication of intended learning, but permeated through the structured approaches to teaching and learning activities. For example, when running group activities, James often established protocols and roles so that students selfmonitored their progress towards their understandings that were communicated or coconstructed. However, while there was clear communication of the aims of learning and the occasional reflection on student learning, I noted that there was not a consistent culture of reflection developed. For example, the learning intentions appeared to support teacher planning. Possible greater interactions with the learning intentions could have enhanced the learning process (Absolum, 2006). 
Furthermore, I observed that interpretation of the conceptual understandings from the scheme translated into 'doing' rather than 'understanding' and this lack of clarity of teaching was also reflected in the students' understandings of the concepts. During the focus group interview for example, students had difficulty describing concepts such as sovereignty and authority. James was aware that teaching for conceptual understandings was an area that the department needed to focus on. During the department interview he pointed out that while they had been working to reduce the number of concepts that they were aiming to teach at each year level, he believed they were still trying to teach too many concepts and they needed to do "less better" (James, I, 11/07) as it was impacting on the teachers' ability to effectively teach the understandings related to these.

At the end of the Introductory Phase Sam, James and I met to discuss the learning story approach for Phase Two and to share observations and reflections. As a result we developed Version Two of the Learning Story Framework (Appendix F). While this phase continued for one month there were no learning stories produced. Instead, this phase served as a reflection time for James regarding his approach to learning and assessment. During the interview James reported that even though he had not written any learning stories he had done a lot of mental notes and when he got 'aha' (Carr et al., 1999) moments he wrote notes or observations. James reported that by thinking about the learning stories it got him to reflect on the aims of the lesson, to consider more clearly what he wanted the students to get out of the lesson, and how he checked this understanding. James also identified how he could "actually see that it is a tool that can be used for any learning context" (James, I, 27/09). James also began to consider ways in which the key competencies could be integrated into this approach.

At the time I responded to the lack of learning stories as a flaw of the framework, so James, Sam and I went about making considerable changes to it. Armed with Version Three (Appendix G) the research moved into the final phase, Inquiry Cycle Two. Once again difficulties were encountered but for different reasons than for Inquiry Cycle One. The nature of the inquiry cycle was significantly affected by events out of our control. The inquiry cycle in James' class ran for three weeks. During the first week, the understandings were related to a new tourism unit based on the Level Five achievement objective, Understand how people's management of resources impacts on environment and social sustainability (Ministry of Education, 
2007a), and the second week's understandings were devoted to the imminent 2012 Rugby World Cup tournament linking in with another Level Five achievement objective: Understand how cultural interaction impacts on cultures and societies (Ministry of Education, 2007a). For the duration of the final week James focused on skills revision for the exam and did not refer to the development of conceptual understandings. However, despite these difficulties the students completed the learning stories for each lesson. The final focus group interviews with the students raised similar issues to the first interview. They found it hard to evaluate whether the Learning Story Framework had supported their development of conceptual understanding, as they did not have a good grasp of what conceptual understandings were. This was in spite of James planning and delivering lessons related to the conceptual understandings. The students' general confusion about the nature of social studies perhaps related to this and the literature review pointed out the academic debate surrounding the subject.

Whilst the students were unable to indicate whether the Learning Story Framework had supported the development of conceptual understandings, they could identify indirect benefits of the Learning Story Framework as an assessment tool to assist with the teaching and learning process. Daniel liked it because everyday after the lesson he could reflect on what he had learnt. "Sometimes we could come out of the lesson not knowing what we have learnt but with this we knew what we learnt and how we learnt it. It gave us more to think about" (Daniel, I, 09/11). Ben also saw how useful learning stories were as a metacognitive tool for learning. Ryan displayed a neutral response to the use of the Learning Story Framework, whilst Jamie expressed his dislike of it, largely due to the parental input. Jamie believed 13 year olds needed to be more independent which did not include parents in the process. This contrasted with the opinions of Ben, Ryan and Daniel who were happy to have their parents involved, and who also reported that their parents enjoyed the extra home contact. Daniel in particular reported that his parents liked seeing what he was doing, how James was teaching him, and what they were being taught. Daniel's positive response to the process, in particular the heightened awareness of his learning by his parents and teachers, provides an insight into the desired use of individualized approaches (Timperley, et al., 2007). "Mine was good, it always said stuff about me, about my learning, what direction I'm heading." (Daniel, I, 09/11) 
The challenges of the inquiry cycles notwithstanding, James identified a number of advantages regarding the students' use of the learning story approach to support the development of conceptual understandings. James reported that he liked the more easy friendly approach of Version Three of the framework (Appendix G). He spoke positively of the benefits of the shared learning journey for all participants and the enhanced awareness of the connection between planning for teaching, learning and assessment. James also appreciated the enhanced communication and openness that developed between all participants. He stated, "I really liked the feedback the guys were giving me, from their point of view, how they saw they lesson and what they got out of it. It was really cool. It made the learning richer, made the teachers and students more accountable, and parents could see that we were actually doing our job" (James, I, 16/11). In addition, James reflected on the dynamic influence the learning stories had on his planning, he said: "The beauty of the learning stories was what I originally planned may not fit, but from their feedback, I altered my planning and coconstructed where they would like to go." (James, I, 27/09).

\subsubsection{Sam's Story:}

Sam had been teaching social studies and geography for five years. Due to a timetable change and a week's leave of absence, Sam had only been teaching his Year 9 class for two weeks before I began to observe. Sam had begun with the new unit on 'Government Past and Present' and during the first few days of observation he was attempting to establish what his students had done during his absence. The students Thomas, Felix, Liam and Black agreed to be part of the research.

During the Introductory Phase I observed that Sam had a good rapport with his students, connecting with their lives (Aitken \& Sinnema, 2008), and developing their professional learning relationships. After the initial few days of catch up, Sam continued with the teaching and learning programme associated with the 'Government Past and Present' unit. When attempting to identify the pedagogical and assessment practices Sam used to support the development of conceptual understanding, I found it difficult to identify the intended learning for the lessons. This in turn made it very difficult to collect evidence based upon unclear aims. There were no learning intentions clearly expressed and no aims were otherwise communicated to the students, making it difficult for students to know and understand the conceptual intent of the learning. 
During the first interview with James and Sam, I raised the issue of clarity of conceptual teaching and learning with Sam and James in order to consider the implications for Inquiry Cycle One. After this discussion the Learning Story Framework was adapted (see Appendix F) and we moved into the next phase spanning three weeks. During this time there were no learning stories completed - this cycle served as a reflection time for Sam to consider his approach towards teaching, learning and assessment. Sam noted in his journal: "After our discussions I discovered that I must include more formative assessment in my teaching. This must be done not only for my own records but for the student to be aware of their learning" (Sam, J, 24/08). This reflection indicated a willingness and awareness of changes in pedagogical practices that were required to be able to collect analyse and use evidence to support conceptual understanding.

A few days later Sam had entered another comment in his journal: "Raising awareness of my lack of formative assessment, I've included a thumb-o-meter in my class. They (the students) work well with it and it gives me a good idea of how well everyone is doing." (Sam, J, 29/8). This action indicated that he was identifying the learning that was taking place, collecting evidence to assess students understanding and encouraging a reflective culture also.

During the second interview at the end of Inquiry Cycle One, Sam displayed his regret that there were "not any [opportunities for] learning stories" (Sam, I, 23/08) as the students were involved in a summative assessment activity. However, during my observations in this inquiry cycle, I noted the opportunity for the recording of a learning story in 11 out of the 12 lessons. This interesting contradiction of opinion perhaps suggests that the exploration of the learning story approach as a way to gather, analyse and use evidence was rather like a continuum, with Sam's pedagogical assessment practice having shifted along, but it still required knowledge and understanding of the approach to move further. Sam pointed out the unexpected benefits of participating in Inquiry Cycle One: "It forced me to look at the focusing question of the lesson" (Sam, I, 27/09). These journal entries were only shared at the end of the research, at which point I re-considered the impact the framework was having and went about co-constructing Version Three with James and Sam.

As the research moved into Inquiry Cycle Two, teaching for conceptual understanding proved problematic. The length and nature of Inquiry Cycle Two was significantly influenced by the change in term dates and the consequent reorganisation 
of the timing of junior exams because of the 2012 Rugby World Cup. Because of the later start to the research Sam was already running one week behind James, so the inquiry cycle ran for only two weeks. For the first week, Sam finished the government unit and, with no finalised scheme in place to guide him, developed conceptual understandings related to carbon footprints. These understandings were unrelated to the scheme of work and developed in isolation, but were linked to the Level Five achievement objective: Understand how people's management of resources impacts on environment and social sustainability (Ministry of Education, 2007a). The successful formulation of these understandings indicated that Sam clearly understood how to develop and communicate conceptual understandings. During week two of this phase, there was a shift from supporting the development of conceptual understandings to a reflection on their skills, as this was the focus of revision for the exam.

Despite the difficulties during this cycle there were a number of positive aspects highlighted. During the observations I noted Sam's change in teaching practice. He consistently expressed the aims of the lessons and illustrated coherent planning from one lesson to another (see Figure 4.2). In the teacher interview Sam confirmed this observation and reflected how useful the learning story approach was for him as a teacher, as it raised the issue of clarity of learning and "improved my outlook on teaching" (Sam, I, 27/09). In the focus group interview three out of the four students indicated their support of the Learning Story Framework. Thomas indicated that the learning stories made him go back and think about his learning whilst others expressed the benefits of enhanced communication with Sam and improvements to the teaching. According to Thomas, the Learning Story Framework specifically helped support the development of conceptual understandings because "you found out what you needed to do more of to understand" (I, 09/11). The complexity and depth of the learning stories indicated varying levels of conceptual understanding as well as the individualized need for support regarding what to reflect upon, and how to critically reflect. In relation to the conceptual understanding: Our actions make an impact on the environment, Felix wrote: "I learnt that a carbon footprint is a measure of the impact our activities have on the environment. I learnt that the main cause relates to the amount of greenhouses gases produced in our everyday lives, and that the single most use of carbon is home - gas, oil and coal which makes up 15\%" (Felix, I, 28/10). This differed to Liam, who about the same 
lesson said: "I learnt about the carbon footprint and how to deal with it" (Liam, I, 28/10). The quality of the next steps box also varied from one student to another, and Blake reported that by the time the learning story sheet was returned to him the teacher had moved on to another aspect of learning so his next steps had become irrelevant. This timing issue is discussed in more detail in Chapter Five.

Finally, the findings indicate that parents utilised the learning stories in differing ways, and those students whose parents were actively involved in the learning stories valued the experience. Two of the parents completed detailed comments; and these were also the most detailed student completed learning stories. Two parents chose to sign the sheets only. Felix's parents really liked to know what was happening and Thomas stated that his mum was very enthusiastic; she would ask, “How'd it go today? Did you do stuff on your project?" (Thomas, 09/11). In conclusion, the learning stories provided a basis for the families to have learning conversations with their children.

Figure 4.2: Communication of learning intentions in each phase of the research

\begin{tabular}{|c|c|c|c|}
\hline & $\begin{array}{l}\text { Introduction } \\
\text { (No. of lessons) }\end{array}$ & $\begin{array}{l}\text { Inquiry Cycle One } \\
\text { (No. of lessons) }\end{array}$ & $\begin{array}{l}\text { Inquiry Cycle } \\
\text { Two } \\
\text { (No. of lessons) }\end{array}$ \\
\hline Learning intentions & 10 & 5 & 9 \\
\hline $\begin{array}{l}\text { Absence of } \\
\text { communication of } \\
\text { intent of lesson }\end{array}$ & 1 & 0 & $4 * *$ \\
\hline $\begin{array}{l}\text { Focus on summative } \\
\text { assessment }\end{array}$ & 0 & $7 *$ & 0 \\
\hline Advance organiser & 4 & 0 & 2 \\
\hline $\begin{array}{l}\text { Number of lessons } \\
\text { opportunities for } \\
\text { learning stories }\end{array}$ & $\mathrm{N} / \mathrm{A}$ & 11 & 12 \\
\hline $\begin{array}{l}\text { Total number of } \\
\text { lessons observed }\end{array}$ & 15 & 12 & 15 \\
\hline
\end{tabular}




\subsubsection{My story: Researcher intervention}

Approaching the research from a sociocultural perspective and using a designbased methodology enabled my participation to extend beyond the traditional researcher role to share in the learning with the other participants. From the outset, my perspective impacted on the research - for example, the focus of conceptual understandings and the decision to use learning stories as the narrative assessment tool upon which to explore the gathering, analysis and use of evidence.

As part of the research process I initially developed Version One of the Learning Story Framework, using early childhood research (Carr, 1999) as a basis for critique and engagement. I envisaged that intervention could be characterised by the exploration of Learning Story Framework. However, the evidence from the Introductory Phase indicated that in order to effectively gather, analyse and use evidence to support the development of conceptual understandings, the learning process needed to be based on clear conceptual understandings, which were communicated and reflected upon. Clarity over the intent of the learning and how students are learning, allows for improved student outcomes (Absolum, 2006). So, in keeping with a sociocultural approach I felt it was vital that I intervened in ways that protected the nature of the relationship between me, James and Sam.

During the meeting to introduce the learning story approach, I described the pedagogical and assessment practices I had observed and sought James and Sam's perspective regarding this. To assist with this process I shared an interpretation of assessment-for-learning from Black and Wiliam (1998): it "refers to all those assessment activities undertaken by teachers, and by students themselves, which provide information, to be used as feedback, to modify the teaching and learning activities in which they are engaged. Such assessments become formative when the evidence is actually used to adapt the teaching to meet the needs of students" (p.2)

Even though James and Sam acknowledged and accepted these findings I found that raising these issues with them was difficult as I felt that the lines between my professional role as an adviser and my role as a researcher were becoming blurred. I wanted to maintain the integrity of the researcher through an appropriate level of intervention whilst nurturing the researcher-participant relationship. In retrospect, I do not think I spent enough time considering their responses to these observations as I was more concerned at that stage about getting through the research. 
Sam was also concerned about the time it was going to take to go through the learning story process (see Figure 3.4). As a result of this issue and to partly address Sam's concern, Version Two of the Learning Story Framework (Appendix F) was developed, It enabled James and Sam to take notes on one piece of paper during a lesson and write up more fully afterwards. During Inquiry Cycle One I observed many opportunities for learning stories in Sam's class, but there were no learning stories recorded or communicated. Learning opportunities are times when students display key learning related to the curriculum outcomes in the context of the learning environment (Goodsir \& Powell, 2010). Aware of the relatively short time frame of the research, and after reflecting that the teachers needed more guidance in identifying learning stories, I decided to intervene. The interventions are shown in Figure 4.3. I highlighted an example of a learning story opportunity, using a key understanding Thomas had displayed. I then attempted to write an example of a learning story for one of his students, Felix. This attempt highlighted the difficulty in writing learning stories when the conceptual understanding was not clearly communicated and I used this opportunity to discuss this with Sam.

I also observed a learning story opportunity in James' class. Daniel had completed a homework assignment on government structure. At the time I reflected; "The paragraph at the end could easily be used to show Daniel's understanding of the ways in which government works." I pointed this understanding out to both Daniel and James in order to illustrate the type of evidence that could be used to write learning stories. I also considered writing a learning story for James, however during a conversation he indicated his confidence with the process, so I believed it was unnecessary to pursue this. James expressed that whilst he had not written any stories there had been informal discussion between him and the students regarding his observations.

At the time of both of these interactions, I reconsidered how I could make the approach more accessible for the participants. I felt uneasy about the progress of the inquiry cycle. I reflected: "I feel unsure about how effective the learning stories have been from a teacher point of view. It has been very difficult to integrate into practice." However, at times checking my perceptions with the teachers proved rather difficult, as their verbal responses were positive. Therefore, it was necessary to ascertain the messages inferred from James and Sam's actions in order to see through what seemed to me as a well-meaning veneer. 
I decided therefore, along with James, Sam and the students to re-write the Learning Story Framework Version Two during Inquiry Cycle One. To give James and Sam the opportunity to engage more deeply with the process and actively follow the sociocultural philosophy of the research process, Version Three of the Learning Story Framework (Appendix G) was developed. Whilst it was an improvement on Version One and Two (Appendix A and F), student feedback indicated that the format was still too 'teachery' and 'dull' and needed more colour and pictures. Attempting to balance the practical needs of the teachers, the interest of the students and the theoretical approach to learning stories caused me some angst through the adaptation process. I was concerned that the Learning Story Framework was moving too far away from its learning story origins.

During Inquiry Cycle Two teacher pedagogical and assessment practice had changed. Compared to the introductory observation period, there was greater use of assessment strategies applied to the gathering, analysis and use of evidence, as well as a more cohesive and planned approach towards teaching and learning. For example, in the lessons that were not focused on summative assessment, there were clearly communicated learning intentions, compared with 10 out of the 16 lessons during the introductory period. However, it was observed that this learning was not necessarily conceptually based and this issue shall be discussed further in Chapter Five. The level of intervention reduced markedly during this final phase of the research and the nature of my role as researcher had altered to become more of a participant in the group and less of the 'expert'. I prompted student completion of learning stories however, and this intervention may have contributed towards James and Sam's lack of ownership over the process.

During the final teacher interviews and focus group interviews James, Sam and the students provided feedback regarding Version Three of the Learning Story Framework. James stated "I really like it, I like the set up, students will be able to see what they have done, it is simplified enough for students and parents" (James, I, 27/09). Both teachers agreed that Version Three made progress on the original. James liked that an example and guidance template accompanied Version Three, in order to help the teachers; students and parents understand the process and intent of the Learning Story Framework. Whilst the students' observations were initially generalised, for example "I learnt what a précis map is" (Ben, I, 27/10), their comments become more in-depth as the process evolved. The completion of some 
stories indicated the students' levels of enjoyment, involvement and needs. For example, "It was fun to learn about précis maps and getting advice..." (Daniel, I, 27/10), compared with "I completed all my work and I think James could of help(ed) us a bit more." (Ryan, I, 27/10). These comments provide an insight into the indirect advantages of the learning stories as an alternative way of communicating with the teacher and parents.

\subsubsection{Moments of convergence and divergence}

During the analysis of James and Sam's journey throughout the research process there were moments of convergence and divergence, rather like a braided river flowing through the landscape, inextricably linked to the system and with multiple tributaries which at times drift apart and then ultimately link back together.

A significant moment of divergence occurred early in the research, during the analysis of the departmental approaches to assessment. I made the assumption that departmental assessment policy in the junior and senior school would cross-feed. However, this did not appear to be the case. While the literature review in Chapter Two alluded to the risk of summative assessment in the senior school potentially hijacking attempts to assess formatively (Mutch, et al., 2008), the very opposite could be seen here. This is because the findings from the department interview suggested that the gathering analysis and use of evidence was an incredibly effective way of preparing for NCEA summative assessments. In theory then, the same processes would support students' achievement at Level 5 of the curriculum. However, practices such as the explicit communication of standards and continual feedback seemed confined to the senior school. Similarly the use of evidence to analyse teaching practice and set goals was not extrapolated to the junior school.

So, if these processes were embedded in the practice of the teachers, why were these, or similar approaches not evident at Year 9? A key to this perhaps lies in the clarity of the Year 11-13 achievement standards requirements. The opportunities for Year 9 and 10 social studies planning has become so fluid and open, it may have inadvertently lost its way. The dichotomy between the apparent simplicity of social studies as presented in The New Zealand Curriculum (Ministry of Education, 2007b) and the complexity of social studies as a subject (Barr, 2005; Mutch, et al., 2008) may have left teachers feeling unsupported and confused. Interpreting the achievement objectives and creating meaningful conceptual understandings in relation to these, is 
a difficult task, especially when it requires strong linkages to elements of the social inquiry process such as values and perspectives, reflection, decision-making and social action. Hence, the teachers may have found it difficult to clarify the outcomes for students at Year 9 and 10. In fact, the department reported their desire to take the time to develop a shared understanding of what these outcomes or understandings may look like. In summary, the complexity of planning for multiple outcomes appeared to have impacted on the teachers' abilities to use reflective practices, as they were unsure what they were reflecting upon.

The difficulty in teaching for conceptual understandings in social studies has been widely acknowledged (Crooks, Flockton, \& Meaney, 2005; Education Review Office, 2006; Barr, 2005) and findings from this case study are no different. Interpreting the conceptual understandings from the scheme of work into everyday practice proved to be a challenge. The Learning outcome statements in the scheme of work were broad and even though the key concepts were identified in this planning they remained somewhat unrelated to the statements and put to one side. There was no observable evidence of these concepts being shared with the students, let alone evidence gathered to monitor the development of these. However, later in the research it was observed that James and Sam drew on other conceptual understandings to plan their individual teaching and learning programme. This evidence suggested that perhaps the unit, and the understandings related to it, needed review.

On reflection, from the evidence I received, I believe I made the assumption that conceptual understandings from the scheme would translate into the teaching and learning programme This may well have impacted on the way in which I intervened as a researcher. My intervention at the time focused on the pedagogical assessment practice and I perhaps should have supported James and Sam with the contextualising and pedagogy associated with developing conceptual understandings.

A further period of divergence occurred in the early stages of the research when the reported methods of gathering, analysing and using evidence differed to those observed. The observed practices focused on short-term practice and planning, such as the checking-in of small tasks to guide the pace of the lesson. It was interesting to note that formative strategies constituted an average of 10 minutes out of the 50 minute lessons, with the remaining time dominated by activities such as teacher-led interpretation of visual material and going over answers as a class. This 
did not necessarily check individual understanding and contained little feed-forward. In general, any assessment of understanding tended to be at a group or class level, or through questioning to elicit understanding. Both James and Sam informally collected evidence regarding student understanding through "walk around time" (Fa'alogo McNaughton, 2011), interacting with students, taking an interest in their learning and ascertaining where they were at. It was observed, however, that these mental checks were more often used for teacher planning, and could have been used more effectively as an opportunity to share their observations with their students.

In summary, teacher practice was dominated by activities that did not necessarily inform the teaching and learning process. When pedagogical approaches were used to gather, analyse and use evidence there was a reliance on informal approaches. These approaches did not reflect the practices that were outlined in the interview and, instead, were rather ad hoc. This indicated to me that the department needed more support for pedagogical and assessment practice associated with the gathering, analysis and use of evidence. As a result, I used the workshops and meetings to explore the value of formative assessment and learning stories. I believe this is not an uncommon challenge for social studies departments and despite excellent supporting documentation, such as the Building conceptual understandings in the social sciences (BCUSS) series (Ministry of Education, 2009a) and the Effective pedagogy in social sciences//tikanga à iwi: best evidence synthesis iteration (Aitken \& Sinnema, 2008), teachers still need assistance to engage with the material. These mixed messages from the interviews and observations made it difficult to ascertain the path of the river. I was mindful that the observations were a snapshot of teaching and my presence may have initially interrupted the natural flow of the teaching and learning in James and Sam's classes. Moreover, studies have shown that putting the theory into practice can prove to be problematic (Timperley, et al., 2007) and requires perseverance over a period of time to ensure sustained changes to teaching.

Another noteworthy moment of divergence occurred during Phase Two of the research. My initial methodological approach for the research took a simplistic path but in practice this approach became more complex (see Figure 4.3). I had envisaged that James and Sam would write the learning stories, but this was not the case and instead they used the opportunity to evaluate their teaching, learning, and assessment practice. On reflection, the evidence intimated that James and Sam needed time to 
consolidate the pedagogical and assessment observations shared at the end of the Introductory phase.

However, out of the divergence comes convergence. James, Sam and I shared the same aim for the research which was to learn something in order to help the students. Our river may have separated occasionally but we stayed flowing in the same direction. Throughout the learning in the first two phases there was a common reflection on practice and shared acceptance of change. James and Sam understood the importance of developing their own and the student's critical reflection, and the need to place more emphasis on strategies that assist with the gathering, analysis and use of evidence.

Another period of convergence between Sam, James and I became evident during Inquiry Cycle Two. The challenges of the previous phases, had made the relationships between us stronger. My involvement in the class shifted to become more of a participant within the community, rather than as researcher. This may have been the result of the analytical lens shifting from the teachers to the students, but may also have grown from the interplay in the earlier phases and the acknowledged shared responsibility of the research between all participants.

Further convergence was evident through the involvement of the whole community in the Learning Story process during Inquiry Cycle Two. Students reported that they liked the extra attention on their learning and appreciated the extra interest. They felt confident to express their opinions freely to James and Sam, which may not have been the case with some of their other teachers. This reinforces the observation that teachers need to consider the development of positive learning relationships in order for students to feel comfortable in their learning (Absolum, 2006). Parental involvement was also valued by the students and teachers, and students reported that generally their parents enjoyed being part of the process and having a window into their secondary world. Appendix I illustrates this community involvement through the two exemplars of learning stories completed by the students, teachers and parents. 
Figure 4.3: Actual learning story implementation process for inquiry cycles one

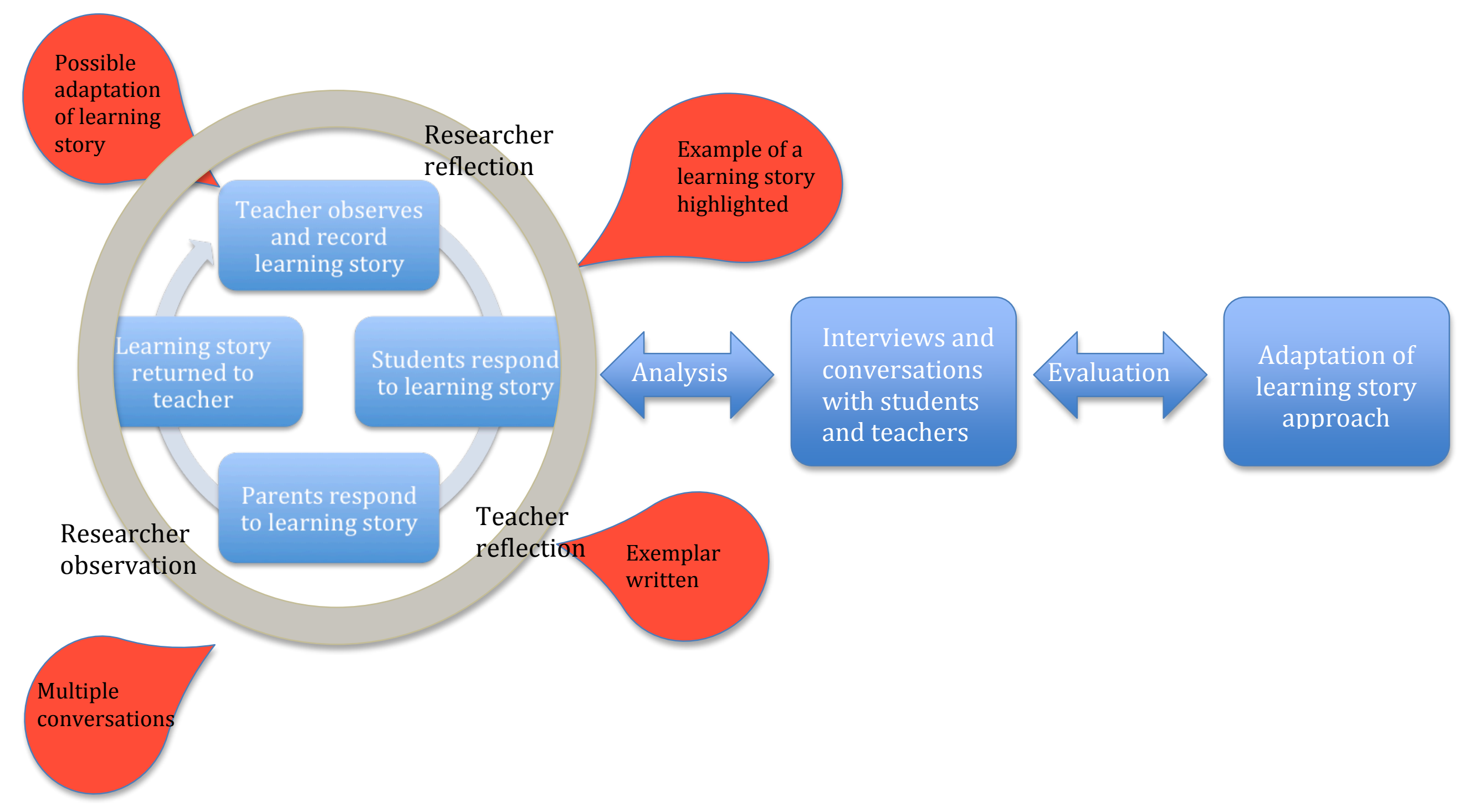




\subsection{Summary}

Participants generally responded positively to the student-led learning stories using the updated Learning Story Framework Version Three (Appendix G). The learning story approach appears to have benefitted the participants through greater clarity of teaching and learning, enhanced communication, a greater emphasis on a reflective culture. It is also evident that the Learning Story Framework can only help support the development of conceptual understandings, if these are clearly defined, and planned for, within the teaching and learning process. These themes will be discussed in more detail in Chapter Five, along with a discussion of the limitations and next steps for this research 


\section{CHAPTER FIVE}

\section{Discussion, recommendations, and conclusions}

\subsection{Introduction}

This chapter applies the findings of the case study research to the original aim of this thesis, which was to examine the use of learning stories as part of gathering, analysing, and using evidence to support the development of social studies conceptual understandings.

The chapter begins with a synthesis of the major findings and their implications for future research, in relation to the evaluation of the Learning Story Framework. I will then present five areas for consideration that have arisen from this research and discussion regarding the role of advisers and researchers within sociocultural research. The chapter will conclude with a brief summary of the importance of applying a sociocultural context when investigating the use of learning stories, a discussion of the methodological limitations of the study, and final thoughts regarding the research findings.

\subsection{Evaluation and adaptation of the Learning Story Framework in a secondary school environment}

The Learning Story Framework was developed in response to social studies teachers' challenges related to the teaching and assessing of conceptual understandings. The initial Learning Story Framework (Appendix A) was based on the early childhood exemplars (Carr, 1999; 2001), and adaptations were made as a response to research findings and feedback from the teachers and students. The principles underpinning the early childhood exemplars and the factors for consideration (see Figure 3.3) are still evident in the final version of the Learning Story Framework (Appendix G). The changes apply to the way the framework is used and the role the community plays in developing the stories. The Learning Story Framework in this case study is intended ultimately for student-led stories where parents and teachers play a supportive, facilitative role. In Inquiry Cycle Two 
capturing of stories was carried out in a systematic way, which is unlike the spontaneity of early childhood learning stories. In a sociocultural sense this may be going against the original intention of the learning stories through the directed observations of conceptual understandings, however the learning stories in Te Wharriki also capture curriculum objectives related to learning dispositions, and in this case the curriculum context is social studies conceptual understanding. The way in which these were captured differs, but this was more due to the pressures on research time during this study, than philosophical differences between the two approaches.

The framework also remains true to its sociocultural origins because of the underpinning features - the nurturing of the community and recognition that learning is placed within a social and cultural environment. The systematic approach of the Framework - identifying a story each lesson, then reflecting on the stories at the end of the week to draw out the most important learning and formulate the next steps, was put in place in order for the research to generate information to reflect upon. This structure resulted in students reflecting on small learning steps with regard to conceptual understanding, rather than longer-term development of a particular concept. Future research opportunities discussed at the end of this section could extend the scope of the learning stories further.

A focus on the long-term development of a concept would go some way in addressing some student concerns about the format of the Learning Story Framework. Felix, for example, felt that the boxes were too small and their size limited what he wanted to write. James and Sam responded positively to the final layout and style of the Learning Story Framework (Appendix G). However, the students were not as enthusiastic. They described the framework design as too "teachery" and "boring", and they wanted to see more colour and pictures. Apart from the format, there were no negative comments made. Furthermore, students understood what they were meant to write, and they reported that the exemplar (Appendix H) assisted with this process.

James and Sam both felt that the process of noticing the learning, taking the sheet home, returning it to school for a teacher comment, and then giving it back to the student was incredibly time-consuming. They valued this process and were frustrated on occasions when, by the time the sheet was returned to the student, the learning opportunity had passed and the feed-forward information had become irrelevant. Sam was also concerned about the practicalities of using the learning story approach for all of the 150 students he taught. This time pressure was also raised 
during the early childhood research, but teachers found that when it became part of the culture of the teaching and learning it integrated well into their practice (Carr, 1999). Furthermore, in the early childhood experience teachers took responsibility for the writing of the stories rather than the student-led stories suggested in this research. The initial implementation of learning stories will require a time element, but this will ultimately be worthwhile as the reflective culture shifts from an assessment for learning culture towards an assessment-as-learning culture whereby students take more responsibility for learning and assessment (Earl, 2003). During Inquiry Cycle Two James noticed how the quality of the learning stories improved over the three weeks, as the students became more comfortable reflecting on their learning and more knowledgeable about the process.

To enable access for all types of learners in Inquiry Cycle Two, students were able to choose the method for recording their learning stories, for example, through a video diary, on their phone, or by completing hard copy sheets. Despite this offer, all students chose to write their responses on the sheets and indicated their support for this medium. However, this may look quite differently from one setting to another and could be an interesting avenue to explore further.

The research showed that the student-led learning stories contributed towards students identifying their own level of understanding of discrete conceptual understandings when these were present in the teaching and learning process. To deepen this understanding, further learning stories could be used to identify the students' understanding about patterns of concepts and the extent to which they relate in multiple contexts (Jonassen, 2006). This will require scaffolding by teachers and integration into their teaching and learning programmes. Whilst this appears to move away from the original approach of learning stories, to capture those ' $a h a$ ' moments (Carr, 1999), it provides a more robust framework for students telling their secondary social studies learning stories. This may also help towards solving the tension regarding immediacy of feedback. If the learning stories are used at a broader level, as opposed to day-to-day conceptual understanding, then reflection and feedback will not be required so immediately.

The student-led learning stories therefore indicated a positive move towards developing self-awareness and reflection of the students' own understanding of social studies ideas; and if students continue to engage in self-assessment they have the potential to further deepen their grasp of conceptual understandings (Minstrell \& 
Kraus, 2007). However, if the focus is just on self-assessment then teachers could use a variety of pedagogical strategies to assist with this. The learning story approach is unique because in conjunction with supporting student self-assessment, through the development of next steps, it also assists with the building of shared understanding of the learning with teachers, parents and whānau. The community then share collective responsibility for this learning.

For learning stories to be effectively used to help support the development of conceptual understanding to happen, both teachers and students need to have a clear picture of what progression looks like for each individual (Ministry of Education, 2009a). The term 'progression' needs to be treated with caution as this should not indicate arbitrary generalised statements that students must work through, but rather an awareness of the context that the conceptual understandings are placed within, and how they are related to aspects of the social inquiry process, such as the exploration of values and perspectives or considering social action. It is also worth considering how these progressions in conceptual understandings relate to other participatory, cultural and affective social studies outcomes (Aitken \& Sinnema, 2008). Avoiding addressing the idea of progression will result in students swimming through a lake of conceptual waters not clearly understanding where they are at and where they need to be. Consideration of the end point (Wood \& Milligan, 2010) of a Year $9 \& 10$ social studies programme may assist teachers to consider the progression students need to exhibit. Considering an adaptation to Susan Drake's (2007) model, asking the questions "what would I like my students to know (understand)?" "To do (skills and competencies)?" And “to be (dispositions, values, citizenship)?” Along with mapping back from the concepts evident in senior social science programmes, to Year $9 \& 10$ could assist with exemplifying more tangible targets for teachers and students.

In future research it would be interesting to explore the use of the Learning Story Framework as a tool to reflect upon longer term development of concept clusters, conceptual understandings, as well as the focus on the smaller learning steps related to conceptual understandings reflected upon in this research. This could allow for a more flexible, open approach - perhaps allowing for the spontaneity of the early childhood exemplars. In order for this to work, however, both teachers and students would need to be aware of and be confident with the content and context of the stories. 
The use of online environments could be a possibility to explore also. In this research the teachers were exploring the idea of using knowledge net. Other possibilities could include student management of their own E-portfolios, and the use of a wiki. The teachers and students in this research liked the idea of the immediacy of access to stories, although there was some feedback that suggested the "personal touch" of the stories might get lost in an online medium, which would need to be taken into consideration.

\subsection{The role of advisers and researchers}

Researcher bias and influence was a factor in this research from the outset due to the sociocultural nature of the research. I was aware that to make meaningful change, there needed to be a strong partnership between the participants and myself (Design-based research collective, 2003). The exploration of the intervention, the Learning Story Framework, was based on collaboration and mutual learning. Furthermore, I was aware of the potential of my own bias impacting on the research process. Therefore, to maintain the integrity of the research, I engaged in reflexivity and kept reflection journals (Gay \& Airasian, 2000), which documented the reasoning behind my decisions and interventions and were used as part of the analysis process.

Whilst these elements of researcher bias had been initially considered, the level of researcher intervention was higher than anticipated and I was aware of the risk of my professional role as an adviser unintentionally becoming part of the process. At the time I viewed my actions as necessary and helpful, yet on considering the evidence I was concerned about the impact my interventions had on the teachers' ownership of the process and the frequency of interactions between the students and teachers in relation to the learning story approach. Working more often with the teachers to guide the students through the learning story process would be a possibility for any future research.

I have used the phrase researcher intervention to describe my response to the findings gained through each phase of the research. On analysis of the findings this phrase has inadvertently set me apart from the community and illustrates the tension of the enactment of a design-based research approach using a sociocultural perspective. This has led me to consider how I may have situated myself and in future, if using a similar approach, I would shift my position to one as described in 
Wagner's co-learning approach (1997). Co-learning agreements would enable participants such as James and Sam to move from a collaborative role to a more mutual researcher-practitioner role relating their learning back in their own environment.

\subsection{Considerations for teachers when using a Learning Story Framework}

During the analysis of the research, a number of significant themes emerged. These themes may be of interest to teachers if they wish to use the Learning Story Framework to its fullest potential.

\section{Reflective culture}

The first theme links to the importance of the presence of a reflective culture. The findings of this research supports a student-centred reflective approach as the students were able to identify their own learning needs and formulate their next steps by identifying the gap in understanding between where they ought to be and where they have reflected they are at (Weeden, Winter \& Broadfoot, 2002), as long as the teacher has made this clear in the teaching. Furthermore, the teachers reported that the students' learning stories gave them the platform to respond to their student's reflections and alter their planning for teaching and learning accordingly. Reflection is an integral element of the teaching and learning process in a classroom that gathers, analyses, and uses evidence to improve student outcomes (Ellis, 2007). Research points toward the active participation of students and teachers within this process (Black \& Wiliam, 1998; Ellis, 2007; Gipps, 1999; Moss, 2008) and in this study, the inclusion of whānau and family, to create a community of learners (Bruner, 1991). To be reflective requires teachers to not only critically consider their teaching approaches and the impact this has on student learning, but also the ability to alter teaching and learning in response to the evidence (Butt, 2002). From a student perspective, taking an active role will increase their understanding and awareness of what they need to do to raise their achievement (Weeden, Winter et al., 2002).

To develop and maintain a classroom culture of critical reflection, authentic processes, procedures, strategies, and practices need to be integrated into the day-today lives of students, teachers, family, and whānau (Ellis, 2007). As long as assessment practices such as learning stories are central to classroom practice and not 
an add-on, research indicates that this will improve student achievement (Assessment Reform Group, 2002).

\section{Relationships}

Relationships, both existing and potential, were shown to be an integral element of the evidence gathering analysing and using process. Entering into the research I observed that both teachers had already established positive relationships with the students in their classes. Nonetheless the teachers' willingness to take risks, to open up as learners, and to engage with the project further strengthened these relationships. The use of focus groups of students also positively impacted on the teacher-student relationship, with students appreciating the extra attention, through the teacher contribution to the learning stories, without the students feeling set apart from the class. In the research, the students expressed their willingness to be honest and open with James and Sam, and suggested that this may not be the case with all teachers. Therefore, it can be inferred that through developing a culture of mutual respect and openness the learning possibilities of the framework will be enhanced, as students feel more confident to express themselves in a safe environment.

\section{Clarity of teaching and learning related to conceptual understanding}

The emphasis on conceptual understandings for this research was driven by the belief that despite understandings being identified as an integral element to the knowledge outcome (Aitken \& Sinemma, 2008), teachers are struggling to not only effectively teach for conceptual understanding (Education Review Office, 2006; National Education Monitoring Project, 2005; 2010), but also closely monitor the development of conceptual understandings (Aitken, 2005).

The findings from this case study both support and conflict with previous research. Understanding and awareness of conceptual teaching and learning was exhibited during the department interview and through departmental planning. It was also observed that putting espoused theory into practice was difficult but when these difficulties were raised and teachers had the opportunity to reflect on their teaching there were changes to their approaches to teaching and learning. Supporting departments therefore, through professional development and time, to reflect on their conceptual teaching and learning practice will ultimately enhance student outcomes. 
My research also suggests that although the department as a whole can draw on the strengths of the varying expertise of social studies teachers, social studies conceptual understandings is one area of professional learning that needs to be considered carefully. Teacher expertise within social studies departments can be diverse. Whilst it is acknowledged that this diversity brings richness to the teaching and learning, it also provides a more practical issue of co-ordination and planning for a team that contain multiple 'hats' and responsibilities. McGee et. al's (2004) work showed that in fact $21 \%$ of secondary social studies teachers held no formal qualifications in a social science subject, and Taylor (2009) found that $61 \%$ of teachers had trained in another subject. Responsibilities, such as the writing of unit plans may fall to a minority of teachers, in an attempt to balance the workload of others. Although this is a well-meaning motive, it could jeopardise the development of teachers' understandings due to their lack of engagement with the material. The findings of this research point towards the need for all social studies teachers to be given the opportunity to engage with the planning and evaluation of the teaching and learning programme. This engagement will lead to clarity of the teaching and learning process. Furthermore, this study has indicated that clarity of understanding and purpose can be shared with the students and will contribute towards improving student outcomes. Clarke (2005) states "In order for formative assessment to take place, we need to be clear about our aims for student learning, not just how we want them to learn but how we want them to learn it." (p.11) This study has, therefore, highlighted the importance of the assessment process being integrated into teaching and learning programmes.

\section{Student-led reflection}

The New Zealand Curriculum places significant emphasis on students' becoming more reflective and self-managing (Ministry of Education, 2007b). Section 5.2 points towards the importance of the active role students' play in the reflection process. In this research student use of the Learning Story Framework placed them at the centre of their learning. Students indicated that they appreciated the opportunity to take ownership of the learning and whilst teachers, parents and whānau would still be involved in the process, they would become more independent (Absolum, 2009) in identifying their own learning needs. 
The variance in student-completed learning stories, in terms of levels of complexity and detailed reflection, indicate the individual nature of learning stories and the need for students to be individually supported during the reflection process. For students to feel truly empowered, they need to feel confident with the process, and as Barrett (2004) points out, this will provide greater benefits to the learning process as students become more intrinsically motivated to learn.

\section{Summary}

The ideas discussed here are not mutually exclusive and like concepts there are connections and relationships evident. Figure 5.2 represents one way in which these ideas could be considered.

\section{Figure 5.2: A sailboat of ideas}

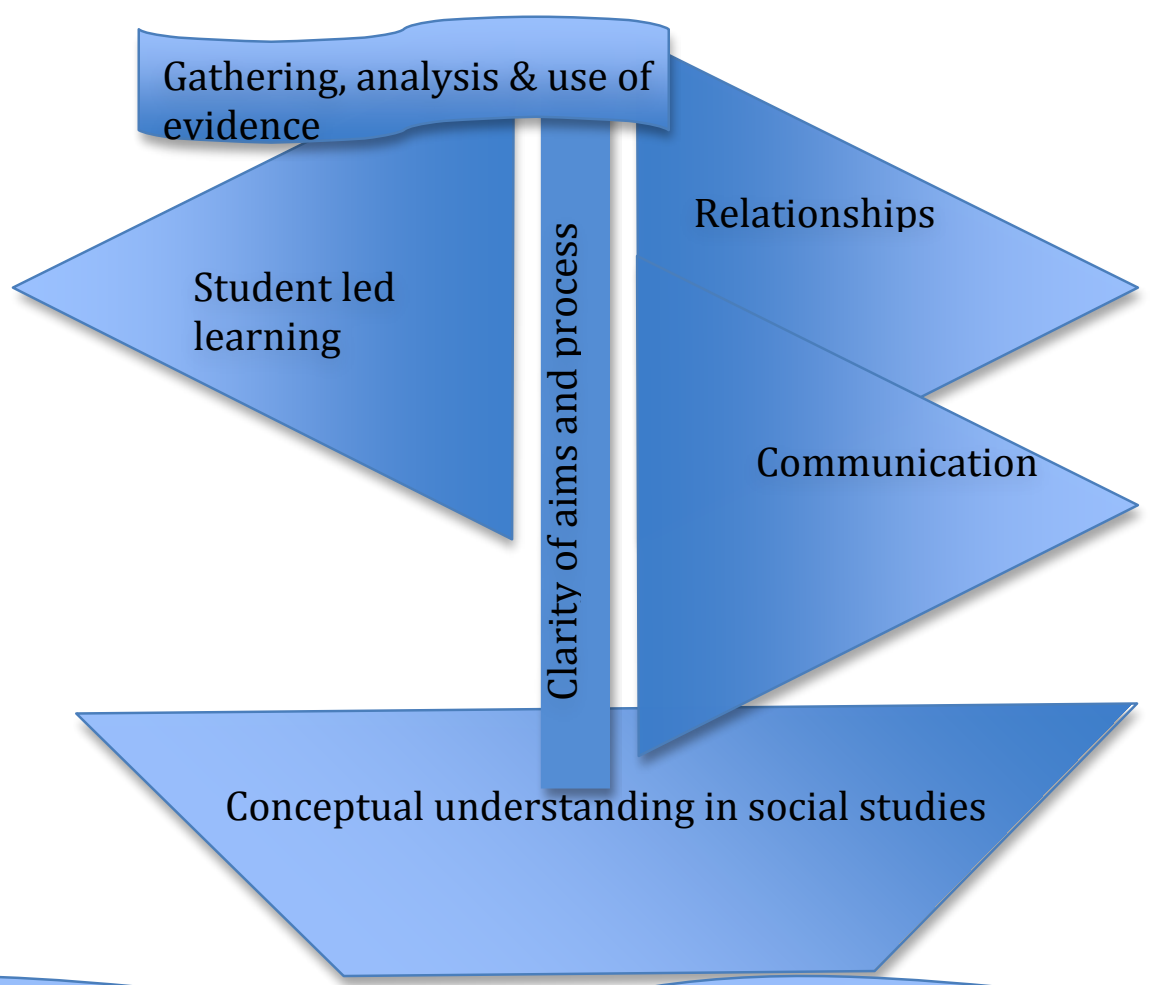

Reflective culture of teaching and learning in a sociocultural context 
The teachers, students, whānau, and families are all participants in a community attempting to navigate the sailboat through the waters to enhance their children's understanding of social studies concepts. Whilst there is a sociocultural collective responsibility, the use of narrative assessments, such as learning stories, puts a focus on individual attainment recognising the full range of achievement (Assessment Reform Group, 2002). In order for the boat to remain afloat and the other ideas to exist, there needs to be a reflective culture of teaching and learning maintained. How and what this looks like will differ from one setting to the next.

The sailboat requires a strong mast to support its sails, and this represents the strength of clarity of the learning process. Clear aims for our students learning are communicated and shared and potentially co-constructed (Clarke, 2001). With the clarity of learning emerges the development of relationships, clear communication, and student-led learning. Without the mast, there is little purpose for the sails.

At the top of the sailboat flies the flag for the gathering, analysis and use of evidence. Throughout this study I have referred to learning stories as reflecting elements of the assessment-for-learning approach. These findings have shown that narrative assessments, such as learning stories, can form an integral element of the teaching and learning process. Lorna Earl's ideas for "assessment-as-learning" emphasise the critical role students play linking the teaching and assessment process by being active, engaged, and critical assessors of their learning, not only by reflecting on what they learn, but also how they learn it (Earl, 2003). Assessment has been shown to improve outcomes for students as long as it is not considered in isolation and teaching and learning is adjusted along the way (Alton-lee, 2003; Black, 1998; McManus, 2008).

\subsection{The sociocultural context}

In conjunction with the influence of sociocultural theory on the methodology and analysis, the influence of sociocultural theory also extended to the learning story context. During this research the participants in this community involved students, teachers, whānau, family and myself. It is through the experience of the learning stories by the communities that makes the stories so powerful (Moore et al., 2008). Inclusion of whānau and family voice was shown to be integral to the concept of collective responsibility. In this research, findings indicated that the parents who were 
actively involved in the learning stories were also reported by their children to value the experience. This value was on various levels - they were interested in being involved in a research project and wished to know more about the teaching and learning experienced by their children. It is this sociocultural emphasis on all members of the participating community that contributes towards its success (Rogoff, 1995).

The learning story approach provided the opportunity to "bridge the communication gap" (Cowie \& Carr, 2003) often evident in secondary settings. James felt that whilst there was frequent email contact prior to this study, the learning stories provided another conduit for communication and the opportunity to develop a greater rapport with parents prior to more formal occasions such as parents' evenings. James and Sam both indicated their desire to make the most of these interactions and thought a more dynamic approach could be utilised, allowing for multiple interactions, as illustrated in Figure 5.3. The blue arrows indicate the original process for the use of learning stories; the red arrows refer to the desired multiple interaction points between all participants.

\section{Figure 5.3: The reviewed process for the use of learning stories}

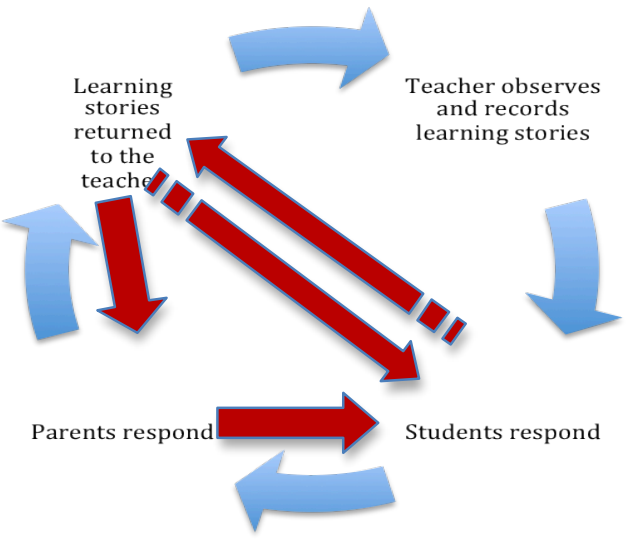

At the beginning of this research, I had hoped that I would have the opportunity to explore the inclusive nature of the learning story approach. Inclusive education can refer "a process of strengthening the capacity of the education system to reach out to all learners." UNESCO $(2009$, p.8)

In my view learning stories have the potential to be inclusive and could be used in a broad range of settings. They have already proved successful in the early 
childhood and primary sectors and for students with special educational needs. I also think that they have the ability to capture rich descriptions of learning in the contexts of culturally responsive pedagogy (Bishop, Berryman, Cavanagh \& Teddy, 2007). I had hoped that I would be able to look at this area more closely through the participants in this case study, however the students who volunteered to participate in the case study did not reflect the cultural diversity required for this focus. If future research was to pay attention to this area, I believe relationships and trust would need to be developed prior to data collection so that students would feel comfortable to be involved in the research.

\subsection{Limitations to the study}

The collection of evidence occurred from late July in term 3 to early November in term 4. Ideally, I would liked to have begun the collection of evidence at the beginning of term 2 , as the timing of the research impacted on the ability to fully assess the impact of learning stories. Other factors included teacher absence, the completion of a common assessment task, systems, structures, changes to programmes of work due to the 2012 Rugby World Cup tournament, and a shorter than usual term 4. Furthermore, both James and Sam indicated that they would have liked to begin the year with the learning story approach, and this is a factor to consider for future research.

A design-based research methodology that uses a qualitative approach for one exploratory case study was chosen as the most appropriate way to undertake this research. As a result, the findings cannot be generalised (Yin, 2009). It is hoped that the findings of this particular research could be useful to other researchers looking at assessment approaches to support the development of conceptual understandings, as I have provided adequate contextual detail to enable others to recognise similar contexts and make comparisons. Now that the learning story approach has undergone some initial research into its use for gathering, analysing and using evidence to support the development of conceptual understandings, future research could focus on the evaluation of the impact student-led stories would have on the development of longer-term conceptual understandings.

Traditionally, design-based research tends to use a more quasi-experimental approach to address issues related to validity. In this research to contribute towards 
trustworthiness of information I engaged in reflexivity, which is critical self-reflection during the process to minimise researcher bias (Denzin \& Lincoln, 2005) and this was recorded in my journals. I used multiple methods of evidence collection (as described in Section 3.7) to ensure triangulation of information. This enabled corroboration to be gained and low inference descriptors were used during the data analysis to minimise researcher interpretation and maintain participant voice.

Participant feedback was used during the interpretive stage to ensure accuracy of researcher interpretation. Now that the intervention, the Learning Story Framework has undergone an initial in-depth examination through a qualitative lens, it has provided the building blocks for further large-scale examination using both ethnographic and qualitative approaches. To draw more participant voice into the research, teachers and students could write their own learning stories as part of the learning process. Participants could also complete research journals. In this research, journals were provided to all participants in this study, but they were significantly under-utilised. However, the insights into perception and practice I did receive were incredibly valuable and it would be worth considering how to get more usage of these.

This research indicates that to grow and maintain effective teaching, learning, and assessment programmes, there needs to be a class culture of reflection. This takes motivation, time, and effort. Students may need to be taught how to reflect, to be critical, and to develop meaningful goals. The learning story approach has been shown to be one way teachers can empower students to take responsibility for their learning - by monitoring, reflecting, and formulating next steps. This development of self-awareness and critical consideration of their own abilities and potential can also be extended to the assessment of peers, which is an area worthy of consideration not fully explored in this study.

\subsection{Conclusion}

This research aimed to investigate the use of learning stories as a way for gathering, analysis, and use of evidence to support the development of conceptual understandings in Year 9 and 10 social studies. The literature indicates the desire to move towards a conceptual basis for the teaching and learning of social studies (Erickson, 2007; Taba, 1962; Milligan \& Wood, 2009). This research has highlighted the difficulties that teachers face when they attempt to plan teaching, learning, and 
assessment programmes that support the development of conceptual understandings. Sustained change will occur if teachers embrace the purpose for teaching in a conceptual manner. Teachers need to co-construct, with the community, the purpose for developing understandings, the understandings they are planning for and pedagogies that could be utilised to develop these understandings. In this study, students were unfamiliar with the notion of concepts, and particular named concepts from the scheme of work. This language needs to become an accepted part of the language of the social studies classroom. It is also vital that teachers consider how to bring these concepts to life in a fun and interesting way using relevant contexts in order for students to relate it back to their own lives (Aitken \& Sinemma, 2008).

Assessment practices of teachers, especially those related to supporting the development of conceptual understandings, are far more complex than this study is able to address. However, this study suggests there is potential for learning stories to form part of a teachers assessment toolkit and could be chosen to integrate into their complex world of monitoring student outcomes. 


\section{REFERENCES}

Absolum, M. (2006). Clarity in the classroom. Auckland: Hodder Education

Absolum, M., Flockton, L., Hattie, J., Hipkins, R., \& Reid, I. (2009). Directions for Assessment in New Zealand (DANZ). Wellington: Ministry of Education.

Aitken, G. (2005). Curriculum design in social studies: learning from the past. $\mathrm{PhD}$ thesis. Auckland University.

Aitken, G., \& Sinnema, C. (2008). Effective pedagogy in social sciences/tikanga $\bar{a}$ iwi: best evidence synthesis iteration. Wellington: Ministry of Education.

Alton-Lee, A. (2003). Quality teaching for diverse students in schooling: best evidence synthesis iteration. Wellington: Ministry of Education.

Alton-Lee, A., \& Nuthall, G. (1992). Children's learning in classrooms: challenges in developing a methodology to explain opportunity to learn. Journal of Classroom Interaction, 27(2), 1-7.

Alton-Lee, A., \& Nuthall, G., \& Patrick, J. (1993). Reframing classroom research: A lesson from the private world of children. Harvard Educational Review, 63(1), $50-84$.

Anderson, G. (1998). Fundamentals of educational research. London: Routledge Falmer.

Anderson, L. W., \& Krathwohl, D. R. (Eds.). (2001). A taxonomy for learning, teaching and assessing: A revision of Bloom's taxonomy of educational objectives. New York: Longman.

Asoko, H. (2002). Developing conceptual understanding in primary science. Cambridge Journal of Education, 32(2), 153-164

Assessment Reform Group. (1999). Assessment for learning: beyond the black box. Cambridge: ARG.

Assessment Reform Group. (2002) Assessment for learning: 10 principles. Research based principles to guide classroom practice. Retrieved from http://assessment-reform-group.org/publications/

Atkins, R. (2010). Assessment practices in New Zealand year 9 and 10 social studies courses: An exploratory case study. (Master's thesis). Available from the New Zealand educ.Item No. TO1564) 
Bagley, S. (2008). High school students' perceptions of narrative evaluations as summative assessment. American Secondary Education. 36(3), 15-32

Bannan-Ritland, B. (2003). The role of design in research: The integrative learning design framework. Educational Researcher, 32(1), 21-24.

Barbour, R. (2008). Introducing qualitative research. London: Sage.

Barr, H. (1999). From the editor. The New Zealand Journal of Social Studies, 8(1), 23.

Barr, H. (2005). Planning and assessing social studies. In P. Benson, P \& R.

Openshaw (Eds.). Toward effective social studies. (51-68). Palmerston North: Kanuka Grove Press

Barr, H., Graham, J., Hunter, P., Keown, P., \& McGee, J. (1997). A position paper: Social studies in the New Zealand school curriculum. Hamilton: The School of Education, University of Waikato.

Barrett, H. (2004). Electronic portfolios as digital stories of deep learning. Retrieved from http://electronicportfolios.org/digistory/epstory.html

Barrett, H. (2005) Researching and Evaluating Digital Storytelling as a Deep Learning Tool. In C. Crawford. (Eds.). Proceedings of Society for Information Technology \& Teacher Education International Conference 2006, 647-654. Chesapeake, VA: AACE.

Baxter, P., \& Jack, S. (2008). Qualitative case study methodology: study design and implementation for novice researchers. The Qualitative Report, 13(4), 544559.

Beck, T. A. (2008). Behind the mask: social studies concepts and english language learners. Social Education, 72(4), 181-184.

Becker, H., \& Greer, B. (1957). Participant observations and interviewing: a comparison. Human Organization, 16(3), 28-32.

Bell, B., \& Cowie, B. (2001). The characteristics of formative assessment in science education. Science Education, 85(5), 536-553.

Bell, P., Hoadley, C., \& Linn, M. (2004). Design-based research in education. In M. C. Linn, E. A. Davis \& P. Bell. Internet environments for science education. New Jersey: Lawrence Erlbaum Associates.

Bennett, R. E. (2011). Formative assessment: a critical review. Assessment in Education: Principles, Policy \& Practice, 18(1), 5-25. 
Benson, P., \& Openshaw, R. (Eds.). (2005). Towards effective social studies. Palmerston North: Kanuka Grove Press

Bishop, R., \& Berryman, M. (2006). Culture speaks. Wellington: Huia Publishers.

Bishop, R., \& Berryman, M., Cavanagh, T., \& Teddy, L. (2007a). Te kōtahitanga phase 3 whānaungatanga: Establishing a culturally responsive pedagogy of relations in mainstream secondary school classrooms. Wellington: Ministry of Education.

Bishop, R., Berryman, M., Powell., A., \& Teddy., L. (2007b). Te kōtahitanga Improving the educational achievement of māori students in mainstream education. Phase 2: Towards a whole school approach. Wellington: Ministry of Education.

Black, P. (1998). Testing: friend or foe? The theory and practice of assessment and testing. London: Falmer Press.

Black, P., \& Wiliam, D. (1998). Inside the black box. London: King's College.

Black, P., Harrison, C., Lee, C., Marshall, B., \& Wiliam, D. (2003). Assessment for learning: putting it into practice. Maidenhead: Open University Press.

Bowen, G. (2009). Document analysis as a qualitative research method. Qualitative Research Journal, 9(2) 27

Bransford, J. D., Brown A, L., \& Cocking, R. R. (Eds.). (1999). How people learn: brain, mind, experience, and school. Washington DC: National Academy Press

Broadfoot, P. (1994). Educational assessment: The myth of measurement. Bristol, England: University of Bristol.

Bronfenbrenner, U. (1979). The ecology of human development: experiments by nature and design. Cambridge: Harvard University Press.

Brown, A. L. (1992). Design experiments: theoretical and methodological challenges in creating complex interventions in classroom settings. Journal of the Learning Sciences, 2(2), 141.

Bruner, J. (1960). Process of education. Cambridge: Harvard University Press.

Bruner, J. (1991). The narrative construction of reality. Critical Inquiry, 18(1), 1-21.

Bruner, J. (1996). The culture of education. Cambridge: Harvard University Press

Bruner, J., \& Haste, H. (1987). Making sense: The child's construction of the world. New York, Routledge. 
Bull, A., Brooking, K., \& Campbell, R. (2008). Successful home-school partnerships. Wellington: Ministry of Education

Butt, G. (2002). Reflective teaching of geography 11-18. London: Continuum

Cambridge, B. (2007). Learning, knowing and reflecting: literacies for the $21 \mathrm{st}$ century. International Journal for the Scholarship of Teaching and Learning, $1(2)$.

Carr, M. (2001). Assessment in early childhood settings: learning stories. London: Paul Chapman

Carr, M. (2004). Assessment in early childhood education. Wellington, Te Tari Puna Ora o Aotearoa. New Zealand Childcare Association.

Carr, M. (1998). Assessing children's learning in early childhood settings: a professional development programme for discussion and reflection. Wellington: NZCER Press.

Carr, M., May, H., Podmore, V., Cubey, P., Hatherly, A., \& Macartney, B. (1999). Learning and teaching stories. New approaches to assessment and evaluation in relation to Te Whāriki. Wellington, Institute for early childhood studies: Victoria University.

Clarke, S. (2001). Unlocking formative assessment. Oxon: Hodder and Stoughton.

Cobb, P., Confrey, J., Di Sessa, A., Lehrer, R., \& Schauble, L. (2003). Design experiments in educational research. Educational Researcher, 32(9), 9-13.

Cohen, L., Manion, L., Morrison, K., \& Morrison, K. (2000). Research Methods in Education. London: Routledge Falmer.

Cole, M., \& Engestrom., Y. (2003). A cultural-historical approach to distributed cognition. In G.S. Salomon. (Ed.), Distributed cognitions, psychological and educational considerations. NY: Cambridge University Press

Collins, A. (1992). Toward a design science of education. In E. Scanlon \& T. O'Shea. (Eds.). New Directions in Educational Technology. Berlin: Springer-Verlag.

Collins, A., Joseph, D., \& Bielaczyc, K. (2004). Design research: theoretical and methodological issues. Journal of the Learning Sciences, 13(1), 15-42.

Conrad, F., \& Schober, M. (1999). Conversational interviewing and data quality. Proceedings of the federal committee on statistical methodology research conference. Retrieved from http://www.bls.gov/osmr/abstract/st/st990250.htm

Cowie, B., \& Bell, B. (1999). A model of formative assessment in science education. Assessment in Education, 6(1), 101-116. 
Cowie, B., \& Carr, M. (2004). The consequences of socio-cultural assessment. In A. Anning, J. Cullen and M. Fleer. (Eds.). Early Childhood Education: Society and Culture. London: Sage.

Cowie, B., Moreland, J., Otrel-Cass, K., \& Jones, A. (2008). Making connections in the teaching of science and technology. Set, 3, 42-44.

Creswell, W. J. (2008). Educational research: Planning and evaluating quantitative and qualitative research. New Jersey: Pearson.

Crooks, T., Flockton, L., \& Meaney, T. (2006). Social Studies assessment results 2005. National Education Monitoring Report 34. Dunedin: University of Otago, Educational Assessment Research Unit.

Cubitt, S. (2005). Understanding social studies. Addressing the challenges posed by recent reviews of the curriculum statement. In P. Benson, R. Openshaw (Eds.), Toward effective social studies, 5-18. Palmerston North: Kanuka Grove Press

Davis, E. (2007). A study of the effects of an experimental spiral physics curriculum taught to sixth grade girls and boys. Graduate school, Baylor University. PhD.

Delandshere, G. (2002). Assessment as inquiry. Teachers College Record, 104(7), 1461-1481.

Dede, C., Nelson, B., Jass Ketelhut, D., Clarke, J., \& Bowman, C. (n.d.). Designbased research strategies for studying situated learning in a multi-user virtual environment. Retrieved from http://64.94.241.248/rivercityproject/documents/dedeICLS04.pdf

Denzin, N., \& Lincoln, Y. (Eds.). (2005). Handbook of qualitative research. Thousand Oaks, CA: Sage.

Department of Education. (1977). Social studies syllabus guidelines, forms 1-4. Wellington: Government printer.

Design-based research collective. (2012). What is design-based research? Retrieved from http://www.designbasedresearch.org/dbr.html

Dewey, J. (1896). The Reflex Arc Concept in Psychology. Psychological Review, 3 , $357-370$.

Dixon, H., \& William, R. (2003). Teachers' understanding and use of formative assessment in literacy learning. New Zealand Annual Review of Education, 12, 95-110.

Drake, S. (2007). Creating standards-based integrated curriculum. (2nd ed.). Sage, CA: Corwin Press 
Dunn, L. (2000). Using learning stories to assess and design programs for young children with special needs in New Zealand. Infant Young Children, 13(2), 7382.

Earl, L. (2003). Assessment as learning: using classroom assessment to maximise student learning. Thousand Oaks, CA: Corwin Press.

Education Review Office. (2001). The new zealand curriculum: An ERO perspective. Wellington: Education Review Office.

Education Review Office. (2006). The quality of teaching in years 4 and 8: social studies. Wellington: Education Review Office.

Education Review Office. (2007). The teaching of Social Studies: Good Practice. Wellington: Education Review Office.

Education Review Office. (2010). Promoting success for māori students: schools' progress. Wellington: Education Review Office.

Eisner, E. (1991). The enlightened eye: qualitative inquiry and the enhancement of educational practice. Toronto: Collier Macmillan Canada.

Ellis, A. (2007). Teaching and learning elementary social studies. Boston: Pearson.

Epstein, T. L. (1997). Sociocultural approaches to young people's historical understanding. Social Education, 61(1), 28-31.

Erickson, H. L. (2007). Concept-based curriculum and instruction for the thinking classroom. Thousand Oaks: Corwin Press.

Fa'alogo McNaughton, B. (2011). Formative assessment in practice: Helping change what's inside the box. Assessment Matters, 3, 140-160.

Flockton, L., \& Crooks, T (2002). Social studies assessment results 2001. National Education Monitoring Report 22. Dunedin: University of Otago, Educational Assessment Research Unit.

Flockton, L., \& Crooks, T. (1998). Social studies assessment results 1997. National Education Monitoring Report 8. Dunedin: University of Otago, Educational Assessment Research Unit

Fraenkel, J. (1992). Hilda Taba's contributions to social studies education. Social Education, 56(3), 172-178.

Gallavan, N., \& Kottler, E. (2009). Constructing rubrics and assessing progress collaboratively with social studies students. The Social Studies. Heldref publications: Washington D.C. 
Gay, L. R., \& Airasian, P. (2000). Educational research: Competencies for analysis and experience. New Jersey: Prentice-Hall.

Gipps, C. (1994). Beyond testing. Towards a theory of educational assessment. London: Falmer Press.

Gipps, C. (1999). Socio-cultural aspects of assessment, Review of Research in Education, 24, 355-392.

Glenn, J. (2010). Using a feedback log to improve academic writing in secondary classrooms. Auckland: University of Auckland.

Goodsir, K., \& Rowell, P. (2010). Learning stories - narratives of the complex ways that children learn. Putting Children First, 35, 12-13

Hargreaves, E., \& McCallum, B. et al. (2000). Learning: the pupil's voice. Cambridge Journal of Education, 30(2), 275-291.

Harlen, W., \& James, M. (1996). Creating a positive impact of assessment on learning. The annual meeting of the American Educational Research Association. New York.

Harlen, W., \& James, M. (1997). Assessment and learning: Differences and relationships between formative and summative assessment. Assessment in Education: Principles, Policy \& Practice, 4(3), 365-380.

Harlen, W., Gipps, C., Broadfoot, P., \& Nuttall, D. (1992). Assessment and the improvement of education. The Curriculum Journal, 3(3), 214-229.

Heritage, M. (2007). Formative Assessment: What Do Teachers Need to Know and Do? Phi Delta Kappan, 89(2), 140-146.

Herman, J., Osmundson, E., Ayala, C., Schneider, S., \& Timms, M. (2006). The nature and impact of teachers' formative assessment practices. (Report No. 703). Los Angeles, CA: National Center for Research on Evaluation

Hutchins, E. (1995). Cognition in the wild. Cambridge, MA: MIT Press Johnson, B., \& Christensen, L. (2008). Educational research: Quantitative, qualitative and mixed approaches. Thousand Oaks, CA: Sage.

Jonassen, D. H. (2006). On the role of concepts in learning and instructional design. Educational Technology, Research and Development, 54(2), 177.

Jones, E. B., \& Pang, V. O., et al. (2001). Social Studies in the Elementary Classroom: Culture Matters. Theory Into Practice, 40(1), 35.

Jorgensen, D. (1989). A methodology for human studies. Thousand Oaks, CA: Sage. 
Karasavvidis, I., (2002). Distributed cognition and educational practice. Journal of Interactive Learning Research. 11.

Kawullich, B. (2005). Participant observation as a data collection method. Forum. Qualitative Social Research, 6(2), 43

Killon, J., Todnew, G. (1991). A process of personal theory building. Educational Leadership, 48(6), 14-16.

Kramp, M. K., \& Humphreys, W. L. (1993). Narrative, self-assessment, and the reflective learner. College Teaching, 41(3), 83.

Krueder, R. A., \& Casey, A. M. (2000). Focus group discussion. Thousand Oaks, CA: Sage.

Lantolf, J. P. (Ed.). (2000). Sociocultural theory and second language learning. Oxford: Oxford University Press.

Lave, J., \& Wenger, E. (1991). Situated learning: legitimate peripheral participation. Cambridge: Cambridge University Press.

Macfarlane, A. (2004). Ka Hiwa Ra! Listen to culture-Māori students' pleas to educators. Wellington: New Zealand Council for Educational Research.

Macfarlane, A., \& Cavanagh, T. et al. (2007). Creating culturally safe schools for māori students. The Australian Journal of Indigenous Education, 36: 65-76.

Margrain, V. (2009). Narratives for learning: Sharing giftedness though learning stories. Reaching Forward: National Conference on Gifted Education. Rotorua.

Marshall, C., \& Rossman, G. (2006). Designing qualitative research. Thousand Oaks, CA: Sage.

McGee, C., Harlow, A., Miller, T., Cowie, B., Hill., Jones, A., \& Donaghy, A. (2002). Curriculum stocktake: national sampling study. Teachers' experiences in curriculum implementation: general curriculum, the arts, health and physical education. Wellington: Ministry of Education

McManus, S. (2008). Attributes of effective formative assessment. Washington D.C.: Council of Chief State School Officers

McNeight, C. (1998). "Wow! These sorts of things are similar to our culture!" Becoming culturally inclusive within the senior secondary school curriculum. Wellington: Victoria University. 
Middleton, D. (2001). Using conceptual foothills in primary science classrooms: a case study on using the building science concepts books. Master's thesis. Perth: Curtin University

Milligan, A., \& Wood, B. (2009). Conceptual understandings as transition points: making sense of a complex social world. Journal of Curriculum Studies, 42(4) Ministry of Education. (1990). Syllabus for schools: Forms 5 to 7 Geography. Wellington: Learning Media Limited.

Ministry of Education. (1991). Social studies forms 3 \& 4: A handbook for teachers. Wellington: Learning Media Limited.

Ministry of Education. (1996). Te Whàriki. Wellington: Learning Media Limited. Ministry of Education. (1997). Social studies in the new zealand curriculum.

Wellington: Learning Media Limited.

Ministry of Education. (2004). An introduction to kei tua o te pae. kei tua o te pae. Wellington: Ministry of Education.

Ministry of Education. (2007a). Guide notes: assessment of concepts in senior social studies, NCEA support material. Wellington: Ministry of Education.

Ministry of Education. (2007b). New zealand curriculum. Wellington, Ministry of Education. Wellington: Ministry of Education.

Ministry of Education. (2009a). Approaches to building conceptual understandings.

Wellington: Learning Media Limited.

Ministry of Education. (2009b). Narrative assessment: a guide for teachers.

Wellington: Learning Media Limited.

Ministry of Education. (2010). Position paper: assessment ko te wharangi takotoranga arunga, a te tāhuhu o te matauranga, te matekitenga. Wellington: Ministry of Education

Ministry of Education. (2006). The new zealand curriculum. Draft for consultation 2006. Wellington: Learning Media.

Minstrell, J., \& Kraus, P. (2007). Applied research on implementing diagnostic instructional tools. Final report to national science foundation.

Mitchell, L. (2008). Assessment practices and aspects of curriculum in early childhood education. Results of the 2007 NZCER national survey for ECE services. Wellington: NZCER Press.

Moore, G., Molloy, S., Morton, M., Davis, K., \& Wright, J. (2008) Narrative Assessment: Identity and equity for disabled students. Cambridge, UK: 34 th 
International Association for Educational Assessment (IAEA) Annual Conference, 7-12 Sep 2008

Moss, P., (Ed). (2008). Sociocultural implications for assessment I: Classroom assessment. Assessment, equity and opportunity to learn. New York: Cambridge University Press.

Mutch, C. (2005). Doing educational research: A practitioners guide in getting started. Wellington: NZCER Press.

Mutch, C., Hunter, P., Milligan, A., Openshaw., R., Siteine. A. (2008). Understanding the social sciences as a learning area: a position paper. Retrieved from http://nzcurriculum.tki.org.nz/Curriculum-resources/NZC-resourcebank/Social-sciences/Key-resources\#resource-1614

National Education Monitoring Project. (2005). Social Studies assessment results 2005. Wellington: Ministry of Education.

National Education Monitoring Project. (2010). Social studies assessment results 2009. Wellington: Ministry of Education.

Natriello, G. (1987). The impact of evaluation processes on students. Educational Psychologist, 22(2), 155-175.

OECD. (2003). Learners for life: student approaches to learning: results from PISA 2000. Paris: OECD.

OECD/CERI. (2008). Learning in the 21 st century: research, innovation and policy. CERI 40th Anniversary International Conference on Learning in the 21st Century. Paris: OECD/CERI. Retrieved from http://www.oecd.org/officialdocuments/publicdisplaydocumentpdf/?cote=ED U/CERI/CD(2008)14\&docLanguage=En

OFSTED. (1998). Secondary education 1993-1997: A review of secondary schools in England. London: HMSO.

Parry, L. J. (2000). Transcending national boundaries: Hilda Taba and the 'new social studies' in Australia, 1969 to 1981. Social Studies, 91(2), 69.

Patton, M. (1999). Enhancing the quality and credibility of qualitative analysis. HSR: Health Services Research, 34(5 part II), 1189-1208.

Patton, M. Q. (2002). Qualitative research and evaluation methods. Thousand Oaks, CA: Sage. 
Paulson, F. L., \& Paulson, P. (1996). Assessing portfolios using the constructivist paradigm. In R. Fogarty. Student Portfolios. Palatine: IRI Skylight Training \& Publishing.

Plummer, J. (2011). Using focus groups to support conceptual development in social studies. Set 1, 16-21.

Rogoff, B. (1995). Observing sociocultural activity on three planes: Participatory appropriation, guided participation, and apprenticeship. In J. V. Wertsch, P. del Rio and A. Alvarez. Sociocultural studies of mind. Cambridge, UK: Cambridge University Press, 139-164.

Rosch, E. (1978). Principles of categorization. In E. Rosch and B. Lloyd. (Eds.), Cognition and categorization. Hillsdale, NJ: Lawrence Erlbaum.

Rule, L. Digital Storytelling. Retrieved from http://electronicportfolios.com/digistory/

Sadler, D. R. (2002). Learning dispositions: Can we really assess them? Assessment in Education, 9(1), 45-51.

Savage, T. V., \& Armstrong, D. G. (2008). Effective teaching in elementary social studies. New Jersey: Pearson.

Sewell, A. M. (2006). Teachers and children learning together: developing a community of learners in a primary classroom. Palmerston North: Massey University.

Smith, A., B. (1999). Quality childcare and joint attention. International Journal of Early Years Education, 7(1), 85-98.

Smith, E., \& Gorard, S. (2005). 'They don't give us our marks': the role of formative feedback in student progress. Assessment in Education: Principles, Policy \& Practice, 12(1), 21-38.

Smith, J., Crooks, T., Gilmore, A., \& White, J. (2010). Social studies assessment results 2009. National Education Monitoring Project 51. Dunedin: University of Otago, Educational Assessment Research Unit.

Sociology Central. (2003). Research methods: Participant observation. Retrieved from www.sociology.org.uk, accessed 15 March 2012

Stake, R. E. (1995). The art of case study research. Thousand Oaks, CA: Sage.

Szymanski Sunal, C., \& Hass, M. (2005). Social studies for the elementary and middle grades: a constructivist approach. Boston: Pearson.

Taba, H. (1962). Curriculum development: theory and practice. New York: Harcourt, Brace and World. 
Taba, H. (1971). A Teacher's handbook to elementary social studies: an inductive approach. Reading, Mass: Addison-Wesley.

Taylor, R. (2009). How can lessons learned from social studies developments inform teaching and learning in year 9 \& 10 social studies classrooms? SocCon. Christchurch. Retrieved from http://www.socialstudies.org.nz/assets/files/ResearchAndPublication/SocCon $\% 20$ paper $\% 20$ for $\% 20$ proceedings.pdf

Tervalon, M., Murray-Garcia, J. (1998). Cultural humility versus cultural competence: a critical distinction in defining training outcomes in multicultural education. Journal of healthcare for the poor and underserved, $9(2), 117-125$.

The Design-Based Research Collective (2003). Design-based research: An emerging paradigm for educational inquiry. Educational Researcher, 32(1), 5-8.

Timperley, H., \& Parr, J. (2004). Using evidence in teaching practice: Implications for professional learning. Auckland: Hodder Moa Beckett.

Timperley, H., Wilson, A., Barrar, H., \& Fung, I. (2007). Teacher professional learning and development: Best evidence synthesis iteration. Wellington: Ministry of Education.

Torrance, H., \& Pryor, J. (2001). Developing formative assessment in the classroom: using action research to explore and modify theory. British Educational Research Journal, 27(5), 615-632.

UNESCO. (2009). Policy guidelines on inclusion in education. United Nationas Educational Scientific \& Cultural Organisation. Retrieved from http://unesdoc.unesco.org/images/0017/001778/177849e.pdf

Vygotsky, L. (1978). Mind in society: the development of higher psychological processes. Cambridge: Harvard University Press.

Wagner, J. (1997). The unavoidable intervention of educational research: A framework for reconsidering researcher-practitioner co-operation. Educational Researcher, 26(7), 13-22

Wearmouth, J., \& McKinney, R., Glynn, T., (2007). Restorative justice in schools: a New Zealand example. Education Research, 49(1), 37-49.

Weeden, P., Winter, J., \& Broadfoot, P. (2002). Assessment: What's in it for schools? London: Routledge. 
Wenger, E. (1998). Communities of practice: Learning, meaning and identity. Cambridge: Cambridge University Press.

Wilkinson, D., \& Birmingham, P. (2003). Using research: a guide for researchers. London: Routledge Falmer.

Wolf, D., Bixby, J., Glenn III, J., \& Gardner, H. (1991). To use their minds well: Investigating new forms of student assessment. Review of Research in Education, 17, 31-74.

Wood, B., \& Milligan, A. (2010). Possibilities for summative assessment in social studies. Set, 2.

Yildirim, A. (2004). Student assessment in high-school social-studies courses in

Turkey: Teachers' and students' perceptions. International Review of Education, 50(2): 157-175.

Yin, R. (1994). Case study research: design and methods. Thousand Oaks, CA: Sage. Yin, R. (2003). Case study research: design and methods. Thousand Oaks, CA: Sage. Yin, R. (2009). Case study research: design and methods. Thousand Oaks, CA: Sage. Yin, R. (2011). Qualitative research from start to finish. London: The Guildford Press. 


\section{APPENDICES}

Appendix A Learning Story Framework: A work in progress, Version One.

Appendix B Outline of semi-structured interview questions.

Appendix C Focus group protocols.

Appendix D Observation template.

Appendix E Sample information sheets and consent forms for participants.

Appendix F Learning story framework: a work in progress, Version Two

Appendix G Learning story framework: a work in progress, Version three.

Appendix H Learning story framework guide: a work in progress, Version three. 
Appendix A: Learning Story Framework: A work in progress, Version One

\begin{tabular}{|l|l|}
\hline \multicolumn{1}{|c|}{ Time: } \\
Date: \\
Context: & Student: \\
\hline $\begin{array}{l}\text { Conceptual understanding: } \\
\text { student in action): } \\
\text { What is happening here? What do you notice? }\end{array}$ & $\begin{array}{l}\text { Learning Intention: } \\
\text { Interpretation and analysis: } \\
\text { What aspects of the conceptual understanding are being displayed? } \\
\text { What other learning is taking place? } \\
\text { How might this assessment contribute towards developing competence? }\end{array}$ \\
\end{tabular}




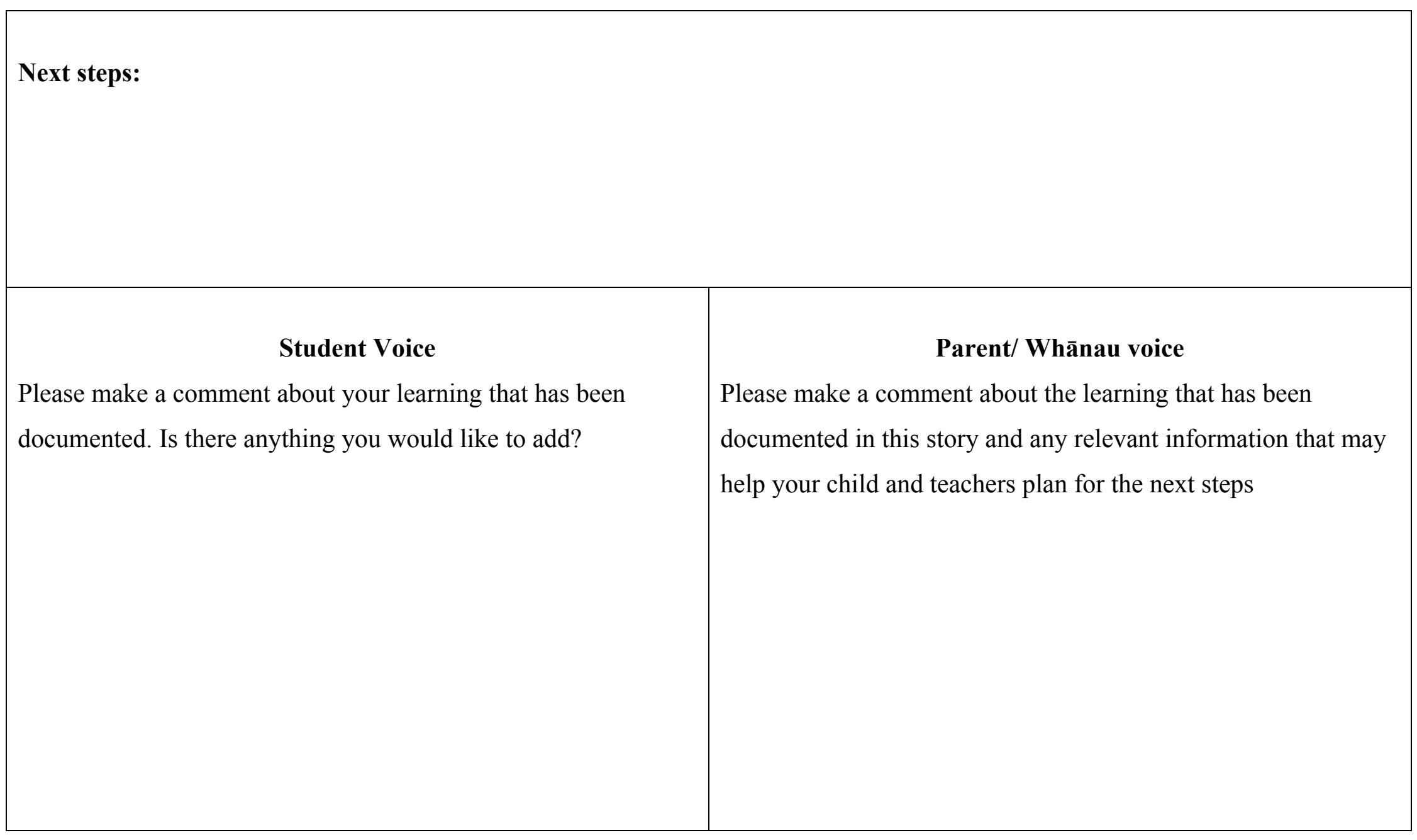

Adapted from Carr (2001) and www.educate.ece.govt.nz 


\section{Version One Learning Story Information}

Learning stories are a way of observing and documenting (writing down) the learning that is taking place and planning next steps in the learning. They have been used extensively in early childhood, but are limited in their use in secondary education. We will be looking at documenting the learning of concepts (ideas) in social studies.

In early childhood the teacher writes the learning stories, but in this research I would like the teachers to try it out first, and then if necessary, after some alterations the students will use it. Parents will be asked to write a brief comment about the learning story too.

The interviews and feedback from everyone will focus on evaluating the use of this learning story approach.

To help write a learning story I have put together the framework. This will be adapted as I receive feedback received from participants. Teachers and students will be given further assistance on how to fill in this framework. 


\section{Appendix B: Outline of semi-structured interview questions}

A) Introductory phase: Department interview

Aim: To assess how formative evidence is currently gathered, analysed and used

1. What is your understanding of formative and summative assessment?

2. What current assessment practices would you view as summative and what are formative?

3. How do you currently assess concepts in social studies?

4. What do you do with the information when you have assessed students?

5. How do you analyse this assessment information?

6. What do you think you do well as a department when assessing concepts?

7. What do you think you need as a department to improve upon when assessing concepts? 


\section{B) Inquiry Cycle One: Student interview}

Aim: To assess how the teachers' application of the learning story approach is contributing towards the gathering, analysis and use of formative evidence

1. What do you think of the learning story process?

2. What did you think about the observations that were made?

3. How has it helped you to reflect on your learning?

4. What do you do/ feel when you have been given feedback?

5. What have you done about that feedback?

6. What do you think of your parents/whānau commenting on the learning story?

7. In what ways has it helped you learn and understand more about the SST concepts?

8. What would you change for next time?

\section{Inquiry Cycle One: Teacher interview}

Aim: To assess how the teachers' application of the learning story approach is contributing towards the gathering, analysis and use of formative evidence

1. What do you think of the learning story process?

2. How did you find making observations about the learning?

3. How do you think it has helped reflect on the learning?

4. How did the students respond to the feedback?

5. What have you done about that feedback?

6. What do you think of parents/whānau commenting on the learning story?

7. In what ways has it helped students learn and understand more about the SST concepts?

8. What would you change for next time? 


\section{C) Inquiry Cycle Two: Student interview}

Aim: To assess how the students' application of the learning story approach is contributing towards the gathering, analysis and use of formative evidence

1. What do you think of the learning story process now?

2. What do you think about you making the observations?

3. How has it helped you to reflect on your learning?

4. How useful was the teacher feedback?

5. How did it make you feel to write your own story and get feedback from the teacher?

6. What have you done about that feedback?

7. What do you think of your parents/whānau commenting on the learning story now?

8. In what ways has it helped you learn and understand more about the SST concepts?

9. What would you do the same/differently?

\section{Inquiry Cycle Two: Teacher interview}

Aim: To assess how the students' application of the learning story approach is contributing towards the gathering, analysis and use of formative evidence

1. What do you think of you the learning story process now?

2. What did you think about the students making the observations?

3. How has it helped the students reflect on their learning?

4. How useful was the teacher feedback?

5. How do you think it made the students feel to go through this process?

6. What have you done about that feedback?

7. What do you think of the parents/whānau commenting on the learning story now?

8. In what ways has it helped students learn and understand more about SST concepts?

9. What would you do the same/differently? 


\section{Appendix C: Focus group protocols}

The following group protocols will be communicated and agreed upon in order to minimise discomfort and ensure all participants are clear about the purpose and format of the interviews.

1. Introduction - I will:

- Introduce myself and ask participants to introduce themselves also

- run through the purpose of the interview and briefly explain why we are examining learning stories and the specific nature of this particular interview

- briefly explain what a focus group interview is and why it is important to hear the participant's honest and thoughtful responses.

2. Format of focus group interview - I will:

- Indicate how long the interview will go for (usually one hour)

- remind participants that the interview will be recorded for my use only and will be disposed of within two years. When a person is talking it will be useful for my research if they say their name first and then their comment

- remind participants that what is said in the room remains confidential, names will never be used. If they wish this to remain confidential then participants will need to follow this protocol also

- remind participants that there is no right or wrong response to any of the questions, people can disagree with each other, however responses must be made in a respectful manner.

3. Questions

- Semi-structured questions will be used during the focus group interview, however if this deviates into a related area then I will facilitate this.

4. Summary

- Towards the end of the interview I will summarise the points made and check that these points are an accurate portrayal of the participant's thoughts. I will note any exceptions to this

- I will invite any other points to be made

- I will thank the participants for their participation. 


\section{Appendix D: Observation template}

Teacher:

Time/date:

Conceptual understanding/Learning Intention:

Context:

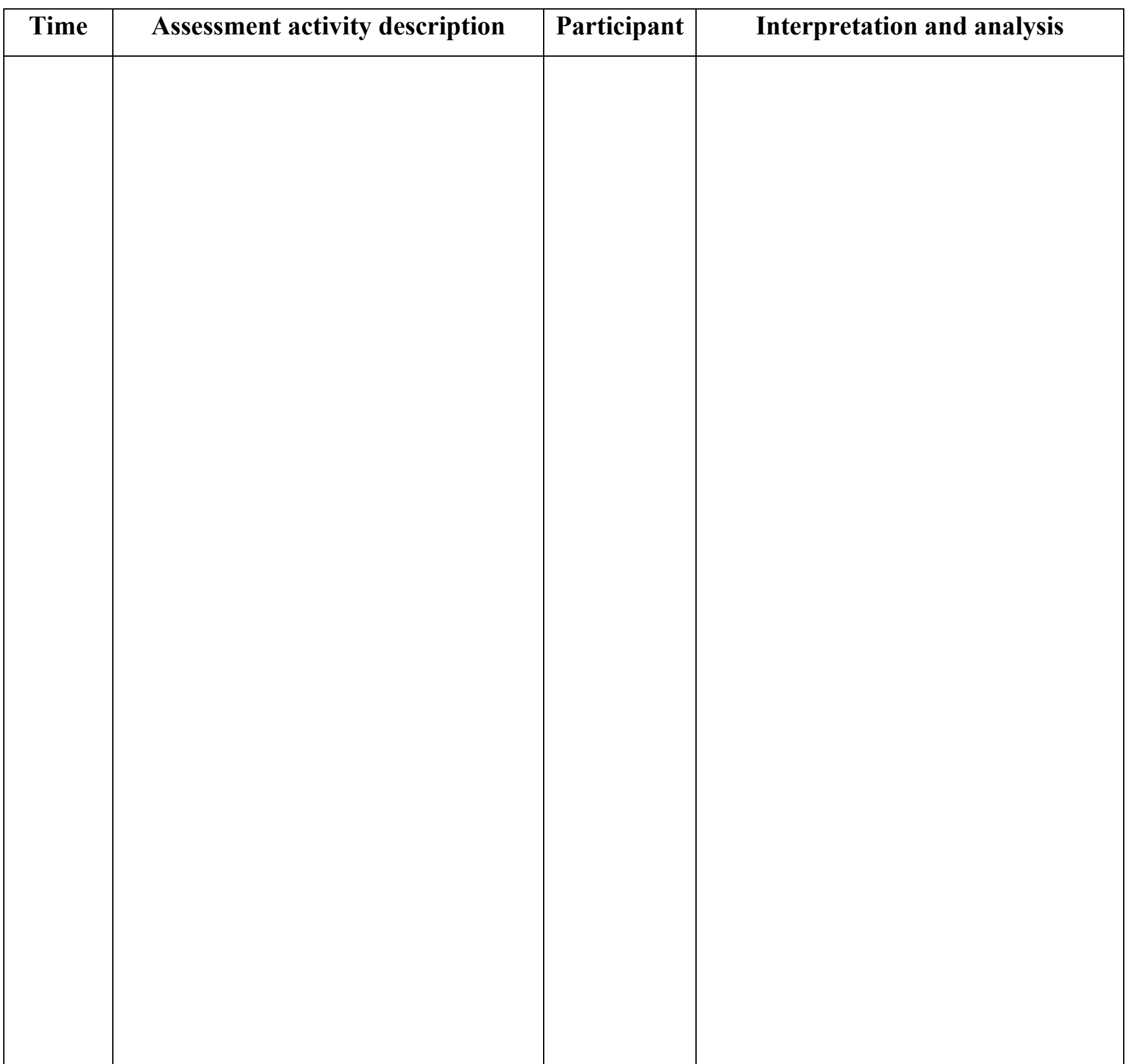




\section{Appendix E: Sample Information sheet and}

consent form for participants

\section{(i) Principal information sheet for a study on an assessment framework called a 'learning story' as part of the gathering analysis and use of evidence in social studies}

Researcher: Amanda Picken: School of Policy and Implementation, Victoria University

Dear Principal

I am a Masters student in education at Victoria University. As part of this degree I am undertaking a research project leading to a thesis. I am researching the impact an assessment framework called a 'learning story' has on the gathering, analysis and use of evidence about students' conceptual understanding in social studies. Learning stories are assessments that observe and write down the learning that is taking place and help plan next steps in the learning. I have attached information about the Learning Story Framework in the Appendix. The University requires that ethics approval be obtained for research involving people. The research has been approved by Victoria University Faculty of Education Ethics Committee.

I am writing to request your permission to ask your social studies department to take part in this project, including two teachers and ten students, five from each teacher's Year Nine class for more in-depth study. There will be an information meeting to introduce the project and the aim is to begin the research in early July and complete in October.

The first phase of the research will involve establishing an understanding of current assessment. To do this, the department will participate in a group interview, two in-depth teachers and ten students will be observed, and secondary material such as department plans, unit plans and examples of student work will be collected. The second phase of the research involves the teacher's inquiry of the implementation of the Learning Story Framework. Teachers and students will initially attend a workshop to assist with the use of the Learning Story Framework. During this phase there will be ongoing reflection and critique of the framework by teachers and students and feedback by parents/guardians/whānau, as well as participant observation. At the end of the inquiry cycle the two teachers and ten students will be participate in group interviews. During the third phase of the research the student will 
implement the Learning Story Framework. Again there will be ongoing reflection and critique of the framework by teachers and students and feedback by parents, guardians and whānau, as well as participant observation. At the end of this inquiry cycle the two teachers and ten students will be participate in group interviews.

Interviews will be held at a time most convenient for the school, with minimal disruption for students and teachers involved. During the data collection phase should any participant feel the need to withdraw from the project they may do so without repercussion. Once analysis of data begins on the 27/08/11, withdrawal will not be possible.

This information will form the basis of my research and will be collated into a written report. It will not be possible for the school to be identified and the identity of participants will be protected by the use of pseudonyms and removal of identifying details. All material will be stored securely; only myself and my supervisors Andrea Milligan and Dayle Anderson will see material collected and will be destroyed two years after the project. The thesis will be submitted for marking to the School of Policy and Implementation and deposited in the University library. It is intended that findings may be presented in papers or at conferences. At the end of the research process I will invite all participants to share in a feedback session and will offer an electronic version of my final thesis.

If you have any further questions, or would like to receive further information about the project please contact me on phone: 043837665 Amanda.picken@xtra.co.nz, or my supervisors Andrea Milligan phone: 044639614 andrea.milligan@,vuw.ac.nz, or Dayle Anderson phone: 044639630 dayle.anderson@vuw.ac.nz at the School of Policy and Implementation. If you have any ethical questions about this research please contact Dr Allison Kirkman, Chair of the Human Ethics Committee, Victoria University of Wellington, phone: 04463 5676, e-mail: Allison.Kirkman@vuw.ac.nz.

Yours sincerely

Amanda Picken 


\section{Learning stories as part of the gathering}

analysis and use of evidence in social studies

\section{(i)Principal consent form}

Please tick as applicable

I have been given an explanation of this research project.

I have had an opportunity to ask questions and seek clarification and understand the information provided.

I understand what will be required from the department, teachers, students and parents/guardians/whānau who participate in the research.

I understand that participation in this study is voluntary and any participant can withdraw from the research up to $27 / 08 / 11$, once the analysis of data

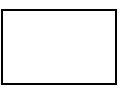
begins.

I understand that the school's identity and identity of participants will be protected. I understand that all data will be stored safely during the research
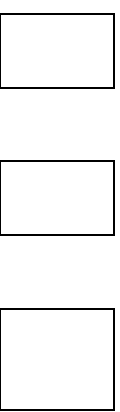
process and destroyed 2 years after completion of the project.

I understand that the research may be used in papers or presentations and in the completion of the thesis write up.

I consent to the social studies teachers and students being invited to be part of the research.

Signed

Name of participant

(Please print clearly)

Date: 


\section{Appendix F: Learning Story Framework: a work in progress, Version two}

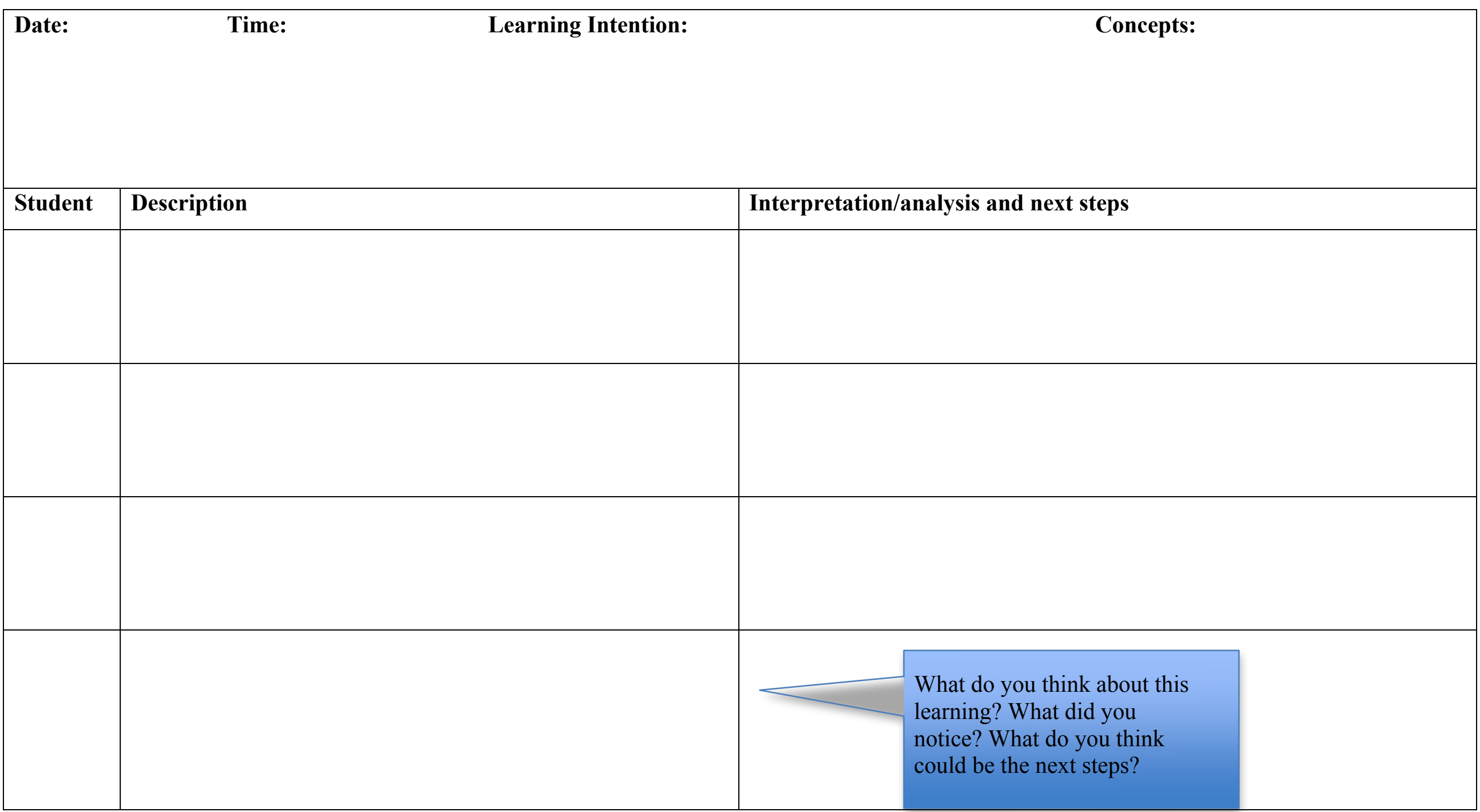


Name:

Appendix G: Learning Story Framework: a work in progress, Version three

Date of lesson:

Learning intention/understanding/idea:

What did I learn todav?

What did I do that showed this learning?

Learning intention/understanding/idea:

Date of lesson:

todav?

What did I do that showed this learning?

Date of lesson:

Learning intention/understanding/idea:

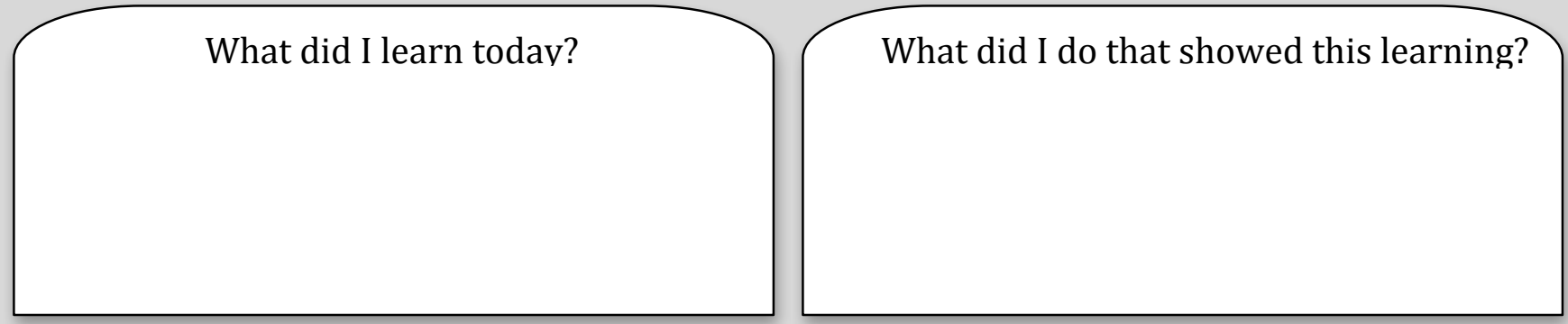

Summary and next steps:

Teacher comment

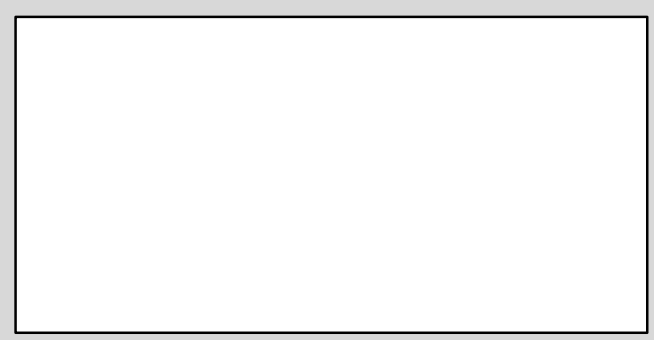

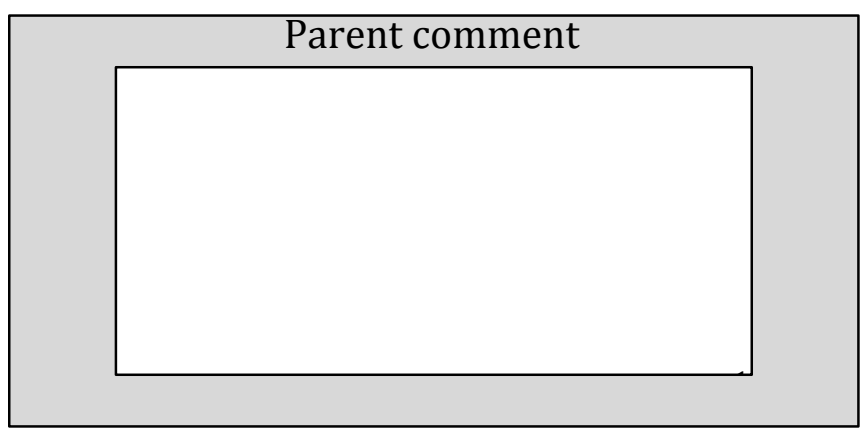


Name:

Appendix H: Learning Story Framework guide: working example, Version three

Date of lesson:

Learning intention/understanding/idea:

What did I learn today?

Have a think about what you were meant to learn. Did you learn what it says? Did you learn something else? If so, what?
What did I do that showed this learning? What activities did you do that was related to this learning? Did you work by yourself or with others? Was the learning shown by your individual/group writing, pictures, discussion, or something else?
Date of lesson:

I learnt:

\section{What did I learn today?}

- Where some places are in NZ

- That there are different reasons to go to places

- How to survey my class
Learning intention/understanding/idea:

What did I do that showed this learning?

I asked my classmates where they have been on holiday

I put this on a map using an atlas by myself
Date of lesson:

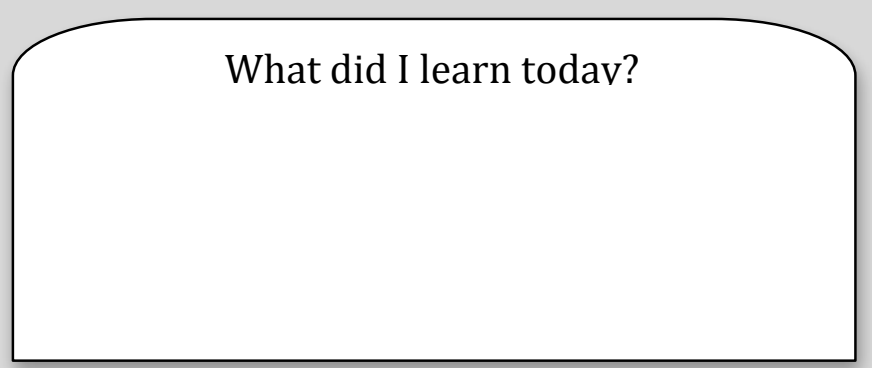

Learning intention/understanding/idea:

What did I do that showed this learning?

\section{Summary and next steps:}

Look at your comments for this week. What was the important learning for you? Do you need to revisit any learning from this week? What would you like to know more about?

E.g. Learning where Rotorua was is important to me because my dad comes from there and we are going in the next holidays. I would like to know more about what jobs there are in tourism. What does tourism do to the environment? What can I do if I go to Queenstown?

\begin{tabular}{|l|}
\hline \multicolumn{1}{|c|}{ Teacher comment } \\
\hline $\begin{array}{l}\text { What do you think about } \\
\text { this learning? Is there } \\
\text { anything else you noticed } \\
\text { that you would like to add? }\end{array}$ \\
\hline
\end{tabular}

\begin{tabular}{|l|}
\hline \multicolumn{2}{|c|}{ Parent comment } \\
$\begin{array}{l}\text { What do you think about this } \\
\text { learning? Is there anything you } \\
\text { would like to add? } \\
\end{array}$ \\
\hline
\end{tabular}




\section{My Learning Story}

Date of lesson: $5 / 10 / 11$ Learning intention/understanding/idea: We are Learning to flescribe relatenuships that anational

What did I learn todav?

1 leant what a stake

holder is. We learnt what

the sponsors $j$ ob is and wing

they spons or teams in by ratoruships that are

What did I do that showed this learning?

we got in groups and

wrote doun advantages

of hosting a major event.

we also went oner riskes of

sponsurship and the risks of

stakeholders on the event

Date of lesson: 6/10/4 Learning intention/understanding/idea: Same as yesterday

What did I learn todav?

What a country reeds to be successful hosts. We also leaned How to be a frundly bulit.
What did I do that showed this learning?

We wrote on paper now

we think people can be

sucessfil hosts and debated what othe grouts thought.

stablusthe Thurgh parhupati un sporking quents 


\section{My Learning Story}

Date of lesson: 28/9 Learning intention/understanding/idea: De-scibe what fourismif

What did Ilearn todav?
that its the learing tower of
$P$ is a not "pizza'
ovearnt diffent locations
oves the world

What did I do that showed this learning?

1 dit an activity zaming all

the aftractons in the world

over the world

told me it was Pisa

Date of lesson: $29 / 9$ Learning intention/understanding/idea: pescibe the patterns off

\section{What did I learn todav?}

about how tourists will go

to a place mores how to

make it more successfur by

offering goods and services demand a supply

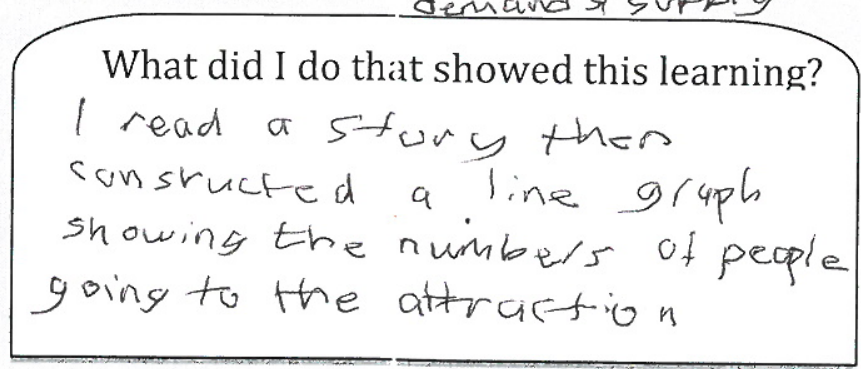

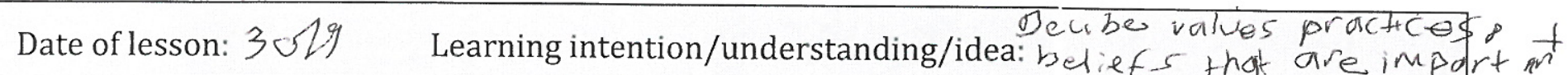

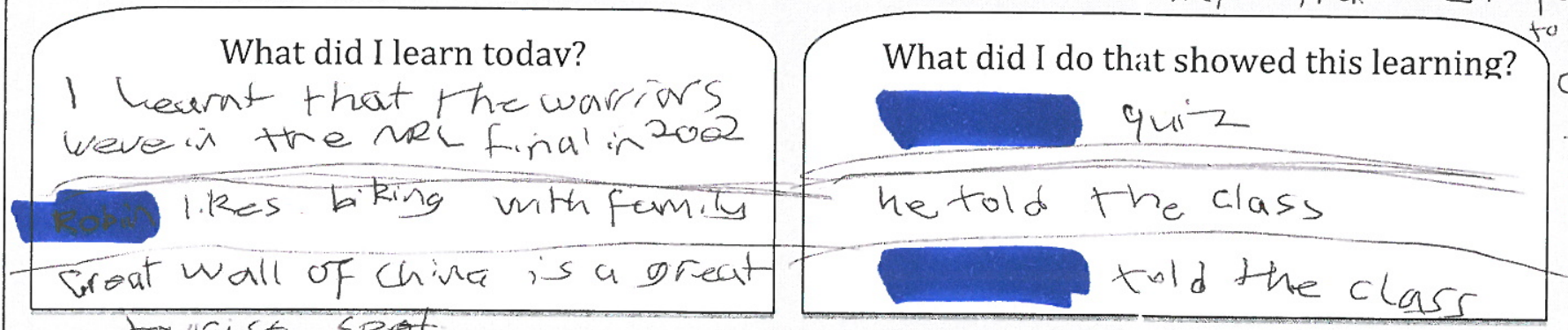

tourist spot

Summary and next steps: Learring how to do a line graph was important because inttre future if want to compare data if will make it a whole of easierp for me toread it.

1 a iso would tike to know more about attractichs * arents aromat the world because when 1 get dder lplanto do a bitof to aveling.

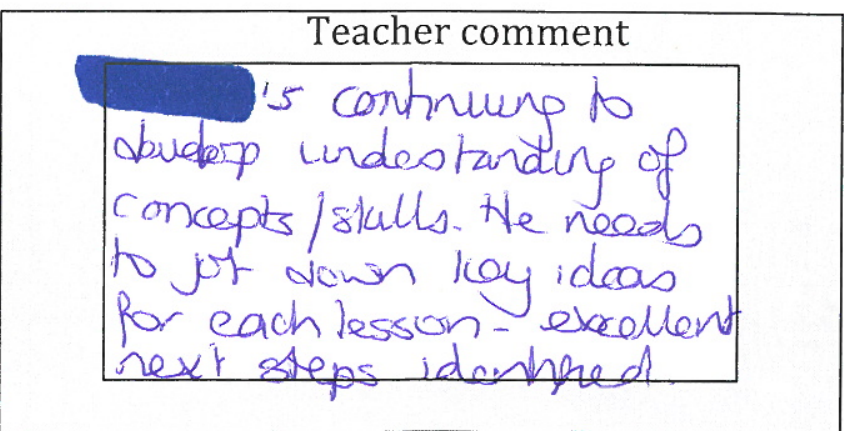

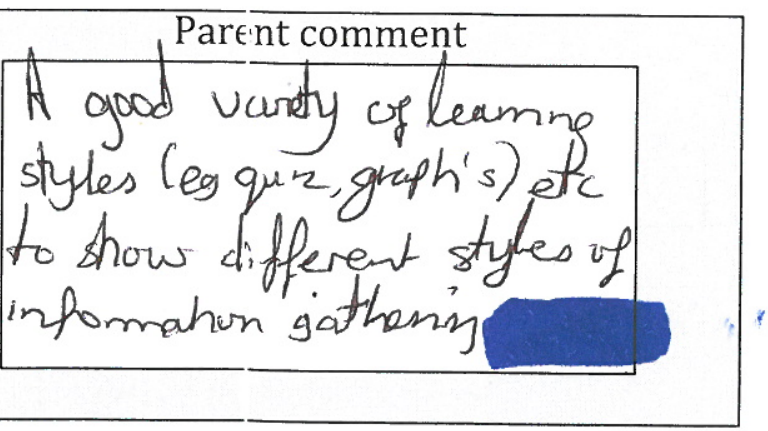

